Portland State University

PDXScholar

Summer 9-2-2014

\title{
The Relationship between Mindfulness and Burnout among Master of Social Work Students
}

Jolanta Maria Piatkowska

Portland State University

Follow this and additional works at: https://pdxscholar.library.pdx.edu/open_access_etds

Part of the Health Psychology Commons, and the Social Work Commons Let us know how access to this document benefits you.

Recommended Citation

Piatkowska, Jolanta Maria, "The Relationship between Mindfulness and Burnout among Master of Social Work Students" (2014). Dissertations and Theses. Paper 1962.

https://doi.org/10.15760/etd.1961

This Dissertation is brought to you for free and open access. It has been accepted for inclusion in Dissertations and Theses by an authorized administrator of PDXScholar. Please contact us if we can make this document more accessible: pdxscholar@pdx.edu. 
The Relationship between Mindfulness and Burnout among Master of Social Work Students

\title{
by
}

Jolanta Maria Piatkowska

A dissertation submitted in partial fulfillment of the requirements for the degree of

Doctor of Philosophy

in

Social Work and Social Research

\author{
Dissertation Committee: \\ Eileen Brennan, Chair \\ Daniel Coleman \\ Victoria Cotrell \\ Thomas Kindermann \\ Julie Rosenzweig
}

Portland State University

2014 


\begin{abstract}
Social work students frequently endure elevated levels of prolonged stress and psychological affliction that might result in serious consequences, such as development of burnout. Some experts suggest that burnout originates in the exposure to chronic interpersonal stressors in the work environment. Yet, there is emerging evidence suggesting that mindfulness practice might be beneficial in alleviating stress. Thus, the purpose of this exploratory study was to examine the relationship between mindfulness and burnout among Master of Social Work students. Burnout, mindfulness, religiosity, spirituality and their potential relationship were discussed and related to previous scholarly literature. Specifically, this study focused on testing the hypothesis that current MSW students who demonstrate higher levels of mindfulness will report less burnout, regardless of the year in the MSW program and regardless of the years of practice in human services. In addition, the hypothesis that students currently involved in direct social work practice (either outside of the MSW program, in the MSW field placement, or both) experience higher levels of burnout than students not yet practicing was scrutinized. Moreover, the hypothesis that as students progress in their studies they will exhibit progressively more burnout was explored. Finally, one of this study's goals was to explore whether patterns/relationships between the religious and spiritual beliefs and practices predict burnout levels among Master of Social Work students. Participants were mostly non-Hispanic White females, with a mean age of 35, married (or in legally recognized unions), and first year students enrolled full-time in the Direct Human Services track. Two years was the most common length of their experience in human
\end{abstract}


services. They came from the metropolitan Portland area (on-campus students) and other regions of Oregon (off-site students). The mindfulness of the participants was measured with the Five Facets Mindfulness Scale and the levels of their burnout with the Maslach Burnout Inventory. Study results indicated that the more mindful the MSW students were, the less burnout they reported experiencing. A large correlation of mindfulness to reduced burnout $(\mathrm{p}<.001)$ was found, a relationship that persisted when controlling for other significant variables through sequential regression analysis. However, neither year in the MSW program, length of practicing in human services, nor religious/spiritual affiliation and practices had any significant influence on burnout among participants. Given the results of this study demonstrated statistically significant relationships between mindfulness and burnout among social work students, it is recommended that appropriate training in mindfulness for the students (and social workers) affected by secondary trauma and burnout should be incorporated in social work education, either as a part of curricula, or in an extra-curricular training program. 


\section{ACKNOWLEDGEMENTS}

GRATITUDE !!! I have been fortunate to have met many amazing professors, who not only excelled in their fields of expertise, but could also be valued for their humanity. Some of them have been serving on my dissertation committee. First, my gratefulness goes to my dissertation chair, Eileen Brennan, who endlessly supported me over the years. Eileen, I could have never made it without your professionalism, wisdom, and understanding. Your mentorship means so much to me that I can only show it by paying it forward. Many heartfelt thanks go to Dan Coleman, my statistical consultant. I have been inspired by you, as a professor and a human being, from the moment we met in a doctoral statistic class. I hope that we can stay in touch and collaborate on many projects in the future. Julie Rosenzweig, you have challenged me many times, exactly when I needed it most. Thanks for everything, for your priceless suggestions to improve this dissertation and, especially, for your original perspectives on research and teaching. Vicki Cotrell, the gentle ways of sharing your knowledge and wisdom with me were truly comforting and inspiring. You made me believe that I can write, and for this I will be always grateful. Thomas Kindermann, I am still amazed that taking your psychology class has resulted in such a wonderful collaboration. I value not only your knowledge, and your constructive contribution to this study, but also ... your European sense of humor. I am honored and humbled by your willingness to serve on my committee.

I also want to express my gratitude to my family (my Mom, brothers Andrzej and Marek, wonderful sister-in-law Dana, and my niece Ania), and to friends who became my American family (Julie, John, and Wanda). Each of you was an important part of my success and I will never forget the encouragement you have offered me for years. To my 
late Dad - thank you for instilling in me the hunger for knowledge, for challenging the way the world functions, for the drive to be better and always do better. I dedicate this dissertation to you with the hope that you know I have finally arrived at the next stop...

To all MSW students at Portland State University, those participating in my doctoral study and those who shared their lives with me during classes - you were my teachers in humility, honestly, and understanding. I will never forget any of you! Moreover, many thanks to the instructors and the School of Social Work staff, for the ongoing assistance and kindness.

Finally, I am grateful for my feline companion, George aka Luluś, whose "purring" presence carried me through many sleepless nights and whose gentle ways comforted me during difficult days. 
TABLE OF CONTENTS

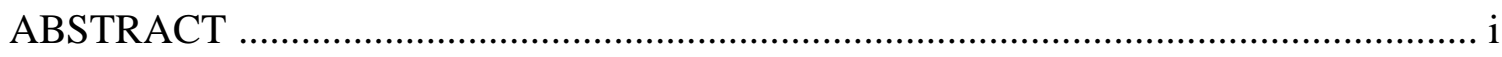

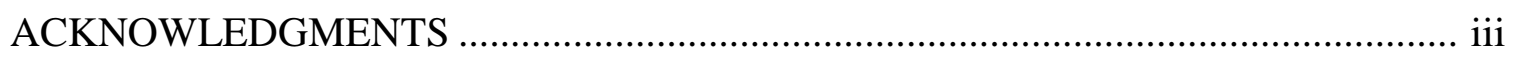

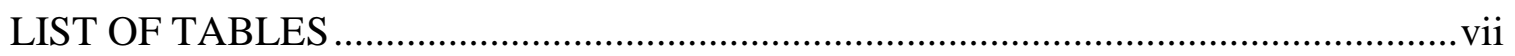

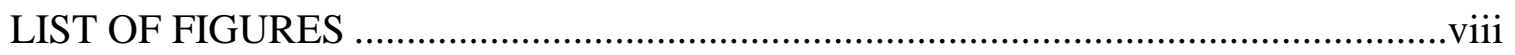

\section{CHAPTER 1: INTRODUCTION1}

Burnout in Human Services ............................................................. 1

Burnout in Social Work ................................................................. 2

Burnout among Social Work Students..................................... 2

Consequences of Burnout ............................................................ 4

Proposed Solutions............................................................ 5

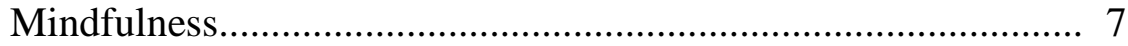

Mindfulness Training................................................... 8

Spirituality and Religiosity ........................................ 9

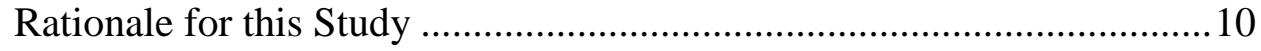

Brief Review of the Content of this Dissertation................................... 11

CHAPTER 2: LITERATURE REVIEW …......................................................... 13

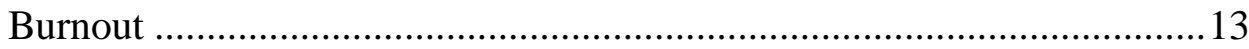

Definitions of Burnout .............................................................. 13

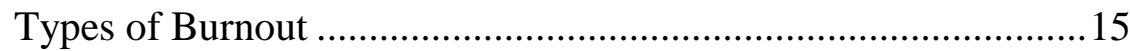

Stages of Burnout.................................................................. 17

Burnout in Various Helping Professions .................................20

Burnout in Mental Health Professions .......................................21

Burnout in Social Work ..........................................................23

Burnout among Social Work Students.....................................26

Consequences of Burnout ......................................................2 27

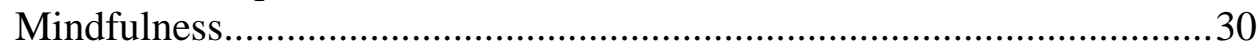

Etiology and Definition of Mindfulness ....................................30

Mindfulness-based Therapies as Clinical Interventions ...............32

Mindfulness-based Therapies as Self-care Tools in Helping Occupations.................................................. 34

Mindfulness as a Self-care Tool in the Social Work

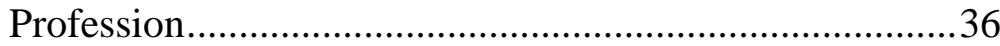

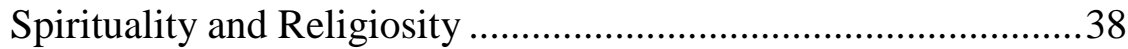

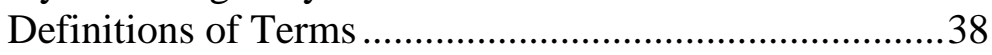

Religion, Spirituality, and Well-being ...........................39

Spirituality, Religiosity, and Burnout in Social Work .....40 
Conclusion ............................................................................ 41

CHAPTER 3: THEORIES AND ASSUMPTIONS .................................................46

Interaction of Person and Environment - Theoretical Bases of Burnout .46 Mindfulness and the Transitional Theory of Stress and Coping ..............50

Research Questions and Hypotheses ...................................................53

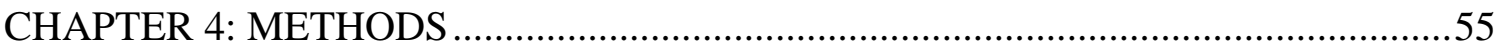

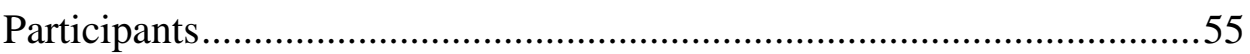

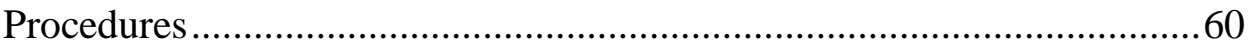

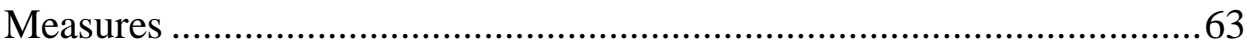

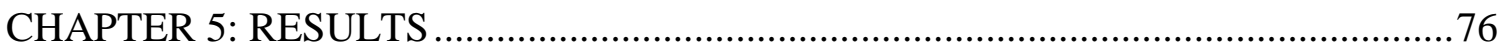

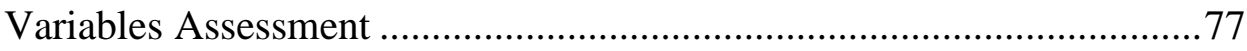

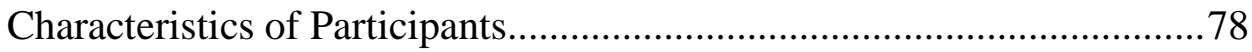

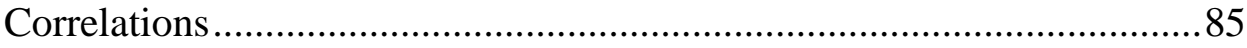

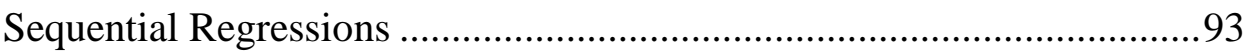

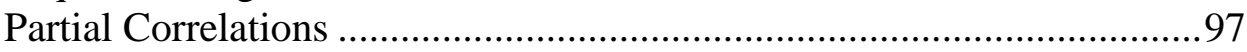

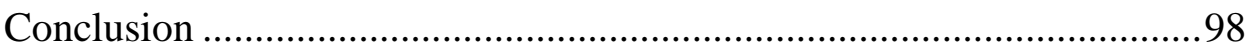

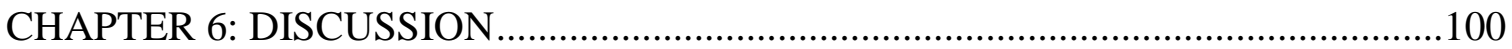

Mindfulness and Burnout...................................................................101

Religiosity/Spirituality, Covariates, and Burnout ................................102

Discrepancies and Consistencies with Previous Studies ........................104

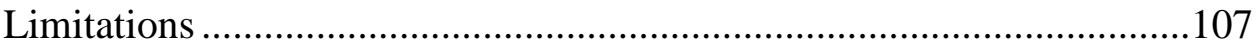

Implications for Social Work Field....................................................109

Recommendations for Future Research and Improved Practice.............110

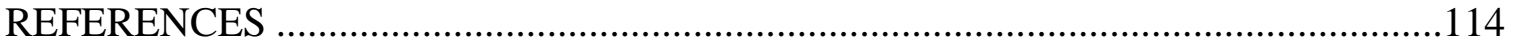

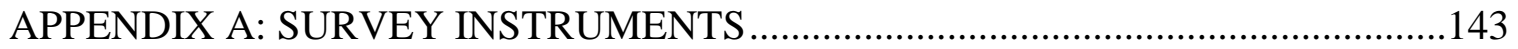

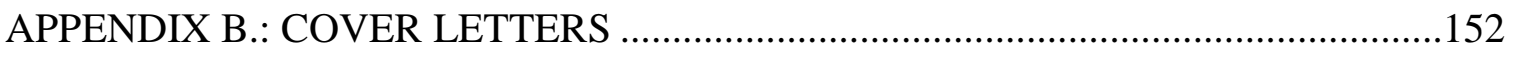




\section{LIST OF TABLES}

Table 1. Demographics of participants ................................................................. 58

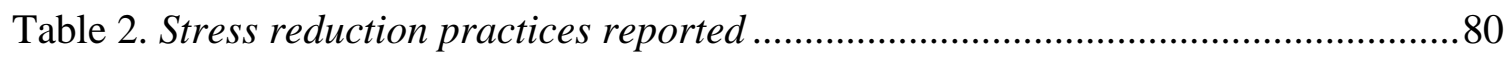

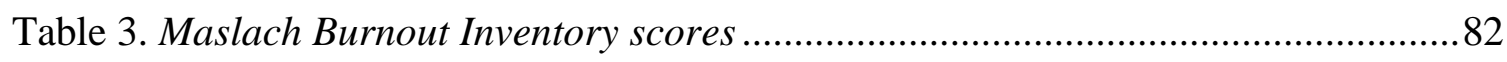

Table 4. Five Facets Mindfulness Questionnaire scores ............................................83

Table 5. Correlations between independent variables and burnout ..............................87

Table 6. Correlations between spiritual and religious affiliation and practices..............89

Table 7. Correlations between other stress reduction practices and burnout.................92

Table 8. Sequential regression model of burnout factors (and MBI sum) and Five

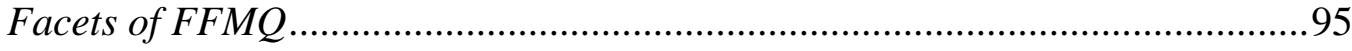

Table 9. Sequential regression model of burnout factors (and MBI sum) and Four

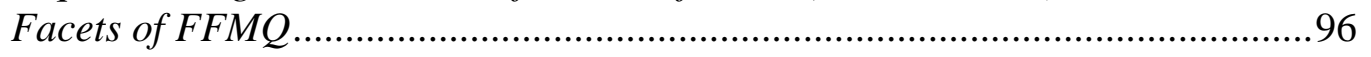

Table 10. Partial correlations between burnout factors and FFMQ............................98 
LIST OF FIGURES

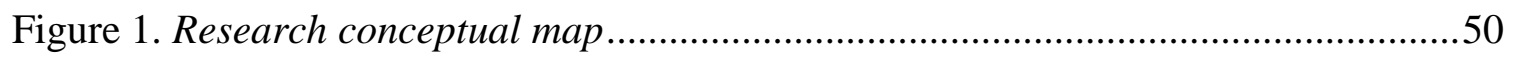




\section{CHAPTER 1: Introduction}

\section{Burnout in Human Services}

Over the years burnout has been identified as one of the most serious occupational hazards in various professions. "Burnout is a prolonged response to chronic emotional and interpersonal stressors on the job" (Maslach, Schaufeli, \& Leiter, 2001, p. 397) and consists of three dimensions: emotional exhaustion, depersonalization (cynicism), and diminished personal accomplishment. "As their emotional resources are depleted, workers feel they are no longer able to give of themselves at a psychological level" (Maslach \& Jackson, 1981, p. 99), which results in emotional exhaustion.

Depersonalization is another aspect of the burnout syndrome and can be characterized by “[...] negative, cynical attitudes and feelings about one's clients" (Maslach \& Jackson, 1981, p. 99). The third aspect of burnout, diminished personal accomplishment is typically demonstrated as a "[...] tendency to evaluate oneself negatively, particularly with regard to one's work with clients. Workers feel unhappy about themselves and dissatisfied with their accomplishments on the job." (Maslach \& Jackson, 1981, p. 99)

It has been documented that the most prone to develop burnout are practitioners directly involved in helping people (Golembiewski \& Munzenrider, 1988; Maslach \& Jackson, 1984; Maslach et al., 2001; Stamm, 2005). Thus, within the past three decades many nurses (Buunk, Ybema, Van der Zee, Schaufeli, \& Gibbons, 2001; Hiscott \& Connop, 1990; Jourdain \& Chênevert, 2010) and physicians (Aftab, Shah, \& Mehmood, 2012; Dyrbye \& Shanafelt, 2011; Leiter, Frank, \& Matheson, 2009), teachers and special educators (Cunningham, 1983; McIntyre, 2011, Maslach et al., 2001), psychologists 
(Ackerley, Burnell, Holder, \& Kurdek, 1988; Suran \& Sheridan, 1985; Viveros \& Herrera, 2009), and mental health workers (Kelloway \& Barling, 2011; Martin \& Schinke, 1998; Rössler, 2012) have been observed to suffer from occupational burnout.

\section{Burnout in Social Work}

Social workers, whether already practicing in the field or still completing their studies, have not been immune to suffering from burnout. Regardless of the specialization practiced, when compared to other helping professionals, they frequently exceed (often reaching 54\%) the national burnout rates (Acker, 1999; Gilbar, 1998; Jayaratne \& Chess, 1984; Jayaratne, Davis-Sacks, \& Chess, 1991; Jayaratne, Himle, \& Chess, 1988; Lloyd, King, \& Chenoweth, 2002; Maslach, 1982; Robichaud, 2004; Siebert, 2006; Um \& Harrison, 1998; Van Hook \& Rothenburg, 2009).

Nonetheless, the rates of burnout vary only slightly among social workers in various fields of specialization. For instance, in the demanding area of child welfare, workers consistently demonstrate high levels of emotional exhaustion (50\%) and depersonalization (54\%), two of the three essential facets of burnout (Jayaratne, Chess, \& Kunkel, 1986). Similarly, higher levels on these two subscales appear in studies of mental health counselors (Acker, 1999) and hospital-based AIDS social workers (Oktay, 1992). Moreover, $60 \%$ of geriatric social workers are believed to experience burnout, at least once in a lifetime (Poulin \& Walter, 1993b). Yet, practicing social work professionals are not the only ones experiencing occupational burnout. It can be found even among students still fulfilling their educational obligations.

\section{Burnout among Social Work Students}

When compared with other human service professionals (e.g., child and family 
services workers, general health workers, and school personnel) social work students are generally more prone to develop burnout (Stamm, 2005) and to endure educational and training-related stress (Collins, Coffey, \& Morris, 2010). Although the studies that have investigated burnout among social work students are still scarce, the growing body of evidence demonstrates alarming results. To begin with, even during the first year of instruction, MSW students show a tendency toward developing clinical burnout, while exhibiting moderate levels of emotional exhaustion and depersonalization (Han, S. E. Lee, \& P. A. Lee, 2012). Tobin and Carson (1994) suggested that this inclination might be triggered by already higher levels of professional stress during social work formative years than those documented for trainees in the psychology and teaching fields. Thus, numerous and excessive stressors that social work students encounter in preparation for the professional life might lead later on to the development of occupational burnout (Pottage \& Huxley, 1996). Moreover, when faced with the realities of practice, idealistic social work students show a tendency to experience emotional exhaustion (Ngai \& Cheung, 2009).

Similarly, an increasing number of researchers have investigated heightened compassion fatigue (the deleterious effects of working with traumatized clients) and burnout among undergraduate and graduate social work students who are engaged in field placements (Harr \& Moore, 2006). Compassion fatigue is often erroneously used as a synonym of vicarious traumatization and secondary traumatic stress, although each one is a separate construct. Secondary traumatic stress (STS) has been defined as "natural and consequential behaviors and emotions resulting from knowing about a traumatizing event experienced by a significant other [or client] and the stress resulting from helping or 
wanting to help a traumatized or suffering person [or client]” (Figley, 1995, p. 7).

Vicarious traumatization (VT) is the process of transforming the service provider's cognitive thinking (e.g., the feelings of control, safety, and even spiritual beliefs) through chronic exposure to their clients' traumatic experiences (Brockhouse, Msetfi, Cohen, \& Joseph, 2011). Compassion fatigue (CF) often relates to a syndrome combining elements of both STS and VT, and it usually occurs over time (Figley, 1995).

Thus, in spite of limited literature on the topic, it appears that social work students, as compared to other human service professions' apprentices, frequently endure elevated levels of prolonged stress and psychological affliction (Dziegielewski, RoestMarti, \& Turnage, 2004; Romph, Royse, \& Dhooper, 1993). This, consequently, may produce serious and long-lasting consequences.

\section{Consequences of Burnout}

The consequences of burnout are numerous and can be observed on an organizational as well as a personal level (Maslach \& Jackson, 1981). Various forms of physical job withdrawal (e.g., spending as little time at work as possible, taking longer breaks, absenteeism) are usually the first signs of burnout. Emotional detachment quickly follows, and burned out individuals who continue at their jobs exhibit lower productivity and effectiveness. Furthermore, decreased work satisfaction and reduced professional commitment, apparent in the next stage, usually have a negative effect on other workers. In this regard, people who experience burnout have the tendency to cause interpersonal conflicts and disrupt the job performance of their co-workers (Jackson \& Maslach, 1982). Furthermore, the quality and continuity of services provided to clients by an individual affected by burnout can be substantially diminished (Maslach \& Pines, 
1979). Ultimately, people who experience burnout are more prone to change careers, or exit the workforce, which entails enormous costs, both direct (e.g., cost of separation, replacement, and training) and indirect, for instance decreases in clients' well-being, lessened placement permanency in social welfare, and lowered client satisfaction with the agency and services provided (Blankertz \& Robinson, 1997; Braddock \& Mitchell, 1992).

Burke and Greenglass (2001) reported that burnout also leads to behaviors that cause deterioration in people's personal lives. Typically, the individual transfers workrelated stress into the home environment, resulting in heightened tension, anxiety, anger, and frustration. People experiencing burnout also tend to withdraw from family and friends, who, with time, have increasing difficulty in continuing their support for the affected individual (Maslach et al., 2001).

Eventually, burnout may lead to health-related problems. People experiencing burnout are more likely to suffer from insomnia, anxiety, and depression, and in extreme cases develop suicidal tendencies. Another serious issue relating to the development of burnout is an excessive use of medication and alcohol, which has been increasingly observed in this population (Maslach et al., 2001).

\section{Proposed Solutions}

Due to the high prevalence of stress, and consequent burnout among social workers, there have been many attempts to counter the effect of this phenomenon. However, since in the majority of the current literature the antecedents of burnout are usually categorized in two major areas: organizational, and individual (i.e. development 
of personal competences), the attempted solutions will also naturally fall into these classifications.

Recently, there have been many published studies that focus on finding solutions to burnout within organizational contexts and structures. Some of the proposed options include: granting time away from work (sanctioned time out), reflective supervision, peer coaching and support, continued training and education, and rotation of job assignments (Hagen, 1989; Jayaratne et al., 1988; Noble \& Irwin, 2009). However, the influence of organizations on the development of burnout is just a part of the whole picture. As Jayaratne eloquently noticed, "a healthy employee leads to a healthy organization" (Robb, 2004, para.10). Thus, it appears imperative to also address burnout solutions on the level of personal competencies.

On this individual level, coping with burnout (and preventing it) typically focuses on stress and time management. However, as Newsom, Christopher, Dahlen, and Christopher (2006) pointed out, very few human service programs teach their students self-care strategies. Yet, in the profession that has one of the highest burnout rates rooted in stressful occupational conditions, the need to build resilience is immense and should begin in the students' formative years (Grant \& Kinman, 2012). Jayaratne and his colleagues (1991) suggested two main goals in preparing social work students to actively cope with stress in their future (or current) work environment. To begin with, they recommended that the schools of social work develop appropriate training for the students to increase their abilities to cope with stressful situations. In addition, schools of social work ought "[...] to build organizational structures that nurture and protect the well-being of individuals. The goal should be to make agency practice good for the health 
and well-being of the practitioner, because the ultimate beneficiary would be the client" (Jayaratne et al., 1991, p. 229). Similarly, Maslach and colleagues (2001) and Jones (2007) emphasized the importance of educating social work students to recognize burnout symptoms, and to employ various strategies to cope with stress, and therefore, prevent burnout. Bride and Figley (2007) upheld the notion that social work curricula should integrate prevention of compassion fatigue and self-care techniques in order to provide students (and later practitioners) with new standards of self-care necessary for their optimal functioning in the profession. It has been shown that intervention programs, even short seminars on the issues of handling stress and preventing burnout, can result in significant improvement in those areas (Dziegielewski, Roest-Marti, \& Turnage, 2004).

Mindfulness. In recent years mindfulness has gained considerable attention as a self-care tool for professionals in helping occupations and as a clinical intervention in a number of mental and physiological health issues, for instance anxiety, depression, chronic pain, fibromyalgia, and psoriasis (Baer, 2003; Hofmann, Sawyer, Witt, \& Oh, 2010). Mindfulness, in contrast to mindlessness (which is often driven by emotional rumination), requires paying attention to the current moment without any judgment (Kabat-Zinn, 1990). Although research on the effects of mindfulness on social work students' well-being is scarce, the available studies offer promising results. For instance, it has been reported that even such a basic self-care tool like a weekly journaling by the graduate social work (SW) students resulted not only in their general stress reduction, but also improved their performance in school assignments and while working with clients (Moore, Bledsoe, Perry, \& Robinson, 2011). 
Mindful awareness (or mindfulness) has been also shown to reduce one of the burnout factors--emotional exhaustion, related to experiences in a field placement, among social work students (Ying, 2008). It was also associated with overall lower emotional contagion (a tendency to synchronize with emotional states and expressions of other people, as described in Neff, 2003) in this population (Ying \& Han, 2007). Finally, positive effects of mindfulness in lowering levels of depression and anxiety (Ying, 2009a), and overall well-being (Ying, 2009b) have been reported.

Mindfulness Training. Mindfulness training in the general population has demonstrated positive effects on well-being and reduction of stress, and therefore on improving individuals' health and functioning (Baer, 2003; Carmody \& Baer, 2008; Grossman, Niemann, Schmidt, \& Walach, 2004; Kabat-Zinn, 1982; Roeser, Skinner, Beers, \& Jennings, 2012; Salmon et al., 2004). In addition, a number of studies on mindfulness-based stress reduction (MBSR) in the field of nursing have shown very promising results in improving well-being and preventing burnout in this helping profession (Cohen-Katz, Wiley, Capuano, Baker, \& Shapiro, 2004; Henry \& Henry, 2003; Poulin, Soloway, Mackenzie, \& Karayolas, 2008). Similarly, incorporating a mindfulness-based wellness program for teachers in training demonstrated their improvement in health and teaching self-efficacy after an 8-week intervention (Poulin et al., 2008). Furthermore, 8-week mindfulness training for Canadian and United States teachers resulted in significant reduction of stress and occupational burnout symptoms among them (Roeser et al., 2013).

Gockel, Burton, James, and Bryer (2012) observed that even short 10-minute mindfulness instruction included in social work clinical interviewing classes resulted in 
long-term benefits; it increased students' self-awareness and improved their ability to exercise better self-care outside practice. Similarly, undergraduate SW students, who underwent between eight and twelve weeks of mindfulness trainings demonstrated enhanced self-awareness, improved ability to cope with educational and training-related stressors (Birnbaum, 2008), and enhanced active listening skills (Goh, 2012).

Spirituality and Religiosity. Over the years, many studies have shown the positive effects of religious and spiritual practices on various aspects of health, mortality rates, overall well-being, and happiness (Cohen \& Koenig, 2002; Jones, 2004; Richards \& Bergin 2005; Siegel, Anderman, \& Schrimshaw, 2001; Tovar-Murray, 2011). For instance, people who receive spiritual and religious support have been observed to lead generally healthier lives. Religion and spirituality are believed to contribute to individuals' overall well-being by providing them with a sense of sacredness in ordinary existence, and offer spiritual comfort when they encounter life challenges (Jones, 2004). In addition, quicker recovery from various physical and emotional health issues, such as heart and liver problems, emphysema, hypertension, depression and anxiety disorders, and substance abuse, have been also demonstrated as a result of religious and spiritual support (George, Larson, Koenig, \& McCullough, 2000). Moreover, spiritual practices might counteract the effects of stress-related behaviors, for instance poor eating habits and substance abuse (Siegel et al., 2001). Finally, religious practices and spiritual beliefs are credited for positively affecting not only health, but also overall happiness (TovarMurray, 2011).

The results of studies investigating the effects of spirituality and religiosity on burnout among professionals in the social work field have not been uniform. On one hand 
some researchers claim that both religious and spiritual practices can significantly reduce burnout rates among professionals in helping occupations, such as social workers (Ciarrocchi, Golden, Piedmont, \& Rodgerson, 2004; Persing, 2000). Other investigators refute any positive influence of these convictions and practices on burnout in helping professions (Figley, 2002; Robichaud, 2004). Another issue, complicating the picture of the relationship between religiosity/spirituality and burnout is the lack of applicable studies with social work student populations. To date, there has been only one report on the topic, which was limited to a small sample of students from a Northern California university, using emotional well-being as an outcome (Ying, 2009b).

\section{Rationale for this Study}

As revealed in the preceding sections, social work students are at high risk of developing burnout already during the formative years and while practicing in the field. Consequently, the need to counter the effects of conditions leading to burnout becomes urgent. Finding long-term solutions to burnout at all levels of person-in-environment functioning: individual (personal and professional), micro (clinical interventions), macro (community), and mezzo (policies) is beyond the scope of this study, as it requires an extended and systemic approach. However, the possible working (evidence-based) solutions to the inner level of social workers' functioning can be addressed in the current study. Christina Maslach (2011), the recognized expert in occupational burnout, recently stated that " $[\ldots]$ the worker's internal experience of burnout plays a mediating role between the impact of external job stressors and work-related outcome (such as absenteeism, or illness)" (p. 44). Still, to date no literature exists on the effects of the practice of mindfulness on all facets of burnout among social work students. Therefore, 
to address the issue of the internal experience of social work professionals (in training and already practicing in the field), this study aimed at exploring the possible influence of mindfulness to prevent, or at a minimum moderate, the effects of burnout among social work students (and social work practitioners), with the ultimate goal of developing a brief mindfulness intervention for these specific populations.

Initially, this research examined the influence of a number of control variables on reported burnout among MSW students. The investigation then proceeded with the evaluation of the relationship between the years of practicing in social work settings and levels of burnout among social work trainees. In addition, the possible influences of the years in the MSW program on experiencing burnout were assessed. Furthermore, the investigation explored the combined effects of both years of practicing social work and the years in the MSW program on burnout. Moreover, the question of whether burnout levels could be mediated by one's spiritual and religious beliefs, years of practice experience, and years in the MSW program was investigated. Controlling for the effects of the aforesaid relationships, this study also explored the direct effects of mindfulness on all factors of experienced burnout in the social work student population.

\section{Brief Review of the Content of this Dissertation}

Following the introduction, this study first attends to the comprehensive review of the literature on burnout, its etiology, prevalence in helping professions and in social work (especially among social work students), and burnout consequences. Next, the literature on the practice of mindfulness, spirituality, and religiosity, three of the solutions proposed in the available research, and their effect on burnout is examined in a similar fashion. Moreover, the theoretical explanations for burnout and mindfulness are explored. 
Subsequently, research questions and hypotheses associated with the major study variables are offered, followed by the overview of the study's methodology (design, sampling, measures, and procedures). Various statistical analyses are presented and discussed in the following chapter. The dissertation concludes with a discussion of study findings, the limitations of the study, its implications for the field of social work, and recommendations for future research. 


\section{CHAPTER 2: Literature Review \\ Burnout}

\section{Definitions of Burnout}

The burnout phenomenon has been observed and described by researchers for almost half a century now. Although for years the term has been used in studying various populations, capacities, and cultures, there is still no uniform definition of the concept. The expression "to burn oneself out," according to Partridge (1961), referred to working hard or dying early, and originated in English slang. Bradley (1969) was first to introduce it in professional literature as a psychological phenomenon, after observing psychological exhaustion in probation officers working with young delinquents. Thus, he was the first to officially perceive the work environment to be responsible for his workers' "burnout" and proposing the reorganization of the workplace as means to amend it.

Freudenberger (1974) was first to provide detailed descriptions of burnout among young volunteers working in a New York drug addiction clinic, and therefore has been regarded as the inventor of the term. Initially, he identified burnout as "failing, wearing out, or becoming exhausted through excessive demands on energy, strength, or resources" (pp. 159-160), after observing workers' gradual transformation from idealistic, devoted enthusiasts into disillusioned, indifferent caregivers, who displayed the symptoms of exhaustion (e.g., sleeplessness, headaches, or high irritability), depression, and social fear. Later, Freudenberger (1983) modified his original definition of burnout and described it as a process, involving an individual's personality, work performance, 
and social relations, as well as a person's interactions with the organizational structure.

He was also among the first clinicians to point to burnout as an occupational hazard in the helping professions, having experienced it twice in his career.

Edelwich (1980) described burnout in a similar way, as:

[...] a progressive loss of idealism, energy, and purpose by people in the helping professions as a result of the conditions of their work. Those conditions range from insufficient training to client overload, from too many hours to too little pay, from inadequate funding to ungrateful clients, from bureaucratic or political constraints to the inherent gap between aspiration and accomplishment. (p. 14)

Comparably, Cherniss (1980) considered burnout to involve a gradual process affecting new professionals, who while being confronted with the realities of their organizational environments undergo a series of negative changes in their attitude and behavior. Correspondingly, when workers in a secularized Western society expect the organizations to provide meaning to their lives, they are prone to experience helplessness, hopelessness, and/or entrapment associated with low self-esteem, the antecedents to burnout (Pines, Aronson, \& Kafry, 1981). In contrast, Hallsten (1993) identified self-esteem issues as contributing factors and prerequisites to the burnout process. Astoundingly, the Diagnostic and Statistical Manual of Mental Disorders ([DSM-V], American Psychiatric Association, 2013) does not provide any official diagnosis for burnout syndrome.

More than three decades ago, Maslach and Jackson (1981) attempted to make the definition of burnout more specific. Based on data gathered from a wide range of human service professionals, they established its three components: excessive emotional exhaustion, depersonalization, and a diminished sense of personal accomplishment. Emotional exhaustion denotes feelings of being overextended and depleted of emotional 
and physical resources. Depersonalization is characterized by a cynical, negative attitude toward clients and co-workers, and disproportionate detachment from various aspects of the job. A reduced sense of personal accomplishment occurs when an individual has strong beliefs of personal incompetence, as well as ineffectiveness and unproductiveness on the job (Maslach \& Jackson, 1984). The Maslach Burnout Inventory (MBI), a multidimensional measure, was developed to unify the assessment of experienced burnout (Maslach \& Jackson, 1981). Originally, the measure was designed for use with people working in human services, health care, and education, and was later adapted to measure burnout in other, not human services, professions. MBI continues, since its creation, to be the most widely used instrument in burnout research in spite of its limited application to the outside, non-work related environments (Wheeler, Vassar, Worley, \& Barnes, 2011).

\section{Types of Burnout}

Gillespie (1982) classified burnout as "active burnout," related to external variables, or "passive burnout" associated with internal variables.

Organizational and environmental factors constitute the external variables that contribute to "active burnout." A negative impact of the organization on the individual can occur through excessive workload and responsibility, or through minimal job expectations. Moreover, unfair treatment and/or lack of appropriate rewards can have a damaging emotional effect on a worker, and thus, create bases for development of "active burnout." Isolation of workers from each other, or allowing interpersonal conflicts in the workplace to prevail may produce similar effects. Even unrealistic pre-employment 
expectations and conflict between individual and organizational goals may also contribute to the development of "active burnout" (Meyer, 1982).

Among environmental factors increasing the risk of "active burnout" stress, anxiety, tension, or hostile interactions with family members, friends, or other important people should be mentioned. Moreover, having an external locus of control (supervisors, customers, or family members) can contribute to development of "active burnout" (Meyer, 1982).

"Passive burnout" has been related to the existence of internal struggles, often developed from unresolved personal and/or career issues. Self-determination theory (SDT) postulates that major intrinsic motivational determinants of behavior are three psychological needs, to feel competent, to feel self-determining, and to feel interpersonally connected (Ryan \& Deci, 2000). When fulfilled, these three needs lead to increased self-motivation, better self-regulation, and more active coping, which positively affect overall well-being. Internal motivation, although inherently common in human beings, nevertheless requires supportive external conditions to be maintained (Deci, Connell, \& Ryan, 1989). Thus, when meeting any of these needs is threatened or thwarted, whether in the home, school, or work environments, stress reactions are triggered, which may lead to serious motivational and health consequences (Ryan \& Deci, 2000). When a person is unable to connect/relate to others, use self-determination and competence, for instance in a workplace, the stress caused by these unmet needs may also lead to the development of burnout. Conversely, it has been shown that fulfillment of the three needs plays a crucial role in regulation of stress, and therefore lowers various symptoms of depression and burnout. Relatedness, in particular, has been shown to be a 
motivational and protective stress-buffering factor (Skinner, Kindermann, Connell, \& Wellborn, 2009; Weinstein \& Ryan, 2011).

Not being able to meet one's idealistic vision of self as a worker or family member, or from an excessive drive to be "the best" at home or on the job all of the time may create feelings of incompetence, dependence, and interpersonal disconnection. These attitudes may also arise as a reaction to specific negative or stressful stimuli on the job or at home, as well as from depression over not being "good enough.” Moreover, seeing oneself as more capable and skillful than others, while at the same time not being able to affect their attitudes or behaviors can create in an individual a sense of desperation and lower his/her morale (Gillespie, 1980-1981).

Although the majority of people experience a combination of "active" and “passive” burnout, which makes it more difficult to manage (Gillespie, 1980-1981), most of the literature on burnout intervention focuses on individual-centered solutions (e.g., resigning from the job, or learning coping skills). This creates paradoxical situations, since the situational and organizational factors play at least as big a role in generating burnout as individual factors (Maslach et al., 2001). Maslach and Goldberg (1998) postulated that a focus on changing the individual, rather than the workforce, prevails because it is easier and cheaper than changing organizations.

\section{Stages of Burnout}

Sofield and Juliano (2000) suggested that development of burnout occurs in four stages. The initial stage is characterized by excessive, obsessive, and exclusive commitment to individual's work. As people progressively reduce time spent on recreation, relationships, or leisure activities, they internalize the belief that their self- 
worth exclusively depends on their work. In this one-dimensional approach to life, individuals at this stage of burnout could be characterized as boring and "sad faced." Their unbalanced lives produce the incapacity to talk about or get involved in anything else but their jobs, which results in receiving limited support from others (Sofield \& Juliano, 2000). This phase is also characterized by elevated stress levels, forgetfulness, persistent irritability and anxiety, and inability to concentrate (Girdin, Everly, \& Dusek, 1996).

Physical and psychological exhaustion, combined with intense questioning of personal growth and the value of one's work occurs in the second stage of burnout (Sofield \& Juliano, 2000). Girdin et al. (1996) also observed that in this phase individuals might be chronically tardy for work, procrastinate, or be late in completing work assignments. Moreover, an increased consumption of food and/or alcohol might occur in this stage. Sofield and Juliano (2000) suggest that during the first two phases of burnout people can still reverse its progression with the help of trusted and caring friends or peers.

During the third phase of burnout the underlying depression becomes evident (Sofield \& Juliano, 2000). Most individuals in this stage tend to withdraw from others and display disappointment in self, in others, and in their work. This state of overall dissatisfaction makes individuals exceptionally judgmental, generating increased isolation from other people. Marked changes in sleeping and eating patterns, constant irritability, and lack of enthusiasm or energy also appear at this stage. Symptomatic of this phase is also the desire to move away from friends, work, and even family/loved 
ones. In extreme cases, the desire and attempts to commit suicide occur (Girdin et al., 1996).

The main characteristic of the final stage of burnout is terminal cynicism. As the loss of the individual's self-esteem progresses, it manifests itself in open hostility toward friends, co-workers, and anybody around. Interpersonal relationships become dominated by cynical attitudes, which in turn, often generate more adverse responses from others. Maintaining emotional detachment from people and events follows, creating a serious impasse in one's life (Girdin et al., 1996). Individuals in this phase usually need specialized professional assistance as they are incapable of accepting help and assistance from friends or loved ones (Sofield \& Juliano, 2000).

Leiter and Maslach (1988) offered a somewhat different approach to stages of developing burnout. According to the authors, burnout progresses sequentially in three distinctive phases: emotional exhaustion, depersonalization, and negative beliefs about personal accomplishments.

Emotional exhaustion appears first, as a direct result of an extended exposure to work-related stress (Leiter \& Maslach, 1988). Feelings of being emotionally and physically overextended are typical for this initial burnout phase. Once the person experiences emotional exhaustion, s/he might attempt to cope with those feelings by detaching and/or depersonalizing from such experiences and people. Cold attitudes toward co-workers and work itself are typically observed in this phase. Therefore, not only does personal exhaustion predict the occurrence of depersonalization, but also personal exhaustion and depersonalization have been shown to have a positive correlation. Depersonalization eventually results in the worker feeling less successful and 
inadequate. Professional projects appear overwhelming and accomplishments insignificant. This leads to a third phase, lowering self-evaluation as a worker in terms of actual personal accomplishments. Thus, depersonalization predicts the worker's perceived level of personal accomplishment and was demonstrated to have a negative correlation with this variable. In contrast, emotional exhaustion and personal accomplishment have not been established as statistically correlated (Leiter \& Maslach, 1988).

\section{Burnout in Various Helping Professions}

Albeit burnout can affect individuals in any occupation, certain types of professionals have been observed to be more prone to its development. Research on burnout in human service professionals began over 35 years ago. It has been hypothesized that social changes in American society, such as industrialization, individualization, breakdown of the family, church, and neighborhood structures, and development of narcissistic/hedonistic attitudes were perfect ground for the growth of professional burnout, especially in populations prone to experiencing "lack of reciprocity" (Schaufeli, 2006). Thus, the research and literature on the topic of burnout was quickly expanding, explaining why many of the available resources have been dated in the 1970s, 1980s, and 1990s. By then, the MBI was used in 93\% of papers, whether published articles, or dissertations on the topic of burnout (Schaufeli \& Enzmann, 1998). Since the turn of the century the interest in burnout has not subsided; however, having covered many areas and populations in the US, the researchers became more focused on global occurrences and specificity, as well as filling in the gaps in the body of knowledge related to burnout (Schaufeli at al., 2009). 
Hence, literature within the last three decades has demonstrated that practitioners in the helping professions experience high levels of burnout (Golembiewski \& Munzenrider, 1988; Maslach \& Jackson, 1984; Maslach et al., 2001). Physicians (Battle, 1981; Taylor, 1982), nurses (Clark, 1980; Yee, 1981), teachers and special educators (Cunningham, 1983, Olson \& Matuskey, 1982; Maslach et al., 2001), psychologists (Suran \& Sheridan, 1985), social workers (Robichaud, 2004), and mental health workers (Maslach et al., 2001) have been identified as ultimate candidates for occupational burnout. Along with job-related stressors (e.g., workload, time pressure, role conflict), these professionals experience high levels of stressors related to contacts with clients, such as difficulties interacting with clients, and frequency of interaction with chronically or terminally ill clients. This increases their risk of burnout by creating a "compounding effect" (Maslach et al., 2001).

\section{Burnout in Mental Health Professions}

Several factors that contribute to burnout have been identified by Maslach (1982) Among mental health and human services employees they include: (1) working with families in crisis; (2) receiving little positive feedback or support; (3) having an external locus of control; (4) a lack of power or control to change problems combined with the influence of funding source requirements; (5) difficulty in defining one's role as a result of conflict between implicit and explicit rules governing the client/worker relationship; (6) difficulty in changing careers due to narrow experience in a field; (7) a demanding workload; (8) low social support; and (9) feeling ineffectual.

Similarly, various correlates of burnout have been studied by other investigators. Within the realm of therapeutic work five general categories of correlates were identified: 
demographic variables, objective work characteristics, types of therapeutic activities, types of therapeutic issues, and factors within the therapeutic setting (Ackerley, Burnell, Holder, \& Kurdek, 1985).

Among demographic factors some researchers have observed negative relationships between age and one of the subscales of burnout, emotional exhaustion (Ackerley et al., 1985; Maslach \& Goldberg, 1998; Maslach et al., 2001). Inconsistent results have been reported for gender. While some studies demonstrated higher burnout levels among women (Freudenberger, 1983; Pines et al., 1981), others identified males as more prone to develop burnout (Ackerley et al., 1985; Maslach et al., 2001). Neither theoretical orientation nor providing interpersonal therapy appeared to affect the amount of burnout in mental health practitioners (Ackerley et al., 1985; Farber \& Heifetz, 1982).

Work characteristics had a noteworthy influence on development of burnout. For instance, private practitioners reported experiencing less emotional exhaustion and depersonalization, as well as more personal accomplishment, and, thus, scored low on burnout (Ackerley et al., 1985; Carroll \& White, 1982; Shinn, 1982). Moreover, the number of years in direct practice was reported to be negatively correlated with emotional exhaustion and depersonalization (Ackerley et al., 1985; Cherniss, 1980; Farber, 1983; Pines et al., 1981). In contrast, a strong positive correlation has been observed between earned income and job satisfaction, as well as between earnings and a sense of personal worth (Ackerley et al., 1985).

As previously noted, Ackerley and colleagues (1985) suggested that the types of therapeutic issues and activities do not appear to have any major impact on the development of burnout. However, among factors within therapeutic settings, clients' 
negative behavior was related to increased burnout levels in therapists (Hellman, Morrison, \& Abramowitz, 1986). Furthermore, perceived lack of control strongly correlated with emotional exhaustion and low personal accomplishment (Ackerley et al., 1985; Hellman et al., 1986). Finally, excessive engagement with clients also resulted in higher burnout scores (Ackerley et al., 1985).

Zapf, Seifert, Schmutte, Mertini, and Holz (2001) revealed that emotion-work variables (e.g., requirements to display or suppress emotions on the job, to be empathic, to emotionally detach from clients or experiences), in addition to job-stressors and clientstressors, markedly impact development of burnout in mental health professionals.

\section{Burnout in Social Work}

Not surprisingly, the growing body of evidence indicates that social workers are at an above-average risk of developing burnout in their organizational environments (Acker, 1999; Gilbar, 1998; Jayaratne \& Chess, 1984; Jayaratne, Davis-Sacks, \& Chess, 1991; Jayaratne, Himle, \& Chess, 1988; Lloyd, King, \& Chenoweth, 2002; Robichaud, 2004; Um \& Harrison, 1998). Siebert (2006), in his study about personal and occupational factors in burnout, reported the rates of current burnout among social workers between $39 \%$ - 54\%, with occurrence of burnout "sometimes in a lifetime" reaching $75 \%$.

Burnout does not affect social workers in one particular specialization, but has been shown to occur in most areas of social work. For instance, in a study of the child welfare field, considered to be one the most demanding areas of social work, the rates of workers' burnout have been close to $50 \%$ on emotional exhaustion and even higher (54\%) on depersonalization (Jayaratne, Chess, \& Kunkel, 1986). Other authors alleged 
the burnout rates among child welfare workers to also be higher than national rates in other helping professions (Maslach, 1982; Van Hook \& Rothenburg, 2009). Similarly, social workers involved in mental health counseling exhibited higher than typical levels of burnout (Acker, 1999). Along the same lines, hospital-based AIDS social workers demonstrated more burnout (heightened rates of emotional exhaustion and depersonalization) than other social workers (Oktay, 1992).

Although it has been claimed (Poulin \& Walter, 1993a) that geriatric social workers experience lower levels of burnout than their counterparts in child and public welfare, and in mental health, the findings in a national longitudinal study of geriatric social workers have also shown that $60 \%$ experienced burnout at least once in their career and that the levels of their burnout showed a relatively stable pattern (Poulin \& Walter, 1993b).

There are several antecedents to burnout identified in the social work profession. To begin with, large caseloads are symptomatic of the social work field, resulting in work overload (Fryer et al., 1989; Maslach \& Leiter, 1997). In addition, the general public is typically not very supportive of social work professionals (Fryer et al., 1989; Fauri, 1978), and hostility of clients is a common occurrence in this career (Cherniss, 1980; Jayaratne \& Chess, 1984). Social workers are also prone to experience lack of control (Maslach \& Leiter, 1997) and either real or perceived unfair treatment (Maslach \& Leiter, 1997). Furthermore, due to diminished opportunities to discharge emotional reactions at work, social workers are more susceptible to emotional exhaustion (Anderson, 2000). Breakdown of the organizational community is also a cause for development of burnout among social workers (Maslach \& Leiter, 1997). Finally, the nature of the social work 
often exposes professionals to suffer secondary traumatic stress or compassion fatigue (Cherniss, 1980).

There have been some valid questions raised about the differences between the constructs of secondary traumatic stress (STS), also called secondary PTSD, and burnout. Thus, it is imperative to briefly explore disparities and similarities of these two concepts. Many researches view them as distinctive constructs, claiming that burnout is a "process," due to excessive and prolonged levels of job stress (Cherniss, 1980; Newell \& MacNeil, 2010, Pross, 2006), while STS is a sudden occurrence, sometimes linked with a single traumatic incident (Figley, 1995; Newell \& MacNeil, 2010, Pross, 2006). In addition, although there is some overlap between the constructs, as both are components of compassion fatigue, based on the studies of social workers using the Professional Quality of Life Scale (ProQOL), each seems to have a unique effect on well-being (Boscarino, Adams, \& Figley, 2010; Conrad \& Kellar-Guenther, 2006). Moreover, even though both concepts are characterized by depression, insomnia, loss of intimacy with friends and family, and both are cumulative (and respond well to adaptive coping skills), there are differences in their causes (Canfield, 2005). On the other hand, in an Australian study, using the Copenhagen Burnout Inventory (CBI), STS and burnout are not considered distinct constructs, but "a state of prolonged physical and psychological exhaustion" (Devilly, Wright, \& Varker, 2009, p. 377). Interestingly, a recent metaanalysis of 41 studies (Cieslak, et al., 2013), under the umbrella of the STS and burnout among professionals working with trauma survivors, suggests that the overlap in constructs depends on measures and theoretical frameworks. For instance, when measured within a compassion fatigue framework, the Professional Quality of Life 
(ProQOL) shared 55\% variance with the Copenhagen Burnout Inventory (CBI). In contrast, while work-related stress was measured by MBI and other than ProQOL-related measures of STS, they shared $30 \%$ of variance in emotional exhaustion, $26 \%$ in depersonalization, and only $12 \%$ in personal accomplishment, with an overall variance of $34 \%\left(\mathrm{EE}: r^{2}=.30\right.$; DP: $r^{2}=.26$; PA: $r^{2}=.12$; Total $\left.r^{2}=.34\right)$. Therefore, in the present study which measures burnout with MBI and uses other than a compassion fatigue framework, secondary traumatic stress and burnout are interpreted as two distinct constructs.

\section{Burnout among Social Work Students}

Although burnout has been shown to affect not only social workers already working in the field, but has been also reported among social work students, there are only a few available studies that have investigated burnout among social work students. In general, from papers that have been written about this population it appears that social work trainees are especially prone to experience educational and training-related stress (Collins, Coffey, \& Morris, 2010). To begin with, an exploratory study of the MSW students with prior work experience demonstrated alarming results (Han, S. E. Lee, \& P. A. Lee, 2012). In this report, the first year social work students already exhibited moderate levels of emotional exhaustion and depersonalization at the beginning of their professional training, which might predispose them for clinical levels of burnout. Furthermore, Tobin and Carson (1994) observed that in a comparison to trainees in psychology and teaching "the student social worker appears to be under considerable stress even before she/he takes up the more onerous responsibilities of a qualified practitioner" (p. 253). Pottage and Huxley (1996) also pointed to the numerous and 
excessive stressors (antecedents to burnout) social work students encounter in their preparation for the professional life. Thus, it is not surprising that in a study of undergraduates, Ngai and Cheung (2009) discovered that social work students tend to experience more emotional exhaustion when their idealistic expectations collide with the realities of practice. In a similar fashion, Harr and Moore (2006) examined the compassion fatigue of social work students (described as "[...] the negative consequences of working with traumatized clients and vicariously experiencing the effects of their traumatic life events.” pp. 351-352) and burnout among undergraduate and graduate social work students in a field placement. By comparing students' scores to the average results for other employed human service professionals (general health workers, childfamily workers, and school personnel), as measured by Professional Quality of Life Scale: Compassion Satisfaction and Fatigue Subscales (ProQOL-CSF-R-IV; Stamm, 2005), they discovered that while compassion levels were similar for the students and the employees, the risk for burnout was higher for the former.

Hence, it appears that social work students could experience elevated levels of stress and psychological distress when compared to trainees in other human service professions (Dziegielewski, Roest-Marti, \& Turnage, 2004; Romph, Royse, \& Dhooper, 1993). This, in turn, may lead to serious and long-lasting consequences.

\section{Consequences of Burnout}

Burnout in human service occupations can have wide spread effects on both the organizations and the personal lives of the workers (Maslach \& Jackson, 1981).

On the personal level burnout often causes deterioration in personal lives by either transference of work-related stress into the home environment or withdrawal from family 
and friends. The stress transference typically appears in the form of emotional and physiological reactions, like anxiety, anger, frustration, and heightened tension. The withdrawal, with time, may result in decreased ability of their loved ones to continue the support for the affected individual (Burke \& Greenglass, 2001; Maslach et al., 2001).

Frequently, burnout may produce health-related problems. Psychological distress (anxiety, depression, low self-esteem, etc.), one of the consequences of burnout, can lead not only to higher turnover rates within an organization, but can also result in serious health problems for an individual (Kim, Ji, \& Kao, 2011; Kim \& Stoner, 2008; Mor Barak, Nissly, \& Levin, 2001). For instance, in the most recent longitudinal study, Kim et al. (2011) have demonstrated that burnout not only resulted in participants' poorer physical health (headaches, respiratory infections, and gastrointestinal symptoms), but that health complaints were negatively associated with years of working in the field. Others (Maslach et al., 2001) recorded other psychological symptoms of burnout: insomnia, anxiety, and depression, and in extreme cases suicidal tendencies.

Depression in this study has been accepted as a construct distinct from burnout. Although a substantial overlap and correlation between these concepts have been established (Maslach \& Jackson, 1986; Meier, 1984), they vary in context specificity, as well as in attributes (Leiter \& Durup, 1994). Depression is considered a global (affecting all aspects of life, not context specific) clinical syndrome (McNair, Lorr, \& Doppleman, 1981), while burnout can be seen as a crisis in one's relationship with work (i.e. affecting quality of social work environment). Leiter and Durup (1994), in a study exploring discriminant validity of MBI and depression confirmed the distinction between the two concepts. While using confirmatory factor analyses between The Profile of Mood States 
[POMS] (McNair et a., 1981), Beck Depression Inventory [BDI] (Beck, Ward, Mendelson, Mock \& Erbaugh, 1961), and MBI, the researchers found support for the differentiation of these two constructs.

Depression is not the only consequence of the psychological distress occurring in burnout. An excessive use of psychoactive substances, especially medication and alcohol, has been frequently observed in human service workers (Maslach, et al., 1986). Ultimately, Drak and Yadama (1996) demonstrated emotional exhaustion to be the key element of burnout relating to high job turnover in the social work field.

On the organizational level burnout can negatively affect the quality and consistency of client services (e.g. avoiding direct and indirect contacts with clients due to the loss of concern for them--disregarding their problems, stereotyping clients and thus, displaying a sarcastic and pejorative attitude toward them; Maslach \& Pines, 1979). Burnout may also lead to various forms of physical job withdrawal (for instance, taking prolonged breaks, cutting work time, absenteeism) that usually coexist with emotional detachment, characterized by lowered productivity and reduced personal commitment, which often leads to serious interpersonal conflicts and disruptions of the performance of co-workers (Jackson \& Maslach, 1982). This often results in prematurely exiting the workforce.

In line with the other research evidence, Kim and Stoner (2008) inferred " [ ... ] that burnout mediates the relationship between social workers' perceived role stress and the intention to quit their current jobs" (p. 8). Other studies have also demonstrated that, in child welfare, annual turnover rates oscillate between 39\% - 50\% (Ben-Dror, 1994; Jayaratne \& Chess, 1984), sometimes even reaching and exceeding 60\% (Geurts, 
Schaufeli, \& De Jonge, 1998). While the direct expenses, such as cost of separation, replacement, and training are easier to assess, and the indirect expenditures are harder to evaluate, the overall price of such high turnover in the social work field can be enormous (Blankertz \& Robinson, 1997; Braddock \& Mitchell, 1992). Consequently, the direct and indirect effects that high turnover rates can have on clients are of special importance in helping professions, and particularly in social work. It is because of high turnover that human service agencies may not only compromise the continuity and quality of care but may also negatively affect clients' well-being. This has been especially true for the most

vulnerable clients, such as people with mental health issues and children (Balfour \& Neff, 1993). For instance, in child welfare system retention challenges have been shown to critically affect children's safety and placement permanency (U.S. General Accounting Office, 2003). Thus, when the rapport and trust with social workers has been minimized or destroyed, children's, families', and communities' satisfaction with the agency and the social services might be irrevocably diminished (Powell \& York, 1992).

\section{Mindfulness}

\section{Etiology and Definition of Mindfulness}

Mindfulness practices, in this study called simply mindfulness, originated in the East, and have become known in the Western world through the increasingly more popular meditative techniques of Buddhism. However, their roots can be traced as far back in human history as yogi practices before 500 B.C., being recorded in the sacred Hindu books of Upanishads (Miller, Fletcher, \& Kabat-Zinn, 1995; Wood, n. d).

To understand Buddhist thought is to understand the Four Noble Truths on which it is based. The First Noble Truth deliberates on the ever present suffering in people's 
lives, from physical limitations and illnesses, through mental and emotional afflictions, to inevitable death experiences. The Second Noble Truth suggests that the origins of the suffering lie in the human tendency for overindulgence, that is, the excessive gratification of one's desires and attachments. However, according to the Third Noble Truth, the suffering is not indispensable, although some experiences might remain unpleasant or painful. Breaking free from suffering is attainable, as the Buddhists claim in the Fourth Noble Truth, by the acquisition of self-awakening. This requires staying mindful of the mechanisms that allow our desires and attachments to guide our thought and actions, leading ultimately to suffering (McIntosh, 1997).

Thus, mindful awareness practices lie central not only to enlightenment, but also to conquering human misery that derives from greed, hatred, and ignorance. Mindfulness helps to overcome these natural tendencies, and as a result, opens the heart and clarifies the mind. What follows through this mental shift is the refinement of people's actions that transcends human mental suffering. This deliverance from personal suffering into peace can be achieved by any individual, regardless of personal beliefs, cultural backgrounds, and life experiences. Perhaps such universalism of this seemingly simple practice could be credited for the ever-growing interest in applying mindfulness practices in the Western world (Kabat-Zinn, 2003; McIntosh, 1997).

Meditation, in general, is a form of mental activity based on intentionally selfregulating one's attention. It does not aim at altering any religious beliefs or changing cognitive functions, but rather at observing them (Goleman \& Schwartz, 1976). Thus, in mindfulness, sometimes also called awareness meditation, in contrast to mindlessness, often driven by emotional rumination, the person is required to suspend judgment of 
his/her internal and external experiences. As Kabat-Zinn (2003) eloquently states, mindfulness in practical terms can be described as "[...] the awareness that emerges through paying attention on purpose, in the present moment, and nonjudgmentally to the unfolding of experience moment by moment," (p. 145).

This definition of Kabat-Zinn's (2003) will be used in the present study, as it includes the essential fundamentals of mindfulness, and describes it without oversimplifying the concept.

\section{Mindfulness-based Therapies as Clinical Interventions}

In the past 30 years Mindfulness-based Therapies (MBT) have gained considerable attention as clinical interventions in addressing a number of mental and physiological health issues (e.g., anxiety, depression, chronic pain, cancer, and psoriasis). For instance, based on the analyses of 39 studies Hofmann et al. (2010) concluded that clinical populations experiencing anxiety and mood disorders respond well to MBT and the affirmative outcomes are maintained even at follow-ups. Similar results were obtained for populations with cancer, psoriasis, and high stress levels by Baer (2003). The author pointed out that some studies in her analysis, which incorporated random assignments, not only have shown positive outcomes with the use of MBT, but fulfilled the criteria for empirically-validated interventions, one of the main criticisms of many studies using mindfulness in clinical settings. Moreover, the propensity of mindfulness practices to assist in decreasing chronic pain in clinical populations has been demonstrated over the years. Although the specific improvements in pain levels, psychological distress, and health-related quality of life vary with the type of pain, the effects of MBT have been evidenced to increase with regular practice. That is, greater 
mindfulness was directly associated with patients' better overall functioning and pain tolerance (Kabat-Zinn, 1982; Kabat-Zinn, Lipworth, \& Burney, 1985; McCracken, Gauntlett-Gilbert, \& Vowles, 2007; Rosenzweig et al., 2010).

The most recent meta-analysis of 209 carefully selected studies of MBT (Khoury et al., 2013) has again demonstrated that these types of interventions had moderately successful effects as shown in pre-post studies on cancer, pain, anxiety, depression, and other psychological disorders. These analyses also demonstrated that MBT is more effective in treating mental conditions, especially anxiety and depression, than when applied to medical/physical ailments. In addition, the analysis has shown that mindfulness plays an important role in the effectiveness of MBT.

Khoury et al. (2013) demonstrated that among the most regarded MBT, Mindfulness-based Stress Reduction (MBSR) and Mindfulness-based Cognitive Therapy (MBCT) have consistently achieved noteworthy statistical results. As the authors clarify, some other well-known MBT, for instance Acceptance and Commitment Therapy (ACT) and Dialectical Behavior Therapy (DBT) were excluded from the analyses, due to the element of mindfulness being one of the components of the treatments and therefore difficult to be established as a primary therapeutic tool in them. All above mentioned therapies incorporate mindfulness in the process, yet MBSR has become the best known, a staple MBT intervention since its inception in 1980s.

MBSR therapy was developed by Kabat-Zinn (1982) and introduced the concept of mindfulness to Western medical settings, at first applying it to the management of chronic pain, and subsequently to other physical and mental conditions (Baer, 2003; Grossman et al., 2004; Salmon et al., 2004). MBCR consists of weekly meetings for 8-10 
weeks in groups of no more than 30 people. The participants are typically taught three sets of relevant skills: body scanning, sitting meditation, and Hatha yoga movements. In body scanning, during a 45-minute session the person sequentially observes consecutive parts of his/her body and its sensations, while lying in the relaxed pose, with the eyes closed. Sitting meditation with the eyes closed aims at wakefully observing the experience of breathing and the Hatha yoga poses direct one's attention to the bodily sensations occurring during gentle stretches and postures. These exercises are not limited to the group meetings, but are to be executed at least six days a week for a minimum of 45 minutes daily. If necessary, audiotapes are used to guide the participants' practices. The main goal of these practices is to focus attention on the sensations occurring from moment to moment, without any judgment and without getting engrossed in thought processes. Eventually, the person realizes that any sensation, whether bodily or cerebral, is transient (Kabat-Zinn, 1982).

\section{Mindfulness-based Therapies as Self-care Tools in Helping Occupations}

Mindfulness practices have also gained considerable attention as self-care tools for professionals in helping occupations. Health care professionals (practicing, and in training) are exposed to a plethora of work-related hazards, which can lead, as mentioned in earlier sections, to exacerbated stress, various physical and emotional problems, and burnout. Thus, in a search for self-care tools to improve well-being in these professional groups the use of mindfulness has been explored. Consequently, mindfulness training in the general population has been observed to have positive effects on well-being and reduction of stress, and therefore on improving individuals' health and functioning (Baer,

2003; Carmody \& Baer, 2008; Grossman, Niemann, Schmidt, \& Walach, 2004; Kabat- 
Zinn, 1982; Salmon et al., 2004). For instance, Shaprio, Brown, and Biegel (2007) reported improvements in mental health among Master level counseling psychology students exposed to mindfulness practices. In particular, stress level, rumination, and anxiety were reduced, while both positive affect and self-compassion improved after the students had been introduced to the MBSR curriculum. Similar outcomes were obtained with by Jain et al. (2007) for premed students, medical students, and nursing students. Even brief, one-month long exposure to mindfulness practices resulted in decreased psychological distress, rumination, and reduction in destructive thoughts and behaviors. Interestingly, the authors suggest that reduction in rumination via mindfulness practices may serve as a mediator in reducing psychological distress. Shapiro, Astin, Bishop, and Cordova (2005) attempted to extend the research on the effect of mindfulness training to practicing clinical health care professionals, including physicians, nurses, social workers, physical therapists, and psychologists. After involvement in an 8-week MBSR program the participants reported significant decreases in perceived stress and increases in life satisfaction. In a similar study by Galantino, Baime, Maguire, Szapary, and Farrar (2005) involving administrators and direct care hospital employees, at the conclusion of the study the participants reported a decrease in emotional exhaustion and the mood improvement. In addition, a number of studies on mindfulness-based stress reduction (MBSR) in the field of nursing have shown very promising results in improving wellbeing and preventing burnout in this population (Cohen-Katz, Wiley, Capuano, Baker, \& Shapiro, 2004; Henry \& Henry, 2003; Poulin, Soloway, Mackenzie, \& Karayolas, 2008). Even after a short 4-week mindfulness intervention, nurses and nurses' aides enrolled in the study reported being more relaxed, feeling more satisfied with life, and exhibited 
fewer burnout symptoms, indicating an improvement in the management of stress (Mackenzie, Poulin, \& Seidman-Carlson, 2006). Similarly, incorporating a mindfulnessbased wellness program for teachers in training demonstrated their improvement in health and teaching self-efficacy after the 8-week intervention (Poulin et al., 2008).

\section{Mindfulness as a Self-care Tool in the Social Work Profession}

Although research on the effects of mindfulness on social work students' wellbeing is scarce, the available studies offer promising results. For instance, it has been reported that even such a basic self-care tool like weekly journaling by the graduate SW students resulted not only in general stress-reduction, but also improved their ability to perform better in school assignments and while working with clients (Moore, Bledsoe, Perry, \& Robinson, 2011).

While it has been shown that social support serves as a reigning form of self-care in this population (Gelman, 2004; Koeske \& Koeske, 1989), Ying (2008) proposed another solution. After conducting her study with the second-year Master of Social Work (MSW) students, based on the self-reports of the participants, she purported that mindful awareness (or mindfulness) and self-detachment, "[...] defined by a reflective, balanced, accurate assessment of reality" (p. 130), two of the essential components of selfcompassion, can have a positive effect on well-being, by reducing students' emotional exhaustion in field placement. Additionally, Ying and Han (2007) observed overall lower emotional contagion, a tendency to synchronize with emotional states and expressions of other people (as described in Neff, 2003), among social work students who exhibited higher levels of mindfulness. Moreover, another Ying (2009a) study indicated that mindfulness had a positive effect on students' mental health (as correlated with lower 
levels of depressive symptoms and anxiety). Correspondingly, in a study comparing the function of religiosity, spirituality, and mindfulness on MSW students' well-being, measured by the Spielberger Trait Anxiety Inventory (Spielberger, Gorsuch, \& Lushene, 1970), and California Psychological Inventory (CPI) - Depression Scale (Gough, 1987), only mindful awareness was positively correlated with their mental health (Ying, 2009b). Thus, the author suggested that pre-existing religious or spiritual practices and/or convictions do not appear to interfere with the practices of mindfulness.

In one of the few existing studies of mindfulness training given to students of social work Gockel, Burton, James, and Bryer (2012) found that such an intervention could have long-lasting positive outcomes. Incorporating even brief 10-minute mindfulness coaching into clinical interviewing classes resulted in long-term beneficial effects, although initially there were no differences in the reported levels of well-being among intervention and nonrandomized cohort control groups. Noteworthy was the participants' increased self-awareness, which allowed students to set appropriate boundaries around their work with clients, and also increased their ability to practice better self-care outside practice. Similar results were obtained by Birnbaum (2008), who noted that enhanced self-awareness and improved ability to cope with educational and training-related stressors, were observed in a group of undergraduate social work students, who underwent eight weeks of mindfulness training. In yet another study, increased self-awareness instigated by 12 weeks of mindfulness exercises has also been shown to improve SW undergraduates' active listening skills (Goh, 2012). Finally, a recent study by Bonifas and Napoli (2013), investigating the incorporation of 16-week mindfulness training into MSW curriculum has demonstrated promising results. Not only 
had the students reported marked improvement in three domains of quality of life: health and functioning, social and economic, psychological and spiritual, but also that the training enhanced their stress management skills.

\section{Spirituality and Religiosity}

\section{Definitions of Terms}

Religiosity and spirituality are frequently used as interchangeable terms (Stanard, Sandhu, \& Painter, 2000). However, they are not synonymous, but rather two distinct concepts that often share intersecting similarities (Hodge, 2000).

Corbett (1990), for instance, defines religiosity as a system of beliefs, experiences, and rituals shared among members of a particular group. However, some researchers emphasize that being religious is to not only participate in communal, regulated, and ideological activities, but also to practice specific rituals individually and develop unique views of the world and humans' role in it. Thus, as Ellwood (1992) accentuates, more often than not, religiousness incorporates spiritual elements, in both communal worship and in personal practice. Accordingly, the abovementioned definition of religiosity (Corbett, 1990) will be utilized here, for it describes the concept in simple, understandable terms and at the same time allows one to differentiate it from spirituality, therefore enabling them to be handled in this study as two separate control variables.

Alternatively, spirituality does not require any theistic connotation (Richards \& Bergin, 2005). It encompasses a more universal approach to life and its implications (May, 1982). Therefore, to have a spiritually meaningful life and purpose individuals do not need to hold any beliefs in God or even in a higher power (Stoll, 1989). 
Benjamin and Looby (1998) reasonably differentiated spirituality and religiosity in terms of universality. They contended that spirituality is a universal concept, because it can exist both in and out of a religious context, while the opposite is not necessarily true. Thus, to put it in simple terms, spirituality can be viewed as an expression of a person's perception of reality, whereas religion is its external demonstration with practices and rituals shared with like-minded individuals (Hodge, 2000). It could be argued, then, that a religious person is frequently a spiritual being, in the finest scenario; however, spiritual people are not necessarily religious (Ellwood, 1992). Hence, May's (1982) definition of spirituality, explicated as the acquisition of meaning and purpose through life experiences, independently of religious affiliations and connotations, will be employed in this investigation.

\section{Religion, Spirituality, and Well-being}

For years religiosity has been shown to positively influence numerous areas of people's lives, such as health, self-esteem, and even mortality rates (Cohen \& Koenig, 2002; Richards \& Bergin 2005; Siegel, Anderman, \& Schrimshaw, 2001). Within the past two decades, the relationship between spirituality and health has begun to be explored as well. Siegel et al. (2001) indicated that spirituality, as an element of religious affiliation, might counteract some health-related stressors (e.g., poor eating habits, substance abuse). Similarly, George, Larson, Koenig, and McCullough (2000), in the review of the available literature on the topic discovered that individuals who receive support for their sense of worth and spiritual identity through religious affiliation heal at a faster rate from certain diseases (e.g., experiencing heart and liver problems, emphysema, hypertension, depression and anxiety disorders, and substance abuse) and lead generally healthier lives. 
Furthermore, Jones (2004) suggested "that being motivated by matters of ultimate concern, attributing sacredness to ordinary activities, receiving spiritual comfort, experiencing a sense of the sacred are all means through which religion makes a unique contribution to human well-being"(p. 326). Finally, Tovar-Murray (2011) demonstrated that religious practices and spiritual beliefs positively affected not only health, but also affected overall happiness. Thus, overall, religious practices and spirituality have been demonstrated to lower the presence of diseases, and decrease mortality rates (Cohen \& Koenig, 2002), as well as contribute to people's overall well-being and happiness (Jones, 2004; Tovar-Murray, 2011).

\section{Spirituality, Religiosity, and Burnout in Social Work}

Even though spirituality and religiosity have also been recognized as positive factors in lowering stress caused by difficult or traumatic life events (Belavich, 1995; Hathaway \& Pargament, 1992), the impact of spirituality and religiosity as buffering effects for burnout among social work practitioners has not been well established. Some researchers recognize them as important elements in reducing professional burnout among practitioners in helping professions, such as social work (Ciarrocchi, Golden, Piedmont, \& Rodgerson, 2004; Persing, 2000), while others fail to observe such a relationship (Figley, 2002; Robichaud, 2004). Moreover, the literature on the relationship between the spirituality/religiosity and burnout among social work students is essentially non-existent. In one recent study by Ying (2009b), limited to a small sample of students from a Northern California university, the relationship between religiosity, spirituality, mindfulness, and emotional well-being (which can be seen as an opposite positive pole of burnout) were explored. Ying's study was based on self-reports of MSW students and 
suggested that although religiosity and spirituality were highly correlated, mindfulness did not correlate with them. Moreover, the majority of participants reported no religious affiliation. This was confirmed by the results, as a tendency of the students to be more spiritual and mindful than religious. Finally, mindfulness was strongly negatively correlated with anxiety and depressive symptoms, while religious traits were positively correlated with anxiety. Although promising, the results had a number of limitations, especially the small sample size, selection bias, content validity of the religiosity and spirituality measures, and the utilization of a cross-sectional design, which limited conclusions on causal relationships between variables.

\section{Conclusion}

Burnout has been consistently identified as one of the most serious occupational hazards in numerous professions. Defined by Maslach, Schaufeli, and Leiter (2001) as "[...] a prolonged response to chronic emotional and interpersonal stressors on the job" (p. 397), it encompasses three dimensions: emotional exhaustion (depletion of emotional resources), depersonalization (cynicism, negativism), and diminished personal accomplishment (unhappiness about self and one's performance).

Practitioners directly involved in helping people have been identified as more prone to experience professional burnout (Golembiewski \& Munzenrider, 1988; Maslach \& Jackson, 1984; Maslach et al., 2001; Stamm, 2005). Nurses and physicians (Aftab et al., 2012; Buunk et al., 2001; Dyrbye \& Shanafelt, 2011; Hiscott \& Connop, 1990; Jourdain \& Chênevert, 2010; Leiter et al., 2009), teachers and special educators (Cunningham, 1983; McIntyre, 2011, Maslach et al., 2001), psychologists and mental health workers (Ackerley et al., 1988; Kelloway, \& Barling, 2011; Martin \& Schinke, 
1998; Rössler, 2012; Suran \& Sheridan, 1985; Viveros \& Herrera, 2009) can succumb to the costly effects of prolonged stress.

However, among other professionals in helping occupations social workers and social work students are most prone to develop occupational burnout (Acker, 1999; Collins et al., 2010; Dziegielewski et al., 2004; Gilbar, 1998; Han et al., 2012; Harr \& Moore, 2006; Jayaratne \& Chess, 1984; Jayaratne et al., 1986; Jayaratne et al., 1988; Jayaratne et al., 1991; Lloyd et al., 2002; Maslach, 1982; Ngai \& Cheung, 2009; Oktay, 1992; Pottage \& Huxley, 1996; Poulin \& Walter, 1993a, 1993b; Robichaud, 2004; Romph et al., 1993; Siebert, 2006; Stamm, 2005; Tobin \& Carson, 1994; Um \& Harrison, 1998; Van Hook \& Rothenburg, 2009)

Maslach and Jackson (1981) argue that the consequences of burnout can be observed on an organizational as well as a personal level. Various forms of physical job withdrawal, emotional detachment, lower productivity and effectiveness are signs of decreased work satisfaction and reduced professional commitment. Interpersonal conflicts and disruption of the job performance of their co-workers (Jackson \& Maslach, 1982), as well as diminished quality and continuity of services provided to clients are also typical for the individuals affected by burnout (Maslach \& Pines, 1979). People who experience burnout are also more prone to change careers, or exit the workforce. The costs of such turnover, both direct and indirect, can be colossal (Blankertz \& Robinson, 1997; Braddock \& Mitchell, 1992).

Burnout can also cause deterioration in people's personal lives (Burke \& Greenglass, 2001). Heightened tension, anxiety, anger, and frustration, withdrawing from family and friends, are also some of the signs of burnout. What typically follows is the 
somatization of stress, exhibited by insomnia, anxiety, and depression, and in extreme cases suicidal tendencies. Excessive use of medication and alcohol has been also observed in people experiencing burnout (Maslach et al., 2001).

Social work, by its nature, generates extensive and prolonged levels of stress, and eventually leads to burnout among many social work professionals and trainees. Numerous attempts have been made to counter the effect of this phenomenon. Within organizational context and structures, granting time away from work (sanctioned time out), reflective supervision, peer coaching and support, continued training and education, and rotation of job assignments have been proposed (Hagen, 1989; Jayaratne et al., 1988; Noble \& Irwin, 2009).

Coping with burnout (and preventing it) on individual/personal level, typically involves stress and time management. Unfortunately, very few social work programs teach their students self-care strategies (Newsom et al., 2006). However, in the social work profession, noted for the highest burnout rates rooted in stressful occupational conditions, the need to build resilience is essential and should begin in the students' formative years (Grant \& Kinman, 2012). Many academics have begun suggesting that social work education include appropriate training for students to increase their abilities to cope with stressful situations (Jayaratne et al., 1991). For instance, Maslach et al., (2001) and Jones (2007) stressed the importance of preparing social work students to recognize burnout symptoms, and to employ various strategies to cope with stress, and therefore, prevent burnout. This idea was also advocated by Bride and Figley (2007), who proposed the integration of self-care techniques into social work curricula, to prevent compassion fatigue and to provide students (and later practitioners) with new standards of 
self-care necessary for their optimal functioning in the profession. Correspondingly, Newell and MacNeil (2010), suggested that information about preventing burnout and secondary traumatic stress should be incorporated into foundation micro and macro and mental health practice SW courses, as well as into field placement seminar and practicum courses. Pilot intervention programs, even short seminars on the issues of handling stress, have shown promising results in improving students' well-being and preventing burnout (Dziegielewski et al., 2004).

Although religiosity and spirituality have been widely recognized as positively influencing people's health, well-being, mortality, and self-esteem (Cohen \& Koenig, 2002; Richards \& Bergin 2005; Siegel, Anderman, \& Schrimshaw, 2001), the impact of spirituality and religiosity as a buffering effect for burnout among social work practitioners has not been consistently shown. Some researchers claim that spirituality and religiosity can play a significant role in reducing professional burnout among practitioners in helping professions, namely social workers (Ciarrocchi et al., 2004; Persing, 2000). Others, like Figley (2002) and Robichaud (2004), fail to observe such a relationship.

For over four decades mindfulness practices have been making their way into the Western world. As observed in the general population, mindfulness can positively affect individuals' well-being and reduce stress, thus, improving their health and levels of functioning (Baer, 2003; Carmody \& Baer, 2008; Grossman et al., 2004; Kabat-Zinn, 1982; Salmon et al., 2004). Similarly, mindful practices have been recognized as self-care instruments for professionals in helping occupations and as clinical interventions for various health concerns (Cohen-Katz et al., 2004; Henry \& Henry, 2003; Poulin et al., 
2008). Research on the effects of mindfulness on social work students' well-being, although scarce, offers promising results. Even brief mindfulness instruction resulted in long-lasting improvements in social work students' self-awareness, which allowed students to set appropriate boundaries around their work with clients, and their ability to practice better self-care outside practice (Gockel et al., 2012). General stress-reduction and improved ability to perform better in school assignments, and while working with clients, have been also observed among MSW students (Moore et al., 2011). Moreover, the positive effect of mindfulness on well-being, by reducing students' emotional exhaustion in field placement, has been reported (Ying, 2008). Likewise, mindfulness was credited with producing a positive effect on students' mental health, as it was correlated with lower levels of depressive symptoms and anxiety (Ying, 2009a), and with lowering students' tendency to synchronize with emotional states and expressions of other people (Ying \& Han, 2007). Mindful awareness, in contrast to spirituality and religiosity, was shown to be positively correlated with MSW students' mental health (Ying, 2009b), indicating that pre-existing religious or spiritual practices and/or convictions do not appear to interfere with the practices of mindfulness.

Overall, it has been revealed that even during the formative years and while practicing in the field, social work apprentices are at high risk of developing burnout. Thus, this study will be directed to address both the urgent need to find solutions for preventing burnout, and the gap in the literature pertaining to the effects of practice of mindfulness on all facets of burnout among social work students. 


\section{CHAPTER 3: Theories and Assumptions}

\section{Interaction of Person and Environment - Theoretical Bases of Burnout}

The number of theoretical models of burnout has been consistently growing over the years (Alarcon, Edwards, \& Menke, 2011; Schaufeli \& Buunk, 2003; Suran \& Sheridan, 1985). However, the best fitting model, suitable for this study, was created by Maslach and Leiter (1997) and later revised by Maslach et al. (2001). The authors suggested that burnout originates in the exposure to chronic interpersonal stressors in the work environment. Although individual and situational factors have been viewed in the past as separate contributors to burnout, recent theoretical developments supported integration of these elements in more explicit ways. Therefore, a model encompassing a person's relationship to his/her work environment was developed (Maslach \& Leiter, 1997). In this model, the greater the mismatch between personal expectations and some (or all) of the six areas of work domains: workload, control, reward, community, fairness, and values, the higher the probability of developing burnout. This, in turn, might affect various outcomes, for instance commitment, engagement, performance, and job satisfaction.

Workload mismatch can occur through overload, when it becomes too intense, too complex (as in multitasking), or too demanding (Maslach et al., 2001). In addition, a lack of skills or ability to perform one's job at the appropriate level, or an obligation to show emotions incongruent with a person's feelings may contribute to excessive workload. The mismatches in this domain are strongly related to emotional exhaustion, one of the aspects of burnout (Maslach et al., 2001). 
In terms of control, two possible mismatches can be identified (Maslach et al., 2001). The most common mismatch occurs when there is insufficient authority to pursue one's work or insufficient control over the resources needed to complete it. This occurs when a company's policies prevent workers from capitalizing on their ability to solve problems and from making decisions regarding important aspects on their job. On the other hand, the mismatch can be reflected in the incapacity to produce expected results, or in having responsibilities that exceed one's ability to deliver, which relates to feelings of inefficacy and reduced personal accomplishment (for example as measured on the MBI; Maslach et al., 2001).

Feelings of inefficacy can also be created by the mismatch between a person's performance on the job and insufficient extrinsic or intrinsic rewards. Extrinsic rewards might include financial compensation (e.g., salary or benefits), as well as social recognition (e.g., acknowledgment, appreciation). Deficiency in the intrinsic motivators, such as pride in one's own performance, may become a critical part of the mismatch. As people spend less quality time with co-workers due to the job demands, their interactions become less satisfying and rewarding and could result in exhaustion and depersonalization (Maslach et al., 2001).

A positive connection with co-workers has been identified as an essential element of a good match between an individual and the work environment (Maslach et al., 2001). Emotional support (e.g., humor, praise, and comfort) and assistance from the people one likes and respects reaffirms people's membership in the community. Conversely, isolation from others, impersonal contacts with co-workers, or unresolved work-related conflicts produce frustration and hostility, and as such are the most destructive to the individual 
and to the community. "The loss of community is evident in greater conflict among people, less mutual support and respect, and a growing sense of isolation" (Maslach \& Leiter, 1997, p. 49).

Trust, openness, and respect are the key elements of a positive work environment. Thus, perceived unfairness in the workplace increases burnout by emotionally upsetting and exhausting the individual. Inequality of workload and financial rewards, mishandling of evaluations and promotions, cheating, and the failure to follow appropriate procedures for grievance and dispute resolution undermines workers' feelings of self-worth and self-respect. It also creates a deep sense of cynicism in relation to authority, which is then projected onto the work environment (Maslach et al., 2001).

Finally, a serious worker-job mismatch may arise from the conflict between the values of the individual and the work requirements. Being forced to do unethical things or being caught between conflicting values of the organization greatly contributes to the development of burnout (Maslach et al., 2001).

Recognizing burnout as primarily a social phenomenon, Maslach et al. (2001) also acknowledged that personal factors can increase the risk for experiencing it. Individual characteristics associated with burnout, in addition to work-related attitudes, include demographic variables and personality traits. Among demographic variables marital status and level of education have been closely linked to increased burnout levels. Unmarried males (single more so than divorced) appear to be more prone to experience burnout, as are individuals with higher levels of education. Younger people also consistently exhibit more burnout than older (in their 30s, or 40s) individuals. According to Maslach et al. (2001), burnout is also higher among people who display low levels of 
hardiness (involvement in daily activities, a sense of control over events, and openness to change); those who believe that their lives are determined mainly by sources outside themselves, such as fate, chance, luck, or powerful others (external locus of control); and by those who use an avoidant coping style (respond to stressful events in a passive, defensive way). Moreover, neurotic individuals (anxious, hostile, depressed, selfconscious, and vulnerable) are also believed to be more prone to experience burnout. Finally, people who are highly competitive, time pressured, and who have an excessive need to control (exhibiting Type-A behaviors) score high on the exhaustion component of burnout, while "feeling types" tend to exhibit more cynicism (Maslach et al., 2001). Consistent with this model, the months of practicing in human services and year in the MSW program (Figure 1) might affect burnout levels among graduate social work students. As previously mentioned, individuals with higher levels of education were more prone to experience burnout. Thus, as students make progress in their studies they should exhibit more symptoms of burnout. Moreover, years of practicing social work could show the influence of either of the six work domains. The mismatch between students' expectations and the conditions they are being exposed to, whether at school or in the field placement (or even at work, if applicable) might lead to more stress, and thus, to the development of burnout. Furthermore, the combined effect of mismatches between work domains, students' attitudes toward them, and some personal characteristics might be observed. For instance, people who exhibit external locus of control when at the same time having a mismatch with control over work/educational circumstances, might show higher burnout levels, especially in regard to efficacy and personal accomplishment. Similarly, students with an avoidant coping style experiencing overload either at school, 
field placement, work (or any combination of these), should demonstrate more symptoms of burnout as measured by the emotional exhaustion subscale. Finally, someone who operates on emotions and experiences unfair treatment from instructors, field placement supervisors, or work managers, will most likely score high on the depersonalization facet of burnout.

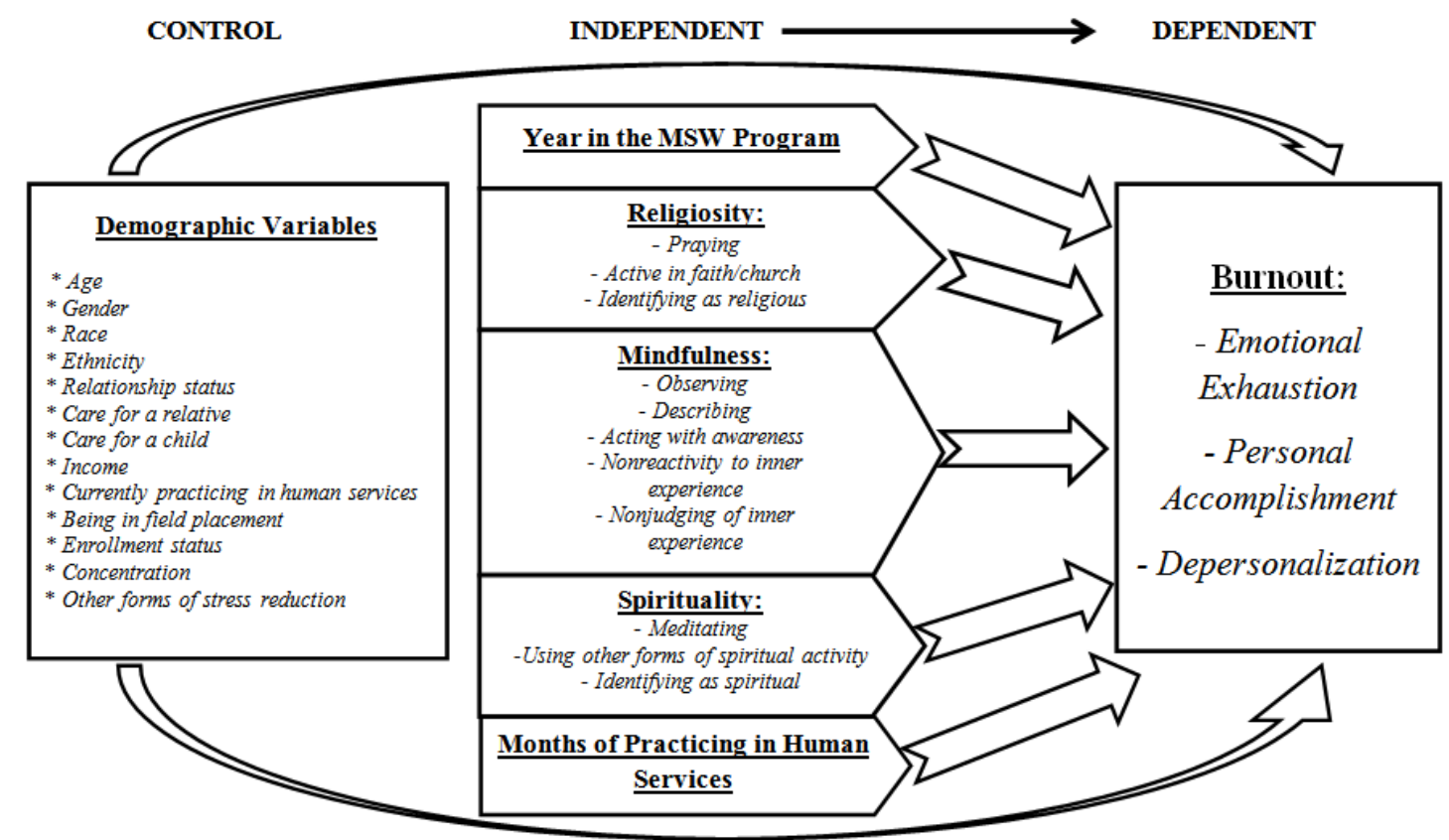

Figure 1. Research Conceptual Map

\section{Mindfulness and the Transitional Theory of Stress and Coping}

It has been proposed that the most effective way to deal with burnout is to combine educational (teaching individuals to acquire new coping skills) and managerial approaches, with the focus on eliminating mismatches between job conditions and expectations (Angerer, 2003; Maslach et al., 2001). Mindfulness training might address both of these approaches, although in different ways. 
The transactional theory of stress and coping (TTSC) offers an eloquent explanation of the pathways mindfulness, as well as spirituality and religiosity, might follow to affect well-being. Developed by psychologist Richard Lazarus, TTSC proposed that stress exists as an effect of transaction between an individual and the environment and that it serves an important function in human life (Lazarus \& Folkman, 1984). Three types of appraisals (primary, secondary, and tertiary), the mediators between the environmental events and human reactions to it, are considered to be at work here. In primary appraisal the person makes a judgment about the situation, as a threat, harm, or a challenge. If a threat is being detected, secondary appraisal is triggered. During this process resources available to the affected person and their effectiveness are being determined. Reappraisal, the third type, serves as a continuous re-evaluator of the situation, that is any changes occurring in the situation are being constantly reexamined and the behavior adjusted to them. The process of appraisal determines the individual's emotional reactions and selection of coping strategies. Toward this end, coping is defined as "[...] constantly changing cognitive and behavioral efforts to manage specific external and/or internal demands that are appraised as taxing or exceeding the resources of the person" (Lazarus \& Folkman, 1984, p. 141). In is imperative to note that coping does not necessitate any mastery, but rather managing the situation through the efforts to reduce, avoid, change, or accept it. Thus, the impact of the stressor is regulated by the individual's appraisal and response.

Emotion-focused coping strategies of the TTSC do not directly affect the situation, but instead aim at decreasing emotional distress, and might include: avoiding, selection, venting, ruminating, and meditating. Stress emotions play an important role in 
the TTSC as they can be linked to the health-related outcomes (Lazarus \& Folkman, 1984). According to the theorists health is comprised of three elements: physical, psychological, and social that can influence each other in meaningful ways. Thus, for instance, finding positive connotations in distressful circumstances can been related to the experience of well-being, in spite of significantly diminished physical functioning (Folkman, 1997).

Shapiro, Carlson, Astin, and Freedman (2006) identified three aspects of mindfulness: intention, attention, and attitude. It has been documented that the intention of meditators can shift from "self-regulation, through self-exploration, to self-liberation" (Shapiro et al., 2006, p. 376). Perhaps, then, the intention could be related to acting with awareness within the Five Facet Mindfulness Questionnaire (Baer, 2006). The practice of paying attention lies at the core of mindfulness (Shapiro et al., 2006). It can be linked to the observing and describing facets in the Five Facet Mindfulness Questionnaire. In addition, the mindfulness pathways can be related to the operationalizing of the TTSC (Lazarus \& Folkman, 1984). In this perspective, the observing and describing facets of mindfulness appear to be associated with the primary appraisal of the theory, especially with the emotion-coping strategies. Finally, the attitude, as described by Shapiro et al., (2006), finds its equivalents in nonreactivity to inner experience and nonjudging of inner experience in Baer et al., (2006), and in the secondary appraisal of the TTSC (Lazarus \& Folkman, 1984). All three are based on the same premise, watchful presence, without any interpretation or judgment. This state of mindfulness allows for the reperceiving, which Shapiro et al., (2006) describe as a mechanism allowing for positive change and outcome. 
Thus, it is very similar to the concept of reappraisal described by Lazarus and Folkman (1984), in which change of attitude, resulting in a positive health outcome, can occur.

Reperceiving/reappraisal allow an individual to step aside, observe, and detach from the internal experience. This shift in one's attitude plays an important role in development of unique stances toward self. Through reperceiving/reappraisal an individual can detach from observed emotions, attitudes, and feelings, and allow for selfregulation, creating an internal order, and leading to improved health (Shapiro et al., 2006).

\section{Research Questions and Hypotheses}

Four research questions and hypotheses were investigated.

1. Does the length of practicing in human services predict levels of burnout for MSW students? Some studies demonstrated intensified burnout with the prolonged stress encountered during the increasing number of the years of social work (usually public)

practice (Schwartz, Tiamiyu, \& Dwyer, 2007; Siebert, 2006). The hypothesis grounded in these studies examined the notion that students currently involved in direct social work practice (either outside of the MSW program, in the MSW field placement, or both) experience higher levels of burnout than students not yet practicing. Thus, the positive relationship between the years of direct SW and the exhibited burnout among students was tested, predicting that as the number of years increase, so will the levels of burnout.

2. Does the year in the MSW program affect the experienced levels of burnout? Based on the review of the literature showing higher predisposition among social work students to the development of emotional exhaustion and compassion fatigue (Han at al., 2012; Harr \& Moore, 2006; Ngai \& Cheung, 2009), the hypothesis that as students 
progress in their studies they will exhibit progressively more burnout was scrutinized. The possibility of compounded effects of both the year in the MSW program and the years of practicing social work was also examined.

3. Do current MSW students who demonstrate higher levels of mindfulness report less burnout, regardless of the year in the MSW program and regardless of the years of practice in human services? In line with the research showing positive effects of mindfulness in coping with stress and difficult or traumatic life events for some of the helping professions (Cohen-Katz et al., 2004; Epstein, 1999; Mackenzie et al., 2006), the effects of mindfulness on burnout was tested. It was hypothesized that: (a) current MSW students who demonstrate mindfulness will report less burnout; (b) students who exhibit higher levels of mindfulness will demonstrate less burnout regardless of the year in the MSW program and regardless of the years of practice. With the inclusion of mindfulness, the effects of years of practice and the year in the MSW program on burnout should be diminished, if the mindful practice plays any mediating role in this relationship.

4. Do religious and spiritual beliefs and practices predict burnout levels among MSW students? The hypothesis, consistent with some available research (Ciarrocchi et al., 2004; Persing, 2000), asserting that burnout levels are predicted by one's spiritual and/or religious beliefs was tested. This effect should occur regardless of years of practicing and the year in the MSW program. 


\section{CHAPER 4: Methods}

This study examined the degree to which students in the Master of Social Work (MSW) program at Portland State University (PSU) in Oregon experience burnout considering their varied years of social work practice, and the extent to which mindfulness levels, years of practicing in the human services field, and year in the MSW program, as well as religious and spiritual (in addition to other stress reduction) practices relate to, and possibly affect, students' experienced burnout levels.

This study utilized the quantitative, correlational, cross-sectional research design. A printed booklet of questionnaires, completed individually by each participant, was used in this study.

\section{Participants}

A non-probability, purposive sampling procedure was used in this research. The selection of units from the population was based on eligibility through set criteria. The sample consisted of the first, second, third year, and advanced standing MSW students at PSU School of Social Work. The prospective participants were solicited in the required Research Methods, Generalist II, and Advanced Practice classes during the first two weeks of March 2014. The sample varied in ethnicity, gender, and their years of practice. To ensure statistically reliable results of this study, a power analysis for bivariate associations, based on Cohen's power primers (1992) was conducted. With the margin of error set at $\alpha=.05, \beta=.80$ (a conventional statistical setting), and the medium effect size $(E S)$ for a significance of product-moment $r$ set at .30 , a minimum sample size of 85 students was required. Correspondingly, with the most conservative margin of error set at 
$\alpha=.01, \beta=.80$, and the same effect size $(E S=.30)$, the number of participants required was to increase to 125 . Whilst the PSU social work students' population has been reported as consisting of 495 individuals (J. Putnam, personal communication, November 9, 2013), the sample of 85 and 125 participants was to be attained through a $17 \%$ and $25 \%$ response rate among Portland State social work students. The actual response rate was good (32\%), as 159 out of 495 target students fully completed questionnaires. Five questionnaires were excluded from the analyses, due to having missed the completion of the important section on burnout.

Participants' characteristics were evaluated to assess their representativeness of the general social work student population in the U.S., by comparing them to the Portland State University records (J. Putnam, personal communication, November 9, 2013) and national data available from the Council on Social Work Education (CSWE). The results indicated that Master of Social Work students in this study had age and gender characteristics comparable to the nationally reported data (CSWE, 2012) and to the general population of the PSU School of Social Work students. Although this sample had a higher (79\%) representativeness of non-Hispanic Whites than in the CSWE report (55\%), it was comparable to the PSU records (76\%). Moreover, the participants had slightly higher enrollment in direct human services (64\%) than reported by the CSWE (55\%), but consistent with the proportions of the MSW students at PSU involved in direct human services (64\%). Following data available from the PSU School of Social Work, the concentration proportions were calculated only for second year and above students (those who made a decision regarding concentration), and the responses from undecided participants were excluded from the comparison. 
The demographic characteristics of the participants are presented in Table 1. The age of the participants ranged from 23 to 60 years, with a mean of 35.2 years $(S D=8.94)$, median of 33 years, and mode of 29.2 years. The respondents' genders were not uniformly distributed, with majority $(81.8 \%)$ being female, $17 \%$ being male, and $1 \%$ other (self-identified as bi-gender, and as biologically female queer). Most participants were not of Hispanic, Latino, or Spanish origin (84.9\%), with only $15.1 \%$ identifying as such. The majority of the responders were also White (81.1\%). The second largest group contained other represented ethnicities, including multiracial respondents (15.1\%): White/ American Indian or Alaska Native (4.7\%), White/Other (3.0\%), White/Asian (1.9\%), Mexican and Mexican/American (1.9\%), Latino-Mix or Cuban/Puerto Rican (1.2\%), Multiracial/Irish (.6\%), and undisclosed (1.9\%). Only 1.9\% of participants identified themselves as Black or African Americans, $1 / 3 \%$ as Asians (1.3\%), and 0.6\% as American Indian or Alaska Native. None of the participants identified as a Pacific Islander.

Married or in legally recognized union individuals accounted for $33.3 \%$ of the sample, and were closely followed by participants living with partner/partners (26.4\%) and single (23.9\%) participants. Divorced respondents accounted for $9.4 \%$ of the sample, while widowed or separated for .6\% each. Other students (5.7\%) disclosed that they were in committed relationship (1.9\%), engaged, but not living together (1.9\%), not living together with a significant other (1.3\%), and one participant (.6\%) reported being engaged. 
Among students, $30.2 \%$ of the participants were caretakers for an adult

friend/relative, while $69.8 \%$ were not. In this sample, only $13.8 \%$ of the students cared for a child under the age of 18 (in contrast to $76.2 \%$, who did not).

Table 1

Demographics of Participants $(N=159)$

\begin{tabular}{|c|c|c|}
\hline Characteristic & $n$ & $\%$ \\
\hline \multicolumn{3}{|l|}{ Age } \\
\hline Younger than 25 & 9 & 8.8 \\
\hline $25-34$ & 80 & 50.3 \\
\hline $35-44$ & 45 & 28.3 \\
\hline 45 and older & 25 & 15.7 \\
\hline \multicolumn{3}{|l|}{ Gender } \\
\hline Female & 130 & 81.8 \\
\hline Male & 27 & 17.0 \\
\hline Other (Bigender; Queer, biologically-F) & 2 & 1.3 \\
\hline \multicolumn{3}{|l|}{ Hispanic, Latino, Spanish Origin } \\
\hline Yes & 24 & 15.1 \\
\hline No & 135 & 84.9 \\
\hline \multicolumn{3}{|l|}{ Ethnicity } \\
\hline White & 129 & 81.1 \\
\hline Black or African American & 3 & 1.9 \\
\hline Asian & 2 & 1.3 \\
\hline American Indian or Alaska Native & 1 & 0.6 \\
\hline Other & 24 & 15.1 \\
\hline \multicolumn{3}{|l|}{ Relationship Status } \\
\hline Married/In Legally Recognized Union & 53 & 33.3 \\
\hline Living with a Partner/Partners & 42 & 26.4 \\
\hline Single & 38 & 23.9 \\
\hline Divorced & 15 & 9.4 \\
\hline Widowed & 1 & 0.6 \\
\hline Separated & 1 & 0.6 \\
\hline Other & 9 & 5.7 \\
\hline Committed Relationship & (3 & 1.9) \\
\hline Engaged/Not Living Together & (3 & 1.9) \\
\hline In Relationship/Not Living Together & $(2$ & 1.3) \\
\hline Engaged & (1 & $0.6)$ \\
\hline \multicolumn{3}{|l|}{ Care for Friend/Relative over 18} \\
\hline Yes & 48 & 30.2 \\
\hline No & 111 & 69.8 \\
\hline
\end{tabular}




\begin{tabular}{|c|c|c|}
\hline \multicolumn{3}{|l|}{ Care for a Child under 18} \\
\hline Yes & 22 & 13.8 \\
\hline No & 137 & 86.2 \\
\hline \multicolumn{3}{|l|}{ Income Available to Student } \\
\hline Under 25,000 & 52 & 32.7 \\
\hline $25,000-49,999$ & 62 & 39.0 \\
\hline $50,000-74,999$ & 24 & 15.1 \\
\hline 75,000 and Over & 21 & 13.2 \\
\hline \multicolumn{3}{|l|}{ Years in Human Services Prior to MSW } \\
\hline Under 2 years & 14 & 8.8 \\
\hline $2-4$ years & 35 & 22.0 \\
\hline $4-6$ years & 42 & 26.4 \\
\hline $6-8$ years & 20 & 12.6 \\
\hline $8-10$ years & 11 & 6.9 \\
\hline $10-12$ years & 8 & 5.0 \\
\hline $12-14$ years & 10 & 6.3 \\
\hline Over 14 years & 19 & 11.9 \\
\hline \multicolumn{3}{|l|}{ Currently Practicing in Human Services } \\
\hline Yes & 113 & 71.1 \\
\hline No & 46 & 28.9 \\
\hline \multicolumn{3}{|l|}{ Year in the MSW Program } \\
\hline First & 83 & 52.2 \\
\hline Second & 63 & 39.6 \\
\hline Third & 11 & 6.9 \\
\hline Fourth and Other & 2 & 1.2 \\
\hline \multicolumn{3}{|l|}{ Enrollment } \\
\hline Full-time & 109 & 68.6 \\
\hline Part-time & 50 & 31.4 \\
\hline \multicolumn{3}{|l|}{ Concentration } \\
\hline Direct Human Services (DHS) & 102 & 64.2 \\
\hline Community Based Practice (CBP) & 21 & 13.2 \\
\hline Social Service Administration and Leadership (SSAL) & 18 & 11.3 \\
\hline Not decided & 18 & 11.3 \\
\hline
\end{tabular}

Many students (39\%) had a usable income between \$25,000-49,999, while $32.7 \%$ had access to less than $\$ 25,000$ a year. Among those with higher incomes, $15.1 \%$ of students reported available income between $\$ 50,000-74,999$, and $13.2 \%$ were able to use 
more than $\$ 75,000$ annually. The most common length of time spent practicing in human services by the students prior to enrolling in MSW program was two years (11.9\%), followed by five $(10.1 \%)$, four $(9.4 \%)$, and less than two years $(8.8 \%)$, with a mean of 6.70 years $(S D=5.54)$. Three participants reported having practiced in human services for 25 years, while one student had 30 years of social work experience. The majority of respondents $(71.1 \%)$ reported currently practicing in human services (outside field placement), and being enrolled as full-time students (68.6\%). In addition, most participants (52.2\%) were in their first year of MSW instruction, followed by the second $(39.6 \%)$, third $(6.9 \%)$, fourth and other year students $(1.2 \%)$. The majority of responders (64.2\%) were enrolled in Direct Human Services (DHS), 13.2\% in Community Based Practice (CBP), 11.3\% specialized in Social Service Administration and Leadership (SSAL), while the same proportion of students (11.2\%) were undecided.

\section{Procedures}

Initially, the Social Work Department MSW program's director and the Distance Option coordinator were contacted to secure permission to conduct this research. Subsequently, upon receiving approval from the PSU's Institutional Review Board, faculty members from the School of Social Work at PSU were informed of the intended study and asked to allow this doctoral student to advertise it to the MSW students in their classes. To improve the response rate (Dillman, 2000), two weeks prior to the onset of the study, all MSW, two-year, three-year, distance, and advanced standing students received an e-mail invitation to participate in this doctoral research (please refer to Appendix B).

The MSW program at the PSU SSW offers two study options to its students, the on-campus, in Portland classes, and the Distance Option, in one of the four off-campus 
sites: Ashland, Bend, Eugene, and Salem. Therefore, two slightly different recruitment procedures were implemented for these program sites.

Portland (on-campus) Procedure. The on-campus students were approached by the researcher during the first and second weeks of March 2014 while participating in the mandatory classes and asked, through an announcement made in class, to take part in the study. If on-campus students chose to participate (as their involvement was entirely voluntary), they were expected to complete the questionnaires provided to them in printed booklets distributed in each classroom. All booklets contained a cover letter explaining the purpose of the study, questionnaires, and the instructions (Appendix B). Students were asked to fill out the questionnaires in their free time and to deposit them in the secure box in the PSU SSW lobby. Each questionnaire was numbered and the participants were provided with the attached corresponding number to keep for a gift certificate drawing. Although some studies have shown that lotteries, in contrast to prepaid financial incentives, might only marginally boost responses rates (Boyd, 2002; Dillman, 2000), for practical reasons the opportunity to win a $\$ 50$ gift certificate to the PSU bookstore was chosen as an incentive to participate in the study. Toward this end, at the conclusion of the study, the drawing was completed and the winning number announced through email. In addition, herbal tea bags were attached to questionnaires as token of appreciation to the participants. The prepaid material incentives have been shown to improve the response rates in research, as they reward every participant equally (Boyd, 2002; Dillman, 2000). Following another Dillman (2000) suggestion for improving response rates all students received a reminder e-mail a week after the onset of the investigation. 
Distance (off-campus) Procedure. The procedures for the recruitment of the distance students were similar to the ones used on the Portland campus. The only differences related to the introduction of the study and distribution/collection of the questionnaires. Before the data collection, the instructors at the distance sites were contacted by this doctoral student and asked to help with the study. During the first two weeks of classes in March the students were asked by their respective instructors to participate in the study, and informed of the voluntary nature of such participation. The booklets including the cover letter, the informed consent, and questionnaires were distributed in class, giving the students an opportunity to complete them (or not) during breaks in the entire day of lectures, or by the following week (Appendix B). By the end of the day (and the following week) student volunteers (to ensure anonymity of the respondents) delivered collected questionnaires to the instructors, who either sealed the prepaid envelopes and mailed them to the researcher, or brought them in person to the campus. The off-campus students also received the herbal tea bags as a material incentive to complete the questionnaires. In addition, similarly to the on-campus students, they were given the opportunity to win a $\$ 50$ gift certificate to an online bookstore. This online bookstore option was chosen because of its convenience and easy availability to the distance students. Similarly to the campus individuals, the distance option scholars also received a reminder e-mail a week after the onset of the investigation (Dillman, 2000).

Survey Procedures. This quantitative study, exploring the relationship between mindfulness, spirituality, religiosity, years of practicing social work, year in the MSW program, and burnout among graduate social work students, used a self-administered written questionnaire consisting of four sections (see Appendix A). In the first two 
sections the participants reported on their mindfulness experiences and practices (The Five Facet Mindfulness Questionnaire, 2006) and on their levels of emotional exhaustion, personal accomplishments, and depersonalization (Maslach Burnout Inventory, 1981). The third segment consisted of religious and spiritual practices questions, as well as questions regarding other stress reduction practices. The questionnaire concluded with a basic demographic and academic status section (see Appendix A for the survey instructions). The students were informed that the involvement in the study was entirely voluntary and the answers were to be collected anonymously.

The heterogeneity of the sample required the results to be collected on various days of the week, due to the participants' availability. Although some replies from the students absent from class were possibly missed, all responses were collected within two weeks.

At the conclusion of the data collection the researcher followed with the appropriate data preparation and statistical procedures. Data were verified and cleaned, with each variable checked for possible outliers and other out-of-range values, and the reverse scores and missing values recoded. Subsequently, the appropriate statistical analyses were implemented.

\section{Measures}

The first two measures, The Five Facet Mindfulness Questionnaire (2006), and Maslach Burnout Inventory (1981), have already been well established and validated, while the spirituality and religiosity, other stress reduction activities, as well as demographic and academic sections used a mélange of useful questions gathered from various resources and adapted to serve the purpose of this study. The Maslach Inventory 
(Maslach \& Jackson, 1981) was employed to measure burnout; the Five Facet Mindfulness Questionnaire (Baer, 2006) was used to investigate five facets of mindfulness. The last two sections consisted of questions created by the researcher based on some established measures of religiosity and spirituality (Corbett, 1990; May, 1982; Plante \& Boccaccini, 1997), the Caregiving in the U.S. 2009 Questionnaire, and The American Community Survey (U.S. Census Bureau, 2012).

The Five Facet Mindfulness Questionnaire. The Five Facet Mindfulness Questionnaire (Baer, 2006) was utilized to measure five factors of mindfulness: observing, describing, acting with awareness, non-judging of inner experience, and nonreactivity to inner experience. This instrument consists of a 39-item questionnaire and comprises five domains: (a) observing (8 items); (b) describing (8 items); (c) acting with awareness (8 items); (d) nonreactivity to inner experience (7 items); and (e) nonjudging of inner experience ( 8 items). Participants were asked to rate how often they notice things happening in their bodies or the surroundings, for instance: I notice how foods and drinks affect my thoughts, bodily sensations, and emotions (observing); Even when I'm feeling terribly upset, I can find a way to put it into words (describing); I find it difficult to stay focused on what's happening in the present (acting with awareness); When I have distressing thoughts or images, Ifeel calm soon after (nonreactivity to inner experience ); I criticize myself for having irrational or inappropriate emotions (nonjudging of inner experience). The answers were rated on a 5-point Likert-type scale ranging from 1 (never or very rarely true) to 5 (very often or always true) and averaged for each component. The higher scores on observation, nonreactivity, and five items on describing indicated being more mindful of certain aspects of daily life (high scores reflected high levels of 
mindfulness). The lower scores (scoring reversed) on acting with awareness, nonjudging, and three items on observing indicated more mindfulness in these areas.

The Kentucky Inventory of Mindfulness Skills (KIMS) created by Baer, Smith, and Allen (2004), was a predecessor of The Five Facet Mindfulness Questionnaire. It included four facets of mindfulness: observing, describing, acting with awareness, and accepting without judgment. However, in a study (Baer et al., 2006) comparing five available mindfulness measures: KIMS, The Cognitive and Affective Mindfulness Scale (Feldman, Hayes, Kumar, \& Greeson, 2004), The Freiburg Mindfulness Inventory (Buchheld, Grossman, \& Walach, 2001), The Mindful Attention Awareness Scale (Brown \& Ryan, 2003), and The Mindfulness Questionnaire (Chadwick, Hember, Mead, Lilley, \& Dagnan, 2005), another element of mindfulness was identified. Based on a thorough factor analyses and the highest loadings of the elements in these inventories, Baer et al. (2006) recognized nonjudging of inner experience as a separate construct within the concept of mindfulness, and created a revised mindfulness measure called The Five Facet Mindfulness Questionnaire (FFMQ). Additionally, the study upheld the former interpretations of mindfulness as a multifaceted construct.

The initial investigation (Baer et al., 2006) of The Five Facet Mindfulness Questionnaire construct validity suggested that this measure had strong psychometric characteristics, including adequate to good internal consistencies (alpha range between .72 and .91) for all facets and significant correlations in predicted directions with a variety of other measures (i.e. The Cognitive and Affective Mindfulness Scale, The Freiburg Mindfulness, The Mindful Attention Awareness Scale, and The Mindfulness Questionnaire). The majority of findings were subsequently confirmed with meditating 
and nonmeditating samples studied by Baer et al. in 2008. However, this investigation revealed that one of the facets of mindfulness, observing, in contrast to the other four factors, was not completely mediating the experience of meditation and psychological adjustment in all participants, but rather, it depended on the level of their experience with meditation. Hence, while for the experienced meditators the observing facet was strongly correlated with well-being, the scores for the nonmeditators failed to show such relationship (Baer et al., 2008). Moreover, these characteristics have been corroborated by studies with other populations: patients with fibromyalgia (Veehof, Klooster, Taal, Westerhof, \& Bohlmeijer, 2011), depression, and anxiety (Bohlmeijer, Peter, Fledderus, Veehof, \& Baer, 2011), and partially among undergraduate students, who reported using mind altering substances, in observing, nonjudging, and nonreactivity subscales of mindfulness (Eisenlohr-Moul, Walsh, Charnigo, Lynam, \& Baer, 2012).

The instrument was also validated with many translated versions of the FFMQ. For instance, the French version replicated original results of the instrument in terms of the internal and construct validity. Therefore, it became established as a valid measure of mindfulness for French clinicians and researchers (Trousselard et al., 2010). Similarly, the psychometrics of the Swedish version of the measure (Lilja et al., 2011), assessed in two separate studies, showed similar results to the original (Baer et al., 2006). The measure was shortened by 10 items, though, due to some issues with adequately translating certain terms (e.g., "distressing thoughts"), as well as complaints regarding the length of the questions and too much reiteration. However, the outcomes, both in regard to respective alphas (ranging from .75 to .90) for all facets of the instrument, and the little correlation between observing and the overall mindfulness results for participants with 
limited meditation experiences were in line with the English version of the instrument. Likewise, in another analysis (Cebolla et al., 2012), the translated Spanish version of the measure resulted in acceptable to very good internal reliability of the facets (Cronbach $\alpha$ range $.80-.91$ ), while the convergent analysis showed high correlations with other related measures (Hayes et al. (2006) Acceptance and Action Questionnaire, Derogatis and Melisaratos' (1983) Brief Symptom Inventory, and Brown and Ryan’s (2003) Mindfulness and Awareness Scale). Comparably, the Dutch version of the scale has also demonstrated overall favorable psychometric properties: construct validity $(\alpha=.88-.96)$, internal consistency (nonmeditating sample $\alpha=.85$; meditating sample $\alpha=.90$ ), and predictive validity of psychological well-being by nonjudging, nonreactivity, and acting with awareness (de Bruin, Topper, Muskens, Bögels, \& Kamphuis, 2012). Furthermore, Hou, Wong, Lo, Mak, and Ma (2013) validated the Chinese version of the Five Facet Mindfulness Questionnaire in Hong Kong in community and clinical samples. The testretest reliability of this translation was .88 , and two factors, describing and acting-withawareness, had significant predictive ability toward mental health, namely the psychological symptoms of depression, anxiety, and stress. Additionally, the structural validity was confirmed by the use of Confirmatory Factor Analysis (CFA). Finally, the study of university students from three different samples in Norway provided bases for this version of the mindfulness questionnaire (Dundas, Vøllestad, Binder, \& Sivertsen, 2013). The results substantiated the original psychometric findings of the FFMQ (Baer et al., 2006), showing acceptable fit of the construct's subscales to the overall mindfulness model. Moreover, the convergent validity was established in this analysis; the correlations between all facets of the FFMQ and the Mindful Attention Awareness Scale 
(Brown \& Ryan, 2003) were significant, except for the inexperienced meditators in observing, exactly as described in the Baer et al. (2006) report.

In this study the FFMQ overall internal consistency was good, with a Cronbach alpha coefficient of .76.

The Maslach Burnout Inventory. Three currently existing versions of the Maslach Burnout Inventory (MBI) include: the original version for the professionals in human services - MBI-HSS (Maslach \& Jackson, 1981), the revised form for the professionals in the field of education - MBI-Educators Survey, or MBI-ES (Maslach, Jackson, Leiter, Schaufeli, \& Schwab, 1986), and the newest version of the measure, intended for professionals in other occupations - MBI-General Survey, or MBI-GS (Schaufeli, Leiter, Maslach, \& Jackson, 1996). Although the MBI-ES varies from the MBI-HSS only in the use of the term "students," instead of "recipients," it has been demonstrated over the years that individuals in other occupations do not necessarily exhibit the characteristics of workers in helping professions. Thus, the MBI-GS was created, to focus on general job performance, rather than on the services relationships. For instance, the fatigue in this version of the instrument, instead of being related to people as its source, associates these feelings with work itself. However, the biggest difference in this version of the MBI-GS has been the introduction of cynicism. While in human services depersonalization has been directly related to personal interactions, the use of cynicism in the general form of the measure allowed burnout to be measured in association with demands of the work, not necessarily in connection with interpersonal transactions (Schaufeli et al., 1996). 
The Maslach Burnout Inventory-Human Services Survey (Maslach \& Jackson, 1981) was used in this study to assess burnout in graduate social work students. This scale was originally developed to measure burnout among workers in various health and service occupations in the US and Canada (i.e. agency administrators, teachers, physicians and nurses, counselors, social and mental health workers, psychiatrists and psychologists, police officers, attorneys, and others), included 47-items, and required responses not only regarding feelings, but also their intensity (Schaufeli, Leiter, \& Maslach, 2009). The numbers were subsequently reduced to 22 statements via factorial analyses, and grouped into three distinct dimensions. Furthermore, the evaluation of these subscales demonstrated good correlation between Emotional Exhaustion (EE) and Depersonalization (DP), and independence of Personal Accomplishments (PA). In addition, based on the evidenced high correlation between frequency and intensity of feelings, the current versions of the MBI include frequencies only (Schaufeli et al., 2009). The MBI-HSS measure, utilized in this study, consists of 22 items, with three subscales measuring distinctive burnout elements: (a) Emotional Exhaustion (9 items), (b) Personal Accomplishments (8 items), and (c) Depersonalization (5 items). Participants were invited to rate how often they experience specific emotions and reactions, for instance: Ifeel burned out from my work (emotional exhaustion); In my work, I deal with emotional problems very calmly (personal accomplishments); I feel I treat some recipients as if they were impersonal objects (depersonalization). The answers were rated on a 7-point Likert-type scale ranging from 0 (never), through 3 (a few times a month) to 7 (every day), and averaged for each subscale. Thus, three independent scores were computed for each participant, not to be used in combination (as one total score), 
for the relationship between these three aspects of burnout have not been studied (Schaufeli et al., 1996). A higher score (mean score of more than 39 points) on the Personal Accomplishments subscale signified less burnout, whereas a higher score on the other two subscales (mean score of 27 or more on EE; 13 and over on DP) implied higher burnout (Maslach et al., 1986).

The psychometric properties of the Maslach Burnout Inventory (MBI) have been tested, and it is widely considered to be a sound instrument (Personal Accomplishment, alpha $=.75$, Emotional Exhaustion, alpha $=.87$, and Depersonalization, alpha $=.77$ (Maslach \& Jackson, 1981). With regards to its reliability, "the MBI has evidenced relatively high internal consistency and test-retest reliability ...” (Lee \& Ashforth, 1990). Toward this end, the reliability coefficients were observed by Maslach et al. (1986) as .90 for the Emotional Exhaustion, .71 for the Personal Accomplishments, and .79 for Depersonalization. Test-retest reliability, based on longitudinal studies of five samples, which consisted of a wide array of participants (e.g., administrators in a health agency, graduate students in social welfare, teachers, supervisors and managers) confirmed that each subscale was consistently reliable, regardless of the time intervals between the testing sessions (Schaufeli et al., 1996). Recent meta-analysis of 45 empirical studies demonstrated average reliabilities as only slightly varied from those originally observed by Maslach et al. (1986), .88 for Emotional Exhaustion, .78 for the Personal Accomplishments, and .71 for Depersonalization (Aguayo, Pecino, de la Fuente Solana, \& Fernández, 2011). In another recent meta-analysis the MBI scale was described as providing adequate internal consistency for research purposes. However, none of the 
subscales met the rigorous standards (alpha coefficients at a minimal level of $\alpha=.80$, and ideally at $\alpha=.95$ ) for diagnostic use (Wheeler et al., 2011).

Convergent validity of the MBI has been established by comparing results of measured burnout for police officers with the observations of their spouse, and for mental health workers with the observations of a co-worker (Maslach et al., 1986). Similarly, Leiter and Durup (1994), in a study with 307 human service professionals in a large Canadian teaching hospital explored convergent and discriminant validities of the MBI in relation to POMS Depression Scale (McNair et al.,1981), and Beck’s Depression Inventory (Beck et al., 1961). The results validated burnout and depression as two separate, although related, constructs. Moreover, Cordes and Dougherty (1993) discussed various studies in which both convergent and discriminant validities of the MBI were examined and substantiated. Additionally, they reported that no significant correlations can be found between MBI scores and the Crowne-Marlowe Social Desirability Scale, thus eliminating the possibility of socially desirable responses.

Although most studies of burnout in other countries have been completed after the MBI was strongly established in the US and Canada, some researchers investigated its psychometric properties in translated versions (Maslach, Schaufeli, \& Leiter, 2001). For instance, German translation of the MBI was used in a study of 449 male and female nurses and nursing students with good results (Büssing \& Perrar, 1992). Similar populations were studied with the use of the Chinese, Italian and Lebanese versions of the MBI and the results confirmed the instrument's acceptable validity and reliability (Cao, Liu, Tian, \& Guo, 2013; Pisanti, Lombardo, Lucidi, Violani, \& Lazzari, 2013; Sabbah, I., Sabbah, H., Sabbah, S., Akoum, \& Droubi, 2012). Satisfactory reliability and 
internal consistency for all three subscales were also corroborated in a Greek study of 536 midwives (Galanakis, Moraitou, Garivaldis, \& Stalikas, 2009). The psychometric properties of the MBI were also investigated in the Dutch translation of the measure (Roelofs, Verbraak, Keijsers, De Bruin, \& Schmidt, 2005). Based on the studies with individuals with and without clinical symptoms, MBI-DV was endorsed as a valid and reliable multidimensional scale, especially useful as a screening tool for detecting clinical levels of burnout. In one of the most recent studies of 1,200 health workers (doctors and nurses) from three different Spanish hospitals good psychometric properties of the MBI were again validated (Gascón et al., 2013). The investigators pointed out that the Maslach Burnout Inventory is a good tool for not only detecting early signs of burnout, but also for assessment of the organizational quality of work conditions, and for development of intervention programs. In the current study the MBI has shown acceptable internal consistency (Cronbach alpha $\alpha=.81$ ), with the reliability coefficients observed for the Emotional Exhaustion $\alpha=.78$, for the Personal Accomplishments $\alpha=.55$, and for Depersonalization $\alpha=.72$.

Stress Reduction Practices, Religious and Spiritual Activities. The third section of the survey consisted of three questions relating to stress reduction activities, religious and spiritual behaviors, and to identifying self (or not) as a religious or spiritual person.

The first question related to stress reduction activities, and included 11 possible answers: Exercise, Go for a walk, Listen to music, Play with a pet, Read a book, Take a bath, Take a nap, Talk to a friend, Watch TV, Write a journal, and Other forms of stress reduction practices. Each of the answers (including other forms of practices) was to be 
rated on a 5-point Likert scale, ranging from 1 (never or very rarely true) to 5 (often to always true).

Informed by the available literature, both spirituality and religiosity were treated in this study as stress-reducing behaviors (Belavich, 1995; Hathaway \& Pargament, 1992). Some of the answers in the second question were based on the existing religious scale, which has shown good internal reliability $($ Cronbach alpha $=.95)$ and validity (Plante \& Boccaccini, 1997). The original scale consisted of 10 items designed to measure religious faith regardless of denomination. However, since this study did not aim to assess the strength of religious convictions, but rather the influence of religiosity on reducing stress, only two of the statements: I consider myself active in my faith or church; and I pray daily were used in the original format. A subsequent statement was modeled on the original ones, but modified to include the spiritual aspect, in addition to religious attributes of the respondents: I meditate daily. The fourth answer was created by the researcher to include an option for specifying the types of other spiritual activities carried out by participants: I use other forms of spiritual practice. These statements required participants to state the frequency of behaviors. The answers were rated on a 5point Likert scale, ranging from 1 (never or very rarely true) to 5 (often to always true).

The last question was also generated by the researcher and asked respondents to identify as spiritual or religious: What term best describes you [religiosity relates to a system of beliefs, experiences, and rituals shared among members of a religious group (Corbett. 1990); spirituality relates to the sense of meaning and purpose acquired through life experiences (May, 1982)]? The possible answers included: Religious, Spiritual, Both Religious and Spiritual, Neither Religious nor Spiritual, and Other. Each 
of the three questions was rated individually, with the last question resulting in multiple answers by some of the individual respondents.

Demographics. Rubin and Babbie (2011) suggested that demographic questions (age, gender, income, education, etc.) should be left until the end of the questionnaire since they do not typically entice the responders and might prevent them from completing the survey if placed in the beginning. Thus, the demographic section, developed by the researcher, has been placed at the conclusion of the survey as the fourth section.

The development of this section has been an iterative process. As such, it involved numerous revisions, based on consultation with other academics, available literature, and pilot testing with the social work doctoral students at PSU. The format of this section was modified to match the layouts of the other questionnaires used in this study.

This demographic section consisted of 16 items, including questions about participants' age, gender, ethnicity, race, relationship status, annual household income, guardianship and caregiving practices, years of practicing in human services, current practice in human services, status of the field placement, year in the MSW program, the enrollment status, concentration, and the motivation to become a social worker. The concentration variable was re-coded into a dichotomous format, where 1 signified Direct Human Services (DHS), and 2 denoted all other categories (Community Based Practice, Social Service Administration and Leadership, and not decided). Questions about age, years (and/or months) of social work practice, and the motivation to become social worker were left as open ended, allowing the researcher to obtain the exact numbers in months (instead of time periods), and the qualitative answers to the last question. Some 
questions in this section (Hispanic origin, race, and marital status) were based on similar items included in The American Community Survey (U.S. Census Bureau, 2012), yet were reworded after the pilot testing and formatted to coordinate with other scales' layout. Two questions relating to caregiving were taken verbatim from the original Caregiving in the U.S. questionnaire: In the last 12 months, has anyone in your household provided unpaid care to a relative or friend 18 years or older to help them take care of themselves?; In the last 12 months, has anyone in your household given unpaid care to any child under the age of 18 because of a medical, behavioral, or other condition or disability? (National Alliance for Caregiving and AARP, 2009). In addition, one question regarding guardianship: Are you a parent or guardian of any child under 18 years of age who lives in your home for at least 6 months a year? was adapted, in a slightly modified form, from the questionnaire used in the National Study of the Changing Workforce (Families and Work Institute [FWI], 2008). 


\section{CHAPTER 5: Results}

This chapter reports the results of analyses of data in five sections: variables assessment, characteristics of participants (demographics, stress reduction practices, spirituality/religiosity, burnout and mindfulness), correlations, sequential regressions, and partial correlations. Initially, after the data were checked and cleaned the evaluation of the descriptive statistics (quantitative and qualitative) was completed to determine characteristics of participants. In addition, stress reduction practices, spirituality/religiosity, burnout, and mindfulness were preliminarily explored with descriptive statistics. The analysis followed the standard procedures for exploring data sets suggested by Tabachnick and Fidell (2001). In order to ensure no violation of the necessary assumptions for the distribution of scores, the normality, linearity, and homoscedasticity were investigated. Next, the correlations among variables of interest were examined in order to determine significant relationships among them. Only statistically significant correlated variables were entered in the sequential regressions, which were used to examine the research questions. The regressions focused on the ability of independent variables to predict the continuous dependent measures, and thus, on answering this study's research questions. Finally, partial correlations were completed to explore specific relationships among individual facets of FFMQ and factors of burnout, controlling for possible confounding variables. All statistical analyses were performed using SPSS 22.

Three primary independent variables were used in this study: religiosity (with three subcategories: identifying self as religious, being active in church or faith, and 
praying daily), spirituality (three subcategories: identifying self as spiritual, meditating daily, and using other forms of spiritual practices), and five facets of mindfulness: observing, describing, nonreactivity to inner experience, nonjudging of inner experience, and acting with awareness.. The dependent variable (DV) was comprised of levels of burnout, with three subcategories of emotional exhaustion, personal accomplishments, and depersonalization. Additionally, two possible covariates: months of practicing in human services and year in the MSW program were included in the analyses to assess for their relationship with burnout. Possible control variables included demographic data: respondents' age, gender, race, ethnicity, relationship status, presence of children in the household, care for a relative or a child, income, currently practicing in human services outside field placement, being in field placement, enrollment status, concentration and other forms of stress reduction practices. In addition, participants' reasons for becoming a social worker were explored using qualitative methods. Possible relationships between variables are presented in Figure 1.

\section{Variables Assessment}

Normality. Normality of the variables' distribution was assessed by the use of descriptive statistics, with the special focus on the variables' skewness and kurtosis. Eight continuous variables were investigated, with most of them having skewness and kurtosis statistics within the conservative bounds recommended by Tabachnick and Fidell (2001). Two subcategories of religiosity/spirituality were not normally distributed. Identifying self as religious only had skewness 4.898/.192 $=25.51$ and kurtosis $22.271 / .383=58.15$, while identifying self as other than religious or spiritual had skewness $3.428 / .192=17.85$ and kurtosis $9.874 / .383=25.78$. These results indicate that both variables had scores 
clustered around low values, and the distribution peaked (clustered at the center), suggesting that many respondents identified themselves as religious only or other than religious or spiritual very rarely, or never.

Linearity and homoscedasticity. The predictive value of religion, spirituality, mindfulness, years of MSW program, and years of practicing in human services for levels of burnout was investigated. Preliminary analyses were performed to ensure no violation of the assumptions of linearity and homoscedasticity. One extreme outlier was found and eliminated from this data set in order to remove its influence on the sequential regressions' results. The tests were repeated, and the updated results revealed that remaining scores' Mahalanobis Distances did not exceed the critical chi-square value $\left(\chi^{2}\right.$ $(\mathrm{df}=14)=36.123, \mathrm{p}<.001)$, indicating no additional unusual cases in the set. In addition, Cook's Distance maximum values did not exceed the value of 1 , suggesting that no cases had an undue influence on the results of the regression model as a whole. The presence of multicollinearity was also tested in the regression models. The Tolerance values were observed at the levels above the commonly used cut-off point of .10. Therefore, it could be inferred that multicollinearity was not present in this data set.

\section{Characteristics of Participants}

Demographic characteristics of the sample have been summarized in Table 1, and include means, median, mode, standard deviations, and frequencies where applicable. Moreover, means $(M)$ and standard deviations $(S D)$ have been computed for stress reduction practices (Table 2), religious and spiritual affiliation and practices, and the Burnout Inventory (Table 3), as well as the four and five facets, and three subscales of the Mindfulness Questionnaire (Table 4). 
Stress reduction practices. The summary of the stress reduction practices reported by the students are presented in Table 2 . The most often used practices were listening to music and playing with an animal/pet. People also often talked to a friend to reduce stress. Most participants reported that they sometimes watched TV, exercised, and went for a walk to deal with stress (the scores were equally distributed). The least used stress reduction practices were writing a journal, taking a nap, as well as taking a bath, or reading a book. As other stress diminishing practices, 27 participants reported using arts, crafts, or play time, and 24 cooking or eating a meal. Some (17 students) used alcohol to de-stress, while others (14 participants) spend time in nature, with the family or significant others (12), or meditated (11). Religious activities (praying, reading a Bible, or church events) were also reported as stress relieving practices by 9 students. Using yoga or doing household chores were indicated by 7 participants, while 6 used therapeutic services or sexual activities to cope with stress. Finally, mindfulness was reported to be used as a stress reduction activity by 3 students.

Religiosity/spirituality. The majority of respondents identified themselves as spiritual only (45.9\%), followed by neither religious nor spiritual (22.6\%), both religious and spiritual (20.8\%), other than religious or spiritual $(6.9 \%)$, and religious only $(3.8 \%)$.

The other category included answers such as: spiritual but rather scientifically minded, not practicing in family faith, pagan, attending church for a child, undecided, not praying but practicing gratefulness, mindful, being present, and agnostic. 
Table 2

Stress Reduction Practices Reported $(N=159)$

\begin{tabular}{|c|c|c|c|c|}
\hline Type of practice & $M$ & Median & Mode & $S . D$. \\
\hline Listen to music & 3.66 & $4^{*}$ & 5 & 1.19 \\
\hline Talk to a friend & 3.64 & 4 & 4 & 1.16 \\
\hline Watch TV & 3.24 & 3 & 3 & 1.34 \\
\hline Play with a pet/animal & 3.13 & 3 & 5 & 1.62 \\
\hline Go for a walk & 3.05 & 3 & 3 & 1.07 \\
\hline Exercise & 3.03 & 3 & 3 & 1.21 \\
\hline Take a bath & 2.62 & 3 & 1 & 1.44 \\
\hline Read a book & 2.60 & 3 & 1 & 1.31 \\
\hline Take a nap & 2.49 & 2 & 1 & 1.32 \\
\hline Write a journal & 1.76 & 1 & 1 & 1.06 \\
\hline \multicolumn{5}{|l|}{ Other: } \\
\hline Arts, crafts, play time $(n=27)$ & 1.49 & 1 & 1 & 1.15 \\
\hline $\operatorname{Cook}(\mathrm{n}=24)$ & 1.48 & 1 & 1 & 1.16 \\
\hline Drink alcohol $(\mathrm{n}=17)$ & 1.26 & 1 & 1 & .80 \\
\hline $\begin{array}{l}\text { Spend time with family/ } \\
\text { significant others }(n=12)\end{array}$ & 1.25 & 1 & 1 & 91 \\
\hline Spend time in nature $(\mathrm{n}=14)$ & 1.24 & 1 & 1 & .81 \\
\hline Meditate $(n=11)$ & 1.21 & 1 & 1 & .81 \\
\hline Religious activities $(\mathrm{n}=9$ ) & 1.18 & 1 & 1 & .77 \\
\hline Yoga $(n=7)$ & 1.10 & 1 & 1 & .48 \\
\hline Household chores $(n=7)$ & 1.15 & 1 & 1 & .71 \\
\hline Sexual activities $(\mathrm{n}=6)$ & 1.11 & 1 & 1 & .60 \\
\hline Therapeutic help $(\mathrm{n}=6)$ & 1.11 & 1 & 1 & .60 \\
\hline Mindfulness $(\mathrm{n}=3)$ & 1.06 & 1 & 1 & .47 \\
\hline
\end{tabular}

Note. 1 - never or very rarely true, 2 -rarely true, 3 - sometimes true, 4 -often true, 5 -very often to always true

Most participants (56\%) reported never (or very rarely) being active in a church or faith, while some (18.2\%) did it very often (or always). The mean response fell between rarely true and sometimes true $(M=2.22, S D=1.60)$. Similar results were 
obtained for students' prayer routines, with almost half $(49.1 \%)$ reporting praying either never, or very rarely. On the opposite end, $19.5 \%$ of participants declared themselves to be praying very often, or always. The mean responses for prayer were observed, again, between rarely and sometimes true $(M=2.39, S D=1.61)$. Meditation was practiced by $11.3 \%$ of the respondents, while $37.1 \%$ did not meditate $(M=2.35, S D=1.36)$. In addition, $40.3 \%$ of the participants did not use other forms of spiritual practice, whereas almost 20\% (19.5\%) did. The mean of spiritual practice for the respondents, although still between rarely and sometimes true, was higher than for the preceding categories $(M=$ 2.61, $S D=1.58)$.

Burnout and mindfulness. Summaries of the three factors of Maslach Burnout Inventory results are presented in Table 3 . The emotional exhaustion scores in this sample were slightly higher $(M=24.28, S D=11.68)$ than the results obtained by Maslach et al. (1986) from the social services subgroup in their sample $(M=21.35, S D=$ 10.51). Similarly, personal accomplishment in this group of respondents $(M=37.25, S D$ $=6.50$; reversed $M=10.75, S D=6.50$ ) was slightly higher than reported in the MBI Manual $(M=32.75, S D=7.71)$. The depersonalization factor in current sample $(M=$ $6.90, S D=5.53)$ was consistent with the Maslach et al. report $(M=7.46, S D=5.11)$. 
Table 3

Maslach Burnout Inventory Scores $(N=159)$

\begin{tabular}{lcccc}
\hline Subscales & $M$ & $S D$ & Possible Range & Actual Range \\
\hline $\begin{array}{l}\text { Emotional } \\
\text { Exhaustion }\end{array}$ & 24.28 & 11.68 & $0-54$ & $0-51$ \\
$\begin{array}{l}\text { Depersonalization } \\
\begin{array}{l}\text { Personal } \\
\text { Accomplishment }\end{array}\end{array}$ & 6.90 & 5.53 & $0-30$ & $0-27$ \\
$\begin{array}{l}\text { Personal } \\
\text { Accomplishment } \\
\text { (reversed) }\end{array}$ & 17.25 & 6.50 & $0-48$ & $16-48$ \\
& 10.75 & 6.50 & $0-48$ & $0-32$ \\
\hline
\end{tabular}

When using the MBI suggested ranges for burnout in social service populations (Maslach et al., 1986), it was found that $73.6 \%$ of the participants experienced high and moderate levels of emotional exhaustion (33.3\% moderate and $40.3 \%$ high). In addition, $50.9 \%$ reported moderate $(28.3 \%)$ and high $(22.6 \%)$ depersonalization. In contrast, the majority of respondents (59.7\%) reported a high level of personal accomplishment, and thus, lower levels of burnout in this category.

Mindfulness scores have been summarized in Table 4. All scores were comparable to the nonmeditating sample described in Lykins and Baer (2009). As such, the subscale of attention, including observing and describing had a comparable mean and standard deviation $(M=56.63, S D=8.29)$ to the nonmeditators' scores $(M=57.00, S D=$ 5.95). The attitude score, including nonjudging, and nonreactivity to inner experience ( $M$ $=48.91, S D=9.32$ ) was slightly lower, but comparable to the Lykins and Baer sample 
$(M=53.70, S D=10.5)$. Intention (acting with awareness) was also comparable $(M=$ $24.94, S D=5.28)$ to the Lykins and Baer sample $(M=28.20, S D=5.7)$. Total FFMQ $(5$ facets) was reported at $M=130.48$ and $S D=18.59$ in the current sample, while in the comparable nonmeditators sample the total mean was $M=138.9$ and the standard deviation $S D=19.2$. Finally, in the total FFMQ with four facets (observing removed) the scores were similar $(M=104.00, S D=15.91)$ to those for the Lykins and Baer nonmeditators $(M=110.7, S D=13.5)$.

Table 4

Five Facets Mindfulness Questionnaire Scores $(N=159)$

\begin{tabular}{|c|c|c|c|c|}
\hline Subscales & $M$ & $S D$ & Possible Range & Actual Range \\
\hline $\begin{array}{l}\text { Attention } \\
\text { (observing and describing) }\end{array}$ & 56.63 & 8.29 & $16-80$ & $33-80$ \\
\hline $\begin{array}{l}\text { Attitude } \\
\text { (nonjudging, and nonreactivity } \\
\text { to inner experience) }\end{array}$ & 48.91 & 9.32 & $15-75$ & $25-71$ \\
\hline $\begin{array}{l}\text { Intention } \\
\text { (acting with awareness) }\end{array}$ & 24.94 & 5.28 & $8-40$ & $10-40$ \\
\hline $\begin{array}{l}\text { Total FFMQ } \\
\text { (5 facets) }\end{array}$ & 130.48 & 18.59 & $39-195$ & $84-176$ \\
\hline $\begin{array}{l}\text { Total FFMQ } \\
\text { (4 facets, no observing) }\end{array}$ & 104.00 & 15.91 & $31-155$ & $61-145$ \\
\hline
\end{tabular}

Reasons for becoming a social worker. The last question in the demographic section related to what motivated the student to become a social worker. The question was open-ended, and as such was analyzed using a content analysis approach. Out of 159 study participants, 146 responded to the question: What led you to become a social 
worker? Some of the participants offered multiple answers to the given question. The researcher read the responses numerous times in the attempt to find major themes. Since theme identification is essential to successful qualitative data analysis, seven general themes (and one with an array of uncategorized responses) were identified in this study through the use of content analysis. The process was repeated by an independent coder (an experienced social worker), and the major themes were compared, discussed, and agreed upon by both coders. Ultimately, the analysis produced five major themes that connected directly to survey question that asked students to identify factors that influenced the decision to become a social worker. These five major themes consisted of: (a) making a difference/creating change in people's lives and communities, (b) helping others, (c) personal experiences, (d) job requirement/job advancement, and (e) having private practice/becoming a therapist. The majority of the respondents $(n=65)$ claimed to want to make a difference, or create change in people's lives and communities. For instance, "To have direct impact on vulnerable people and policies," or "Desire to affect change with clients, more long term than just crisis intervention," and "Creating social change, improving lives of individuals, families, and communities." Similarly, many $(n=$ 60), of the participants within the study identified themselves as having a strong desire to help others. The following are quotes from the participants' opinions regarding this issue: "To help empower children and families to have full and happy lives," "Love helping people find their strength, dedication, making the best they can be," "Desire to help others, especially abused kids." Of the 146 participants answering the open ended question, 37 participants reported having personal experiences that may have influenced their decision to pursue a career in social work. Examples of the responses were: 
"Survivor of sexual abuse, want to help others heal," "Poverty, my own and others, also child abuse," "My own recovery and spiritual practice." Some participants $(n=20)$ also reported being motivated by the job requirement or a possibility of job advancement, such as "Most jobs in the field require MSW," "Need MSW to continue goals," "Take job to the next level, want to help people." Finally, some respondents $(n=11)$ disclosed being motivated by the possibility of having a private practice, or becoming a therapist. The following are quotes from their statements: "Want to provide private practice therapy," "Interest in health psychology, plan to become LCSW and practice as mental health therapist," "Enjoy working with children, want to become LCSW and registered play therapist." Some of the miscellaneous reasons offered by the participants were: "Opportunity to do a wide array of work," "Ability to manage my feelings and emotions," "Interest in human behavior and exploring human condition," "See movement in social work," and "Can do it now - grown kids."

\section{Correlations}

The Pearson's product-moment correlation coefficients revealed a number of statistically significant relationships among variables of interest. Due to the large number of variables separate correlation analyses were conducted with subsets of study variables.

Demographics. Among demographic variables only four were found to be significantly correlated with overall burnout: age $(r=-.21, p=.008)$, caring for a child under the age of $18(r=.19, p=.017)$, income $(r=-.18, p=.023)$, and concentration $(r=$ $.23, p=.003)$. Thus, it appears that younger students, with less income, who are not caretakers of a child (higher number indicating not being a caretaker), and are on other than the direct human services track (higher number indicating other tracks) are more 
prone to report burnout.

Correlations between mindfulness and burnout. In the next correlational analysis, the relationships between religious and spiritual affiliation, mindfulness, months in human services, year in the MSW program, and burnout were assessed. Twenty seven statistically significant correlations were found (summary of the correlations is presented in Table 5). First, emotional exhaustion was negatively correlated with all facets and sums of mindfulness - attention: observing and describing $(r=-.19, p=.018)$, attention with describing only $(r=-.16, p=.041)$, attitude: nonreactivity to inner experience, and nonjudging of inner experience $(r=-.40 p=.000)$, acting with awareness $(r=-.42 p$ $=.000)$, with the sum of all five facets of mindfulness $(r=-.40, p=.000)$, and with the sum of four facets of mindfulness, with the observing facet removed $(r=-.43, p=.000)$. This implies that less emotional exhaustion associates with more reported mindfulness.

Moreover, the negative perception of personal accomplishment has been also negatively correlated with all facets and sums of mindfulness - attention: observing and describing $(r=-.35, p=.000)$, attention with describing only $(r=-.35, p=.000)$, attitude: nonreactivity to inner experience, and nonjudging of inner experience $(r=-.35$, $p=.000)$, intention/acting with awareness $(r=-.23 p=.003)$, with the sum of all five facets of mindfulness $(r=-.40, p=.000)$, and with the sum of four facets of mindfulness, the observing facet removed $(r=-.41, p=.000)$. The results suggest that more mindfulness is associated with less negative perception of personal accomplishment (and less burnout). 
TABLE 5. Correlations between Independent Variables and Burnout $(\mathrm{N}=159)$

\begin{tabular}{|c|c|c|c|c|}
\hline & $E E$ & $P A$ & $D P$ & MBISum \\
\hline FFMQ(Attention) & $-.187^{*}$ & $-.348^{* *}$ & $-.226^{* *}$ & $-.299^{\star * *}$ \\
\hline FFMQ(AttentionNoObserving) & $-.162 *$ & $-.352^{\text {** }}$ & $-.206^{* *}$ & $-.280^{* \star}$ \\
\hline FFMQ(Attitude) & $-.399^{* *}$ & $-.352^{* *}$ & $-.279^{* *}$ & $-.447^{* *}$ \\
\hline FFMQ(Intention) & $-.417^{* *}$ & $-.233^{\star \star *}$ & $-.340^{* *}$ & $-.435^{\star \star}$ \\
\hline FFMQ(SumFourFacets) & $-.402^{* *}$ & $-.405^{\star *}$ & $-.348^{* *}$ & $-.502^{* *}$ \\
\hline FFMQ(SumFiveFacets) & $-.428^{* \star *}$ & $-.398^{\star *}$ & $-.337^{\text {** }}$ & $-.481^{* *}$ \\
\hline Months in Human Services & -.104 & $-.249^{* *}$ & $-.180^{*}$ & $-.201^{*}$ \\
\hline Year in MSW Program & .096 & .115 & .030 & .107 \\
\hline Spiritual Ony & -.025 & -.066 & -.022 & -.044 \\
\hline Religious Only & -.039 & -.008 & -.050 & -.041 \\
\hline Both Religious and Spiritual &. .035 & .058 & -.022 & -.008 \\
\hline Neither Religious nor Spiritual & .059 & .028 & .084 & .070 \\
\hline Pray daily & $-.154^{\mathrm{t}}$ & $-.154^{\mathrm{t}}$ & $-.175^{\mathrm{t}}$ & $-.198^{\mathrm{t}}$ \\
\hline Active in faith/church & -.108 & .005 & -.043 & -.077 \\
\hline Meditate daily & -.011 & -.104 &. .058 & -.059 \\
\hline Other forms of spiritual practices & -.062 & -.171 & $-.180^{*}$ & -.149 \\
\hline
\end{tabular}

Note: *Correlation significant at 0.05 (2-tailed), ${ }^{* *}$ correlation significant at 0.01 level (2-tailed), ${ }^{\text {t }}$ non-significant trend EE-Emotional Exhaustion, PA-Personal Accomplishment, DP-Depersonalization, Attention (observing and describing), Attitude (nonjudging and nonreacting to inner experience), Intention (acting with awareness)

Similarly, depersonalization was negatively correlated with all facets and sums of mindfulness - attention: observing and describing $(r=-.23, p=.004)$, attention with describing only ( $r=-.21, p=.009)$, attitude: nonreactivity to inner experience, and nonjudging of inner experience $(r=-.28, p .000)$, acting with awareness $(r=-.34 p$ $=.000)$, with the sum of all five facets of mindfulness $(r=-.34, p=.000)$, and with the sum of four facets of mindfulness, the observing facet removed $(r=-.35, p=.000)$. Again, this indicates that less depersonalization is associated with more mindfulness, in all facets and sums. The sum of all burnout subscales has also been negatively correlated 
with all facets and sums of mindfulness - attention: observing and describing $(r=-.30, p$ $=.000)$, attention with describing only ( $r=-.28, p=.000)$, attitude: nonreactivity to inner experience, and nonjudging of inner experience $(r=-.45, p=.000)$, intention/acting with awareness ( $r=-.44, p=.000)$, with the sum of all five facets of mindfulness $(r=-.48, p$ $=.000)$, and with the sum of four facets of mindfulness, the observing facet removed $(r=$ $-.50, p=.000)$. These results indicate that more mindfulness is associated with less burnout, in all facets, two subscales, and sums.

Length of practicing in human services and burnout. The length of practicing in human services prior to entering the MSW program was negatively correlated with the overall burnout $(\mathrm{r}=-.20, \mathrm{p}=.011)$, with the depersonalization $(\mathrm{r}=-.18, \mathrm{p}=.023)$, and with personal accomplishment $(\mathrm{r}=-.25, \mathrm{p}=.002)$. The results suggest that less prior experience in the human services field was associated with more reported overall burnout, more depersonalization, but also more negative perception of personal accomplishment. Months of practicing in human services was also positively correlated with attention: observing and describing $(r=.30, p=.000)$, attention with describing only ( $r=.27, p=.001)$, attitude: nonreactivity to inner experience, and nonjudging of inner experience ( $r=.18 p=.026)$, with the sum of all five facets of mindfulness $(r=.23$, $p=.004$ ), and with the sum of four facets of mindfulness, with the observing facet removed $(r=.21, p=.009)$. This indicates that the more years spent practicing in human services, the more reported overall mindfulness, especially more attention paid, and more nonjudgmental and nonreactive attitudes in a person.

Attention: observing and describing was also positively correlated with being spiritual only $(r=.19, p=.015)$, and negatively with being neither religious nor spiritual 
$(r=-.17, p=.036)$. This implies that the more one identifies self as spiritual, the more attention the person pays, while the opposite is true for the individuals identifying as neither religious nor spiritual. One of the elements of being religious, namely praying daily, showed non-significant trend levels in relation to all factors of burnout and the MBI cumulative score (Table 5).

Relationships between religiosity and spirituality. In order to determine the strength of the relationships between religious and spiritual practices and religious/spiritual affiliation correlations between these variables were examined (Table $6)$.

Table 6

Correlations between Spiritual and Religious Affiliation and Practices $(N=159)$

\begin{tabular}{lcccc}
\hline & Religious only & Spiritual only & Both & |Neither \\
\hline Active in faith/church & $.24^{* *}$ & $-.16^{*}$ & $.50^{* *}$ & $-.41^{* *}$ \\
Pray daily & $.18^{*}$ & -.01 & $.43^{* *}$ & $-.46^{* *}$ \\
Meditate daily & -.08 & $.23^{* *}$ & .06 & $-.33^{* *}$ \\
Use other spiritual practices & -.08 & $.19 *$ & $.22 * *$ & $-.42^{* *}$ \\
\end{tabular}

Note. ${ }^{*} \mathrm{p}<0.05$ (2-tailed), $* * \mathrm{p}<0.01$ level (2-tailed)

Twelve statistically significant correlations were found. Positive, small correlations were demonstrated between identifying self as religious only and being active in faith/church $(r=.24, p=.002)$, as well as identifying self as religious only and praying daily $(r=.18, p=.024)$. This implies an association between religiosity, being 
active in church/faith life, and daily prayer. In addition, identification as only a spiritual person was positively correlated to meditating daily $(r=.23, p=.004)$, and to using other forms of spiritual practices $(r=.19, p=.018)$. Furthermore, self-identified spiritual only respondents showed a negative and small correlation with being active in faith/church ( $r$ $=-.16, p=.045)$. Reports of participants claiming to be both religious and spiritual showed a positive and large correlation with being active in faith/church $(r=.50, p$ $=.000)$, a medium correlation with praying daily $(r=.43, p=.000)$, and a small correlation with using other forms of spiritual practices $(r=.22, p=.006)$. Finally, considering self neither religious nor spiritual showed a negative correlation with being active in faith/church $(r=-.41, p=.000)$, praying daily $(r=-.46, p=.000)$, meditating daily $(r=-.33, p=.000)$, using other forms of spiritual practices $(r=-.42, p=.000)$, being spiritual only $(r=-.50, p=.000)$, and being both religious and spiritual $(r=-.28, p$ $=.000)$. Pearson's chi square tests revealed that spiritual only and religious only participants were significantly different from each other in this study $\left(\chi^{2}=5.293, p=\right.$ $.021)$.

Religiosity, spirituality, and burnout. However, the two independent variables, spirituality and religiosity were excluded from the further analyses due to the statistically non-significant results in the preliminary bivariate tests with all three factors of burnout. Emotional exhaustion was non-significantly correlated to identifying self as active in church/faith $(r=-.11, p=.175)$, meditating daily $(r=-.01, p=.895)$, and using other forms of spiritual practice $(r=-.06, p=.435)$, while praying daily showed only a nonsignificant trend $(r=-.15, p=.062)$. Moreover, emotional exhaustion was also nonsignificantly correlated with being religious only $(r=-.04, p=.628)$, spiritual only $(r=-$ 
$.03, p=.753)$, both religious and spiritual $(r=-.04, p=.663)$, and neither religious nor spiritual ( $r=.06, p=.457)$. Another factor of burnout, personal accomplishment, showed similar, non-significant correlations with identifying self as active in church/faith $(r=.01, p=.953)$, meditating daily $(r=-.10, p=.195)$, and $u$ sing other forms of spiritual practice $(r=-.17, p=.131)$, while praying daily showed a non-significant trend $(r=-.15$, $p=.063)$. Additionally, identifying self as religious only $(r=-.01, p=.924)$, spiritual only $(r=-.07, p=.412)$, both religious and spiritual $(r=.06, p=.466)$, and neither religious nor spiritual ( $r=.03, p=.726)$ were also non-significantly correlated with personal accomplishment. Finally, depersonalization followed the same non-significant path of the other burnout factors. It was not significantly correlated with identifying self as active in church/faith $(r=-.04, p=.594)$, meditating daily $(r=-.06, p=.471)$, and using other forms of spiritual practice $(r=-.18, p=.123)$, while praying daily showed non-significant trend $(r=-.18, p=.067)$. Additionally, being religious only $(r=-.05, p$ $=.529)$, spiritual only $(r=-.02, p=.782)$, both religious and spiritual $(r=-.02, p=.787)$, and neither religious nor spiritual $(r=.08, p=.295)$ were also non-significantly correlated with depersonalization.

Stress reduction practices and burnout. There were three statistically significant results observed in the final correlation analysis, which explored relationships between other stress reduction practices and burnout (summarized in Table 7). Talking to a friend was negatively and weakly correlated with the overall burnout $(r=-.25, p$ $=.001$ ), indicating that more burnout was reported by people who talked less to friends. Additionally, talking to a friend was negatively (and in a small way) associated with the emotional exhaustion ( $r=-.25, p=.002$ ), again implying that the more one is using 
friendly talk, the less emotional exhaustion the person reports. Finally, talking to a friend was negatively (even if in a small way) correlated with the personal accomplishment $(r=$ $-.17, p=.031)$, indicating that the more the participants talked with friends, the less negative their perceptions of personal accomplishments were.

All other stress reduction practices did not reach statistical significance in correlation with three factors of burnout or the sum of burnout.

Year in the MSW program and burnout. Year in the MSW program variable was excluded from the further (partial correlations and regression) analyses due to the statistically non-significant results in this preliminary bivariate analyses with all three factors of burnout: emotional exhaustion $(r=.10, \mathrm{p}=.229)$, personal accomplishments $(\mathrm{r}$ $=.12, \mathrm{p}=.150)$, and depersonalization $(\mathrm{r}=.03, \mathrm{p}=.711)$. Moreover, the cumulative score for the burnout was also non-significant in correlation analyses to year in the MSW $\operatorname{program}(\mathrm{r}=.11, \mathrm{p}=.180)$.

Table 7

Correlations between Other Stress Reduction Practices and Burnout ( $N=159)$

\begin{tabular}{lllll}
\hline & EE & PA & DP & MBI Sum \\
\hline Stress Reduction Practices & & & & \\
\hline Exercise & -.03 & -.06 & .02 & -.03 \\
Go for a walk & -.08 & -.11 & .06 & -.17 \\
Listen to music & .05 & .04 & .00 & .05 \\
Play with a pet/animal & .06 & -.03 & -.01 & .02 \\
Read a book & .08 & .05 & -.09 & .04 \\
Take a bath & -.12 & -.00 & -.02 & -.07 \\
Take a nap & -.07 & .05 & -.02 & -.03 \\
Talk to a friend & $-.25 * *$ & $-.17 *$ & $-.15 *$ & $-.25 * *$ \\
Watch TV & -.01 & .05 & .01 & .01 \\
Write a journal & -.09 & -.02 & -.09 & -.09 \\
\hline
\end{tabular}

Note. ${ }^{*} \mathrm{p}<0.05$ (2-tailed), ${ }^{* *} \mathrm{p}<0.01$ level ( 2 -tailed), ${ }^{\mathrm{t}}$ non-significant trend

EE- Emotional Exhaustion, PA- Personal Accomplishment, DP- Depersonalization 


\section{Sequential Regressions}

Sequential regressions were performed to answer the research questions. The sequential regression tests were run for this data set in order to investigate the unique contribution of independent variables to the model as a whole. In total, 10 regression models were analyzed and reported in Table 8 and Table 9. The results were evaluated in relation to the four research questions asked in this study:

\section{Does the length of practicing in human services predict levels of burnout for MSW students?}

The results from the first regression models (Table 8) indicated that months of practicing in human services did not significantly predict any of the burnout factors (controlling for age, caring for a child under the age of 18, income, and concentration): emotional exhaustion $B=.01, S E_{\mathrm{B}}=.02, \beta=.08, t=.32, p=.37$, depersonalization $B=.01$, $S E_{\mathrm{B}}=.01, \beta=.06, t=.26, p=.78$, and personal accomplishment $B=-.01, S E_{\mathrm{B}}=.01, \beta=-$ $.09, t=-1.32, p=.35$. It also did not significantly predict the MBI $\operatorname{sum} B=.01, S E_{\mathrm{B}}=.03$, $\beta=.04, t=-.17, p=.64$. However, concentration $B=4.70, S E_{\mathrm{B}}=1.74, \beta=.08, t=3.01, p=$ .01 , income $B=-1.81, S E_{\mathrm{B}}=.87, \beta=-.16, t=-2.02, p=.04$, and stress reduction (talking to a friend) $B=-1.78, S E_{\mathrm{B}}=.73, \beta=-.18, t=-1.03, p=.02$, significantly contributed to the overall model with emotional exhaustion. In addition, income $B=-2.62, S E_{\mathrm{B}}=1.35, \beta=-$ $.14, t=-1.84, p=.05$, concentration $B=6.52, S E_{\mathrm{B}}=2.69, \beta=.17, t=2.71, p=.02$, and stress reduction (talking to a friend) $B=-2.49, S E_{\mathrm{B}}=1.13, \beta=-.15, t=-1.03, p=.03$ significantly contributed to the MBI sum. Age demonstrated a non-significant trend to contribute to the depersonalization. 


\section{Does the year in the MSW program affect the experienced levels of burnout?}

This covariate, year in the MSW program, was excluded from further regression analyses due to the statistically non-significant results in the preliminary bivariate tests with all three factors of burnout (please refer to the description in the Correlations subsection).

\section{Do current MSW students who demonstrate higher levels of mindfulness report less burnout, regardless of the year in the MSW program and regardless of the years of practice in human services?}

Eight sequential regression models explored the unique contribution of the sums of the mindfulness scores (five facets, as well as four facets, with observing removed) to the prediction of burnout (each of the three factors, and the cumulative burnout score), while controlling for demographics (age, caring for a child under the age of 18, income, concentration, and months practicing in human services), and one stress reduction practice that was significantly correlated with burnout (talking to a friend).

The first set of four models tested the unique contribution of the sum of the five facets of mindfulness (as one cumulative score) in predicting three factors (and their sum) of burnout (detailed results in Table 8). The sequential multiple regression revealed that when control variables: age, caring for a child under the age of 18, income, concentration, months practicing in human services, and talking to a friend were entered in Block 1, their unique contribution to the model was $17 \%$ of the variance for emotional exhaustion, $14 \%$ for personal accomplishment, $13 \%$ for depersonalization, and $20 \%$ for the cumulative score for burnout. By far the strongest IV contributor to the cumulative MBI sum was concentration, followed by talking to a friend, and income. Care for a 
child showed a non-significant trend level. Concentration, talking to a friend, and income were also significant contributor to the emotional exhaustion, while age significantly contributed to depersonalization.

Table 8

Sequential Regression Model of Burnout Factors (and MBI Sum) with Independent Variables of Age, Care for Child, Income, Concentration, Stress Reduction Practice, Months Practicing in Human Services, and Mindfulness - Five Facets (N=157).

\begin{tabular}{|c|c|c|c|c|c|c|c|c|c|c|c|c|c|c|c|c|}
\hline \multirow{3}{*}{$\begin{array}{l}\text { Independent } \\
\text { Variable }\end{array}$} & \multicolumn{4}{|c|}{ Emotional Exhaustion } & \multicolumn{4}{|c|}{ Personal Accomplishment } & \multicolumn{4}{|c|}{ Depersonalization } & \multicolumn{4}{|c|}{ MBI Sum } \\
\hline & \multicolumn{4}{|c|}{$R^{2}=.26$} & \multicolumn{4}{|c|}{$R^{2}=.23$} & \multicolumn{4}{|c|}{$R^{2}=.19$} & \multicolumn{4}{|c|}{$R^{2}=.33$} \\
\hline & $B$ & $S E_{\mathrm{B}}$ & $B$ & $p$ & $B$ & $S E_{B}$ & 6 & $p$ & $B$ & $S E_{B}$ & 6 & $p$ & $B$ & $S E_{\mathrm{B}}$ & 6 & $p$ \\
\hline \multicolumn{17}{|l|}{ Block 1} \\
\hline Age & -.00 & .01 & -.02 & .81 & -.00 & .01 & -.05 & .59 & -.01 & .01 & -.25 & .07 & -.02 & .02 & -.11 & .21 \\
\hline Care for a Child & 3.82 & 2.59 & .11 & .14 & 1.31 & 1.47 & .07 & .37 & 1.74 & 1.28 & .11 & .18 & 6.85 & 3.50 & .13 & .09 \\
\hline Income & -1.81 & .87 & -.16 & .04 & -.83 & .50 & -.13 & .10 & .01 & .43 & .00 & .98 & -2.62 & 1.35 & -.14 & .05 \\
\hline Concentration & 4.70 & 1.74 & .19 & .01 & 1.59 & .99 & .12 & .11 & .24 & .86 & .02 & .78 & 6.52 & 2.69 & .17 & .02 \\
\hline Months & .01 & .02 & .08 & .37 & -.01 & .01 & -.09 & .35 & .01 & .01 & .06 & .50 & .01 & .03 & .04 & .64 \\
\hline Stress Reduction & -1.78 & .73 & -.18 & .02 & -.43 & .42 & -.08 & .31 & -.28 & .36 & -.06 & .44 & -2.49 & 1.13 & -.15 & .03 \\
\hline \multicolumn{17}{|l|}{ Block 2} \\
\hline FFMQ & -.20 & .05 & -.32 & .00 & -.11 & .03 & -.32 & .00 & -.08 & .02 & -.26 & .00 & -.39 & .07 & -.38 & .00 \\
\hline
\end{tabular}

Note. Stress Reduction| Talk to a Friend, Months-month of practicing in human services, MBI-Maslach Bumout Inventory, FFMQ-Five Facets Mindfulness Questionnaire, Four Facets Mindfulness Questionnaire with Observing Removed

When mindfulness (five facets cumulative score) was entered in the second block, it accounted for a significant amount of additional variance $\left(\Delta\right.$ in $R^{2}=.09,[F(7,150)=$ $7.44, p<.000]$ for emotional exhaustion; $\Delta$ in $R^{2}=.09,[F(7,150)=6.21, p<.000]$ for personal accomplishment, $\Delta$ in $R^{2=} .06,[F(7,150)=4.98, p<.000]$ for depersonalization, and $\Delta$ in $R^{2}=.13,[F(7,150)=10.55, p<.000]$ for the prediction of burnout as a whole. In the second block all three variables: concentration, talking to a friend, and income reached significance for emotional exhaustion and the cumulative score of the MBI. Together, the independent variables with the sum of the five facets of mindfulness accounted for $26 \%$ of the variance in emotional exhaustion, $23 \%$ in personal 
accomplishment, $19 \%$ in depersonalization, and $33 \%$ in the variance of the cumulative score for burnout. Age, again, showed a non-significant trend level for depersonalization.

Similarly, statistically significant results were obtained for the sum of four facets of mindfulness (with observing removed) and the burnout scores (Table 9). As in the previous models, the unique contribution of the sum of the four facets of mindfulness (as one cumulative score) in predicting three factors (and their sum) of burnout was tested.

Table 9

Sequential Regression Model of Burnout Factors (and MBI Sum) with Independent Variables of Age, Care for Child, Income, Concentration, Stress Reduction Practice, Months Practicing in Human Services, and Mindfulness - Four Facets (N=157).

\begin{tabular}{|c|c|c|c|c|c|c|c|c|c|c|c|c|c|c|c|c|}
\hline \multirow{3}{*}{$\begin{array}{l}\text { Independent } \\
\text { Variable }\end{array}$} & \multicolumn{4}{|c|}{ Emotional Exhaustion } & \multicolumn{4}{|c|}{ Personal Accomplishment } & \multicolumn{4}{|c|}{ Depersonalization } & \multicolumn{4}{|c|}{ MBI Sum } \\
\hline & \multicolumn{4}{|c|}{$R^{2}=.28$} & \multicolumn{4}{|c|}{$R^{2}=.23$} & \multicolumn{4}{|c|}{$R^{2}=.20$} & \multicolumn{4}{|c|}{$R^{2}=.35$} \\
\hline & B & $S E_{B}$ & B & $p$ & B & $S E_{B}$ & B & $p$ & B & $S E_{B}$ & 8 & $p$ & B & $S E_{\mathrm{B}}$ & B & $p$ \\
\hline \multicolumn{17}{|l|}{ Block 1} \\
\hline Age & -.00 & .01 & -.03 & .75 & -.00 & .01 & -.06 & .53 & -.01 & .01 & -.26 & .00 & -.02 & .02 & -.11 & .17 \\
\hline Care for a Child & 3.96 & 2.55 & .12 & .12 & 1.32 & 1.46 & .07 & .34 & 1.80 & 1.27 & .11 & .16 & 7.13 & 3.93 & .13 & .07 \\
\hline Income & -1.83 & .86 & -.16 & .04 & -.84 & .49 & -.13 & .09 & .00 & .43 & .00 & .96 & -2.67 & 1.33 & -.14 & .05 \\
\hline Concentration & 4.47 & 1.72 & .18 & .01 & 1.50 & 99. & .11 & .13 & .16 & .86 & .01 & .86 & 6.12 & 2.61 & .16 & .02 \\
\hline Months & .02 & .02 & .08 & .34 & -.01 & .01 & -.09 & .35 & .01 & .01 & .07 & .48 & .01 & .02 & .04 & .61 \\
\hline Stress Reduction & -1.70 & .73 & -.17 & .02 & -.40 & .42 & -.07 & .34 & -.25 & .36 & -.05 & .48 & -2.35 & 1.12 & -.14 & .04 \\
\hline \multicolumn{17}{|l|}{ Block 2} \\
\hline Four Facets & -.26 & .05 & -.35 & .00 & -.13 & .03 & -.33 & .00 & -.10 & .03 & -.28 & .00 & -.49 & .08 & -.41 & .00 \\
\hline
\end{tabular}

Note. Stress Reduction -Talk to a Friend, Months- month of practicing in human services, MBI - Maslach Bumout Inventory, FFMQ-Five Facets Mindfulness Questionnaire, Four Facets Mindfulness Questionnaire with Observing Removed.

Again, the sequential multiple regression revealed that when control variables: age, caring for a child under the age of 18, income, concentration, months practicing in human services, and stress reduction (talking to a friend) were entered in the first block, they significantly contributed to the variance in the whole model. Their unique contribution to the model was $17 \%$ of the variance for emotional exhaustion, $13 \%$ for personal accomplishment, $13 \%$ for depersonalization, and $20 \%$ for the cumulative score 
for burnout. Once again, the strongest IV contributor to the emotional exhaustion and the overall burnout score was concentration, followed by stress reduction (talking to a friend), and income. When mindfulness (four facets cumulative score) was entered in the second block, it accounted for a significant amount of additional variance ( $\Delta$ in $R^{2}=.11$, $[F(7,150)=8.15, p<.000]$ for emotional exhaustion; $\Delta$ in $R^{2}=.10,[F(7,150)=6.50, p<$ $.000]$ for personal accomplishment, $\Delta$ in $R^{2}=.07,[\mathrm{~F}(7,150)=5.32, p<.000]$ for depersonalization, and $\Delta$ in $\mathrm{R}^{2}=.15,[F(7,150)=11,58, p<.000]$ for the prediction of burnout as a whole). In the second block all three variables: concentration, stress reduction (talking to a friend), and income reached significance for the emotional exhaustion and the overall MBI score. Age was a significant contributor to depersonalization. All other IVs were non-significant contributors to the variance in the models. Together, the independent variables with the sum of the four facets (observing removed) of mindfulness accounted for $28 \%$ of the variance in emotional exhaustion, $23 \%$ in personal accomplishment, $20 \%$ in depersonalization, and $35 \%$ in the variance of the cumulative score for burnout.

\section{Do the religious and spiritual beliefs and practices predict burnout levels among MSW students?}

Due to the statistically non-significant results in the preliminary bivariate tests with all three factors of burnout (please refer to the description in the Correlations subsection), the two independent variables, spirituality and religiosity were excluded from the regression analyses.

\section{Partial Correlations}

Partial correlations (Table 10) were used next as follow-up analyses to indicate 
what dimensions of FFMQ were stronger or weaker in predicting particular dimensions of burnout. They revealed that when controlling for age, care for a child under the age of 18, income, concentration, and talking to a friend as a stress reduction practice, mindfulness (measured as a composite score of the five facets) was significantly negatively correlated with each factor of burnout: emotional exhaustion (partial $\mathrm{r}=-.33, \mathrm{p}$ $=.000$ ), personal accomplishment (partial $\mathrm{r}=-.33, \mathrm{p}=.000$ ), and depersonalization (partial $\mathrm{r}=-.26, \mathrm{p}=.001)$. Moreover, mindfulness had also a statistically significant inverse relation with the sum of burnout scores (partial $\mathrm{r}=-.400, \mathrm{p}=.000$ ). This indicates that high levels of mindfulness are correlated with less burnout in participants.

\section{Table 10}

Partial Correlations between Burnout Factors and FFMQ, Controlling for Age, Care for a Child under the Age of 18, Income, Concentration, and Talking to a Friend as a Stress Reduction Practice $(N-157)$.

\begin{tabular}{|c|c|c|c|c|c|c|c|c|}
\hline & \multicolumn{2}{|c|}{ Emotional Exhaustion } & \multicolumn{2}{|c|}{ PersonalAccomplishment } & \multicolumn{2}{|c|}{ Depersonalization } & \multicolumn{2}{|c|}{$\underline{\text { MBISum }}$} \\
\hline & $\underset{w}{r}$ & $p$ & $r$ & $p$ & $r$ & $p$ & $r$ & $p$ \\
\hline$F F M Q$ & $-.328 * *$ & .000 & $-.327 * *$ & .000 & $-.260^{* *}$ & .001 & $-.400 * *$ & .000 \\
\hline Four Facets & $-.358 * *$ & .000 & $-.340^{* *}$ & .000 & $-.281^{* *}$ & .000 & $-.429 * *$ & .000 \\
\hline
\end{tabular}

Note: ** correlation significant at 0.01 level (2-tailed), FFMQ-Five Facets Mindfulness Questionnaire, Four Facets- Mindfulness Questionnaire with Observing Removed

\section{Conclusion}

This was the first study to explore the relationship between mindfulness and burnout among graduate social work students, especially while using the combination of the whole FFMQ and MBI scales. The analyses of the FFMQ included all five 
mindfulness facets and four facets, with the observing facet removed. Some literature suggests that the observing facet of mindfulness might not completely mediate the experience of mindfulness and psychological adjustment for non-meditating samples. Therefore, the true influence of mindfulness on respondents' well-being might not be detected if they are not experienced meditators (Veehof et al., 2011; Bohlmeijer et al., 2011; Eisenlohr-Moul et al., 2012). Although this study's participants reported minimal involvement in meditation, and therefore could be considered non-meditators, removing the observing factor from the analyses did not change results in any substantial way. 


\section{CHAPTER 6: Discussion}

The main purpose of this study was to examine the relationship between mindfulness and burnout among MSW students from the metropolitan Portland area and from program's satellite locations in Oregon. Specifically, this study mainly focused on testing the hypothesis that the more mindfulness the participants exhibited the lower levels of burnout they would experience and report. Additionally, three other questions were explored. First, whether the length of practicing in human services predicts levels of burnout was examined. The hypothesis predicted that as the number of years of practice increased, so should the levels of burnout. Second, the relationship between the year in the MSW program and the experience of burnout was examined, with the hypothesis that as students progress in their studies they should exhibit progressively more burnout. Finally, the question of whether there is a relationship between students' spirituality, religiosity, and all factors of burnout was investigated. It was hypothesized that burnout levels should be predicted by one's spiritual and/or religious beliefs and practices, and that this effect should occur regardless of years of practicing and the year in the MSW program.

There were three major findings in this study: the essential predictive value of mindfulness for burnout, the absence of relationship between religiosity/spirituality (independent variables), months of practicing in human services, and year in the MSW program (two covariates) and burnout, and discrepancies and consistencies with previous studies. 


\section{Mindfulness and Burnout}

The main and strongest finding in this study was demonstrating statistically significant relationships between mindfulness and all factors of burnout. The robust relationship of mindfulness to observed burnout supports the hypothesis that mindfulness can exert positive effects on coping with stress and difficult or traumatic life events for professionals practicing in human services (Cohen-Katz et al., 2004; Epstein, 1999; Mackenzie et al., 2006). Consistent with the relevant literature on burnout in helping professions (Golembiewski \& Munzenrider, 1988; Maslach \& Jackson, 1984; Maslach et al., 2001), this study's participants reported elevated burnout levels on all three factors: emotional exhaustion, personal accomplishment, and depersonalization comparable to those reported by Maslach et al. (1986). In comparison to the reported burnout levels in social service populations (Maslach et al., 1986), it was found that $73.6 \%$ of the participants experienced high and moderate levels of emotional exhaustion $33.3 \%$ moderate and $40.3 \%$ high) and $50.9 \%$ reported moderate $(28.3 \%)$ and high $(22.6 \%)$ depersonalization. These results are also consistent with studies reporting higher than average burnout rates among social workers (Acker, 1999; Gilbar, 1998; Jayaratne \& Chess, 1984; Jayaratne, et al., 1991; Jayaratne, et al., 1988; Lloyd, et al., 2002; Maslach, 1982; Robichaud, 2004; Siebert, 2006; Um \& Harrison, 1998; Van Hook \& Rothenburg, 2009). In contrast, the majority of respondents (59.7\%) reported high level of personal accomplishment, and thus, lower levels of burnout in this category. Perhaps students develop the sense of personal accomplishment while acquiring necessary social work skills and knowledge during the years of instruction. 
Results also showed that mindfulness (measured by a cumulative score of five facets) might serve as a protective factor for participants, preventing high burnout levels (Table 8).This pattern was also true for four facets of mindfulness (with observing removed) relating to burnout (Table 9). Although in some previous studies (Baer et al., 2008, Bohlmeijer et al., 2011, Eisenlohr-Moul et al., 2012, Veehof et al., 2011) one of the facets of mindfulness, observing, was strongly correlated with well-being for the experienced meditators, but not for the non-meditators, this study has not shown similar differences in scores. Albeit such discrepancies were not detected in this study, the results are worth reporting, since they contribute to the body of knowledge regarding mindfulness, its factors, and their relationships.

\section{Religiosity/Spirituality, Covariates, and Burnout}

Significant associations between religiosity, being active in church/faith life and daily prayer were observed in this study on the level of the bivariate analyses. Moreover, identifying oneself as only a spiritual person was significantly and positively correlated with meditating daily, and with using other forms of spiritual practices. Furthermore, responses from self-identified spiritual only participants indicated that the more one identified as exclusively spiritual person, the less active in faith or church the individual was. Consistently, reports of participants claiming to be both religious and spiritual showed positive correlations with being active in faith/church, praying daily, and with using other forms of spiritual practices. However, the correlational analyses did not reveal any statistically significant relationships between the spirituality and religiosity variables and any of the three factors of burnout. This finding is in line with the mixed results coming from studies investigating the effects of spirituality and religiosity on 
burnout among professionals in the social work field, especially with the results refuting any positive influence of these convictions and practices on burnout in helping professions (Figley, 2002; Robichaud, 2004). Perhaps the inclusion of more objective measures on spirituality and religiosity would help to clarify their relationships with burnout. This could be accomplished if the definitions and measures of these constructs encompass not only religious and spiritual beliefs of various individuals, but additionally their personal expectations, practices, and behaviors. For instance, instruments gauging factors such as prayer and meditation rituals, intensity and frequency of taking regular time for self-improvement, and/or being part of communities involved in providing services to others might provide better measurements of people's spiritual and religious lives.

Although bivariate analyses have shown some weak but significant relationships between the length of practicing in human services prior to entering the MSW program and the overall burnout, depersonalization, and the personal accomplishment, the results from the sequential regression models indicated that months of practicing in human services did not significantly influence any of the burnout factors. This is contrary to the reports that demonstrated the relationship between prolonged stress encountered during the increasing number of years of social work (usually public) practice and burnout levels (Schwartz, et al., 2007; Siebert, 2006). Perhaps these contradicting results are due to the limited variance associated with the sample size, affecting the subscales of burnout.

Year in the MSW program had not shown any statistically significant results in the preliminary bivariate tests with all three factors of burnout: emotional exhaustion, personal accomplishments, and depersonalization, and the cumulative score for burnout. 
Although contrary to the available literature suggesting a predisposition among social work students to develop emotional exhaustion and compassion fatigue (Han at al., 2012; Harr \& Moore, 2006; Ngai \& Cheung, 2009), the result is not surprising, in the light of the fact that majority $(52 \%)$ of the respondents were in their first year of instruction. Although the normality test for this variable was within conservative limits, the distribution of the scores has been obviously skewed, limiting the variability and thus, possibly affecting the obtained significance levels.

\section{Discrepancies and Consistencies with Previous Studies}

There were some surprising findings in this study. For instance, over $25 \%$ of students reported having available annual income of $\$ 50,000$ and more. Perhaps it could be explained by the substantial percentage of the respondents being over 30 years old and married, and thus, more advanced in their career and having two sources of income available. Moreover, income had a significant relationship with emotional exhaustion, suggesting that it can be a protective factor lessening the development of burnout, and thus, and a detrimental factor for students with less income available. Another surprising finding was that majority of the participants were neither a primary caregiver nor a legal guardian of the underage children, or adult family/friends. These results are contrary to the reports by the National Alliance for Caregiving and AARP (2009) and the National Study of the Changing Workforce (FWI, 2008). One plausible explanation is the specificity of this population of respondents, not necessarily being the typical representatives of the national general population. Since there are no studies relating to caregivers' characteristics and experiences among social work students, this issue should be of interest in future studies of this population, as the American general population has 
been ageing, and requiring increased involvement in care by close family members and/or friends (National Alliance for Caregiving and AARP, 2009; FWI, 2008).

While the literature (Maslach et al., 2001) has identified that the unmarried males have increased chances for experiencing burnout, such an association has not been documented in this study. In addition, contrary to the theoretical model suggesting that individuals with higher levels of education are more prone to experience burnout (Maslach et al., 2001), for students in this study the relationships between the year in the MSW program and burnout was not established.

Less surprisingly, the participants reported talking to a friend as a main stress reduction practice, while writing a journal and reading a book were their least favorite stress reduction endeavors. Moreover, talking to a friend as a stress reduction practice, was related to reduced emotional exhaustion and the overall burnout levels, and at the same time appeared diminish negative perceptions of personal accomplishment (indicating less burnout). Since one of the characteristics of social work instruction is to train students to express and exchange their feelings, emotions, and thoughts, and it is plausible that this acquired skill might transfer to their private lives. Another possible explanation, however untested, would be that social workers are naturally (more than an average person) inclined to talk about their experiences. In contrast, the level of required scholastic reading and writing involved in graduate social work education could support the idea that it might prevent students from seeing these activities as stress reducing.

Not surprisingly, based on the results obtained from the open-ended question, the respondents in this study have appeared to be driven by the desire to help others, to make a difference or create change in people's lives and communities, to serve social justice, 
and the desire to improve, change, help, or give back to communities. This is consistent with the literature claiming that many social work students are very idealistic, and thus, prone to emotional exhaustion, especially when their expectations collide with their practice experiences (Ngai \& Cheung, 2009). It is pertinent, however, to note that 37 students ( $25 \%$ of the respondents) disclosed that personal experiences (many traumatic in nature, such as sexual abuse) led them to seek social work education. This is highly valuable information, since it indicates that some students in this program might suffer from the Post-Traumatic Stress Disorder (PTSD) or secondary traumatic stress, and thus, could benefit from using mindfulness techniques to address these issues.

In line with the literature, a statistically significant negative association between age and depersonalization (one of the burnout factors) was reported in this study, implying that younger respondents, in contrast to older ones, are characterized by more depersonalization (Maslach et al., 2001). As Leiter and Maslach (1988) noted, a person experiencing emotional exhaustion might attempt to cope with those feelings by detaching and/or depersonalizing. It may result in feeling less successful and inadequate, while professional projects appear overwhelming and accomplishments insignificant. Thus, shockingly, some of the younger students showing higher levels of depersonalization appear to be already heading to the final stage of the burnout, the lack of personal accomplishment (Maslach et al., 2001). Surprisingly, the other two factors of burnout have not been affected by the age of the respondents. Moreover, although this association was observed in a model including four facets of mindfulness, the inclusion of all five facets of the FFMQ showed a non-significant trend level. Perhaps the differences are due to the relatively small sample size in this study. However, it is also 
feasible that the results have been influenced due to the influence of the observing facet, which has shown to affect the burnout scores in some studies (Baer et al., 2008, Bohlmeijer et al., 2011, Eisenlohr-Moul et al., 2012, Veehof et al., 2011).

The other outcomes in this study indicated that the type of concentration significantly affected one of the factors of burnout, emotional exhaustion. It reveals that students who are not enrolled in the direct human services track report more emotional exhaustion. Possibly, students in the direct human services concentration are being better prepared to deal with stress, trauma, and difficult situations they encounter in the social work practice, either through the clinical and practice courses they are required to take, or through the self-care guidance offered in the program. This finding also points out to the fact that students in other than direct human services concentration should get the same assistance in preparation for working in the field as the other students. Since burnout has been recognized as an organizational factor, students who prepare to function in such capacities ought to receive, at least, similar training as their direct human services counterparts.

\section{Limitations}

While the main results of this study were statistically significant, they should be viewed with caution. This study had a number of strengths, but also encountered some limitations. A non-randomized selection procedure was used in this study and presents with some weaknesses relating to external validity. However, such issues are commonly encountered in exploratory studies, such as the current one, and can be addressed in the future, with more rigorous designs. The main issue in cross-sectional designs is their inability to support conclusive inferences about causality, although they can establish 
plausibility. Moreover, this type of design prevents the investigation of how results obtained from different subscales might change with intensifying mindfulness practices. These issues could be addressed in future research, especially with some promising new developments in the measures of mindfulness (Erisman \& Roemer, 2012). Thus, overall, this study can be considered strong with respect to internal validity, especially with the utilization of multiple regressions and controlling for alternative variables.

Another limitation of this study might be its relatively small sample size.

Although the response rate was good, out of 495 target students 159 (32\%) fully completed their questionnaires, this number can still possibly weaken the statistical power of the outcomes. Moreover, the use of a convenience sample of students from one university, further limited generalizability of the study. In addition, the sample selection bias could be of importance here, since only one third of the invited students participated in the study, thus, limiting the generalizability of the findings to the whole MSW student population at Portland State University. Furthermore, another limitation was the study's reliance on participants' self-reports. Therefore, there was no independent verification of the extent of burnout, spiritual, religious, and other stress reducing practices, or mindfulness in respondents. This limitation could be eliminated in a planned experimental design study of mindfulness training for social work students.

In sum, although a strong relationship between mindfulness and burnout among MSW students was observed in this study, the extent of its causation and interpretation of the results, need further exploration, combining stricter design controls with more sophisticated measures of mindfulness. 


\section{Implications for Social Work Field}

The central focus of this study was to detect potential statistically meaningful interactions between mindfulness and burnout among graduate social work students. Thus, this study might have significant implications for the social work field given that the potentially positive role of mindfulness in preventing and/or reducing burnout among this population was demonstrated. It could open new directions in educating social work students, considering the fact that even social work apprentices are already prone to experience excessive stress, which can lead to occupational burnout. Teaching social work students how to recognize and minimize stress, by using mindfulness techniques, could have numerous positive outcomes. These outcomes could occur, in line with the effects of burnout on individuals in helping professions, on two levels: organizational and personal (Maslach \& Jackson, 1981).

On the organizational level, mindfulness practice could affect a worker's performance and attitude. For instance, physical job withdrawal (e.g., spending as little time at work as possible, taking longer breaks, absenteeism) common among people suffering from burnout might be eliminated or reduced. Additionally, with enhanced emotional well-being, resulting from mindfulness practices, students' productivity and effectiveness in academia, as well as in their field placements might show marked improvement. Furthermore, control over stressful situations could lead to increased job satisfaction and heightened professional commitment, causing students to have fewer interpersonal conflicts at the field placement or at work. This, in turn, might have positive effects on other people's morale and job performance. Additionally, the quality and continuity of services provided to clients by mindful professionals can be substantially 
improved (O'Sullivan \& Bates, 2014). Ultimately, social work students already practicing in the field, who have been exposed to mindfulness practice, might be less prone to change careers, or exit the workforce. This, consecutively, would minimize the enormous costs of such turnovers (Kang, 2012), both direct (e.g., cost of separation, replacement, and training) and indirect (e.g., clients' well-being, placement permanency in social welfare, clients' satisfaction with the agency and services provided).

On a personal level teaching social work students to reduce stress and burnout by the practice of mindfulness might lead to an improved home life. By minimizing the tendency to withdraw from family and friends, common in individuals experiencing burnout (Burke \& Greenglass, 2001), social work students might feel less tension, anxiety, anger, and frustration. This, in turn, might be extremely beneficial for the students and for their interactions with significant others. Moreover, preparing social work students to actively cope with stress could lead to improvement in their overall health. In particular, social work students practicing mindfulness techniques might display lower rates of insomnia, anxiety, and depression (Ying, 2009a), and perhaps even suicidal tendencies (Maslach et al., 2001). Finally, the excessive use of medication and alcohol, also common in this population, could be reduced or entirely eliminated by training students to practice mindfulness (Maslach et al., 2001).

\section{Recommendations for Future Research and Improved Practice}

Future research might take two directions, given the results of this study demonstrated statistically significant relationships between mindfulness and burnout among social work students.

First, appropriate training in mindfulness for the students, to increase their ability 
to cope with stressful situations, would be developed by this researcher. It could be offered, as a pilot study, for graduate social work students. The stress reduction activities would be based on mindfulness training, as designed by Kabat-Zinn (1982). They would include three components: sweeping-body scanning, meditation, and Hatha yoga movements. The original Kabat-Zinn study was designed as a 10-week intervention. However, some other studies suggested that even shorter 4-week instruction could have a long-lasting positive effect on students' well-being (Birnbaum, 2008; Dziegielewski et al., 2004; Gockel et al., 2012. Therefore, each of three intervention groups would be exposed to mindfulness training for a different period of time: 4 weeks, 7 weeks, and 10 weeks respectively. In addition, to follow conscientious research practices, three equivalent waitlist groups would be created and enrolled in mindfulness training at the conclusion of each section of the primary intervention. Consistently with the experimental design criteria that control for many threats to the internal validity, the assignment to groups will be random (Rubin \& Babbie, 2011).

Second, built on the findings from the pilot study, the inclusion of mindfulness training in graduate social work curriculum could be proposed. It would be of utmost importance to offer social work students courses that would prepare them for the stressful and demanding professional work. This might be achieved through educating them in recognizing burnout symptoms, and in employing mindfulness practices to cope with stress, and therefore, preventing burnout. Promoting well-being among social work students even before they enter the work force (as they combine their studies with working in a social work capacity) ultimately would also benefit their clients (Gockel et al., 2012). The new standards of self-care ought to be implemented in social work 
education, for optimal functioning of the students and later, practitioners. Thus, a course in mindfulness training, based on the pilot study and its findings, could be designed and implemented at universities offering a graduate degree in social work.

Future research could also aim at exploring the differences between distance and campus students, linking burnout and mindfulness to organizational culture of the profession, examining mindfulness and burnout as a process occurring over time, studying the ways burnout could predict educational engagement and outcomes among social work students, investigating the effects that mindfulness training in continuing education might have on social work professionals, and considering he differences between students enrolled in social work program being employed in human services or in other fields.

To conclude, for years social work professionals have been seriously afflicted by burnout. The extent of this problem has been extensively documented for professionals already working in the field. This study is an important contributor to the literature on burnout in helping professions, since it has shown that burnout can affect social work students, even as early as in the first year of instruction. Yet, this investigation also offers a relatively simple solution to decrease stress levels (one of the important antecedents to burnout) among students. The solutions proposed in the previous sections have been grounded in the finding that mindfulness can, and in fact does predict reported levels of burnout among social work students. It appears that it is a responsibility of the social work educators to provide students with the necessary tools that might prevent them from experiencing burnout, or at least to minimize its effects. If we can do anything 
to guard our future social work professionals from this serious problem, we should make it our priority now. 


\section{References}

Acker, G. M. (1999). The impact of clients' mental illness on social workers' job satisfaction and burnout. Health \& Social Work, 24(2), 112-119.

Ackerley, G. D., Burnell, J., Holder, D. C., \& Kurdek, L. A. (1988). Burnout among licensed psychologists. Professional Psychology: Research and Practice, 19(6), 624-631.

Aftab, N., Shah, A. A., \& Mehmood, R. (2012). Relationship of self efficacy and burnout among physicians. Academic Research International, 2(2). Retrieved from http://www.savap.org.pk/journals/ARInt./Vol.2\%282\%29/2012\%282.2$60 \% 29 . p d f$

Aguayo, R., Pecino, C. V., de la Fuente Solana, E. I., \& Fernández, L. M. L. (2011). A meta-analytic reliability generalization study of the Maslach Burnout Inventory. International Journal of Clinical and Health Psychology, 11(2), 343-361.

Alarcon, G. M., Edwards, J. M., \& Menke, L. E. (2011). Student burnout and engagement: A test of the conservation of resources theory. The Journal of Psychology, 145(3), 211-227.

American Psychiatric Association. (2013). Diagnostic and statistical manual of mental disorders- $V$. Washington, DC: Author.

Anderson, D. (2000). Coping strategies and burnout among veteran child protection workers. Child Abuse \& Neglect, 24(6), 839-848.

Angerer, J. M. (2003). Job burnout. Journal of Employment Counseling, 40(3), 98-107.

Baer, R. A. (2003). Mindfulness training as a clinical intervention: A conceptual and empirical review. Clinical Psychology: Science and Practice, 10, 125-143. 
Baer, R. A., Smith, G. T., \& Allen, K. B. (2004). Assessment of mindfulness by selfreport: The Kentucky Inventory of Mindfulness Skills. Assessment, 11, 191-206.

Baer, R. A., Smith, G. T., Hopkins, J., Krietemeyer, J., \& Toney, L. (2006). Using selfreport assessment methods to explore facets of mindfulness. Assessment, 13, 27-45.

Baer, R. A., Smith, G. T., Lykins, E., Button, D., Krietemeyer, J., Sauer, S...Willimas, J. M. G. (2008). Construct validity of the Five Facet Mindfulness Questionnaire in meditating and nonmeditating samples. Assessment, 15, 329-342.

Balfour, D. L., \& Neff, D. M. (1993). Predicting and managing turnover in human service agencies: A case study of an organization in crisis. Public Personnel Management, 22(3), 473-486.

Battle, C. U. (1981). The iatrogenic disease called burnout. Journal of the American Medical Women's Association, 36, 357-359.

Baron, R. M., \& Kenny, D. A. (1986). The moderator-mediator variable distinction in social psychological research: Conceptual, strategic, and statistical considerations. Journal of Personality and Social Psychology, 51(6), 1173-1175.

Beck, A. T., Ward, C. H., Mendelson, M., Mock, J., \& Erbaugh, J. (1961). An inventory for measuring depression. Archives of General Psychiatry, 4(6), 561-567.

Belavich, T. G. (June, 1995). The role of religion in coping with daily hassles. Paper presented at the annual convention of the American Psychological Association, New York, NY. (ERIC Document Reproduction Service No. ED 393 042).

Ben-Dror, R. (1994). Employee turnover in community mental health organization: A developmental stages study. Community Mental Health Journal, 30(3), 243-57. 
Benjamin, P., \& Looby, J. (1998). Defining the nature of spirituality in the context of Maslow's and Rogers's theories. Counseling and Values, 42(2), 92-100.

Birnbaum, L. (2008). The use of mindfulness training to create an "Accompanying Place" for social work students. Social Work Education, 27(8), 837-852.

Blankertz, L. E., \& Robinson, S. E. (1997). Turnover intentions of community mental health workers in psychosocial rehabilitation services. Community Mental Health Journal, 33(6), 517-529.

Bohlmeijer, E., Peter, M., Fledderus, M., Veehof, M., \& Baer, R. (2011). Psychometric properties of the Five Facet Mindfulness Questionnaire in depressed adults and development of a short form. Assessment, 18(3), 308-320.

Bonifas, R. P., \& Napoli, M. (2013). Mindfully increasing quality of life: A promising curriculum for MSW students. Social Work Education, (ahead-of-print), 1-16. doi:

http://www.tandfonline.com/doi/abs/10.1080/02615479.2013.838215\#.UnH8LhDi $H c A$

Boscarino, J. A., Adams, R. E., \& Figley, C. R. (2010). Secondary trauma issues for psychiatrists. The Psychiatric Times, 27(11), 24-29.

Bradley, H. B. (1969). Community - based treatment for young adult offenders. Crime and Delinquency, 15, 359-370.

Braddock, D., \& Mitchell, D. (1992). Residential services and developmental disabilities in the United States. M. J. Begab (Ed.). Washington, DC: American Association on Mental Retardation. 
Bride, B. E., \& Figley, C. R. (2007). The fatigue of compassionate social workers: An introduction to the special issue on compassion fatigue. Clinical Social Work Journal, 35(3), 151-153.

Brockhouse, R., Msetfi, R. M., Cohen, K., \& Joseph, S. (2011). Vicarious exposure to trauma and growth in therapists: The moderating effects of sense of coherence, organizational support, and empathy. Journal of Traumatic Stress, 24(6), 735742.

Brown, K. W., \& Ryan, R. M. (2003). The benefits of being present: Mindfulness and its role in psychological well-being. Journal of Personality and Social Psychology, $84,822-848$.

Buchheld, N., Grossman, P., \& Walach, H. (2001). Measuring mindfulness in insight meditation (Vipassana) and meditation-based psychotherapy: The development of the Freiburg Mindfulness Inventory (FMI). Journal for Meditation and Meditation Research, 1, 11-34.

Burke, R. J., \& Greenglass, E. R. (2001). Hospital restructuring, work-family conflict and psychological burnout among nursing staff. Psychology and Health: The International Review of Health Psychology, 16, 583-594.

Buunk, B. P., Ybema, J. F., Van der Zee, K., Schaufeli, W. B., \& Gibbons, F. X. (2001). Affect generated by social comparisons among nurses high and low in burnout. Journal of Applied Social Psychology, 31, 1500-1520. 
Büssing, A., \& Perrar K. M. (1992). Die Messung von Burnout. Untersuchung einer deustchen Fassung des Maslach Burnout Inventory (MBI-D) (The measurement of burnout: Investigation on the German version of the MBI). Diagnostica, 38(4), $328-353$.

Canfield, J. (2005). Secondary traumatization, burnout, and vicarious traumatization: A review of the literature as it relates to therapists who treat trauma. Smith College Studies in Social Work, 75(2), 81-101.

Cao, X., Liu, X., Tian, L., \& Guo, Y. (2013). The reliability and validity of the Chinese version of nurses' self-concept questionnaire. Journal of Nursing Management, 21(4), 657-667. doi:10.1111/j.1365-2834.2012.01419.x

Carmody, J., \& Baer, R. A. (2008). Relationships between mindfulness practice and levels of mindfulness, medical and psychological symptoms and well-being in a mindfulness-based stress reduction program. Journal of Behavioral Medicine, 31, $23-33$.

Carroll, J. F. X., \& White. W. L. (1982). Theory building: Integrating individual and environmental factors within an ecological framework. In W. S. Paine (Ed.), Job stress and burnout: Research, theory, and intervention perspectives (pp. 41-60). Beverly Hills, CA: Sage.

Cebolla, A., García-Palacios, A., Soler, J., Guillen, V., Baños, R., \& Botella, C. (2012). Psychometric properties of the Spanish validation of the Five Facets of Mindfulness Questionnaire (FFMQ). The European Journal of Psychiatry, 26(2), 118-126. 
Chadwick,P., Hember, M., Symes, J., Peters, E., Kuipers, E. \& Dagnan, D. (2008).

Responding mindfully to unpleasant thoughts and images: Reliability and validity of the Mindfulness Questionnaire. British Journal of Clinical Psychology, 47(4), 451-455.

Cherniss, C. (1980). Professional burnout in human service organizations (pp. 1-17). New York, NY: Praeger.

Ciarrocchi, J., Golden, J., Piedmont, R., \& Rodgerson, T. (2004). Spirituality and burnout: An incremental validity study. Journal of Psychology and Theology, 32, 115-125.

Cieslak, R., Shoji, K., Douglas, A., Melville, E., Luszczynska, A., \& Benight, C. C. (2013). A Meta-analysis of the relationship between job burnout and secondary traumatic stress among workers with indirect exposure to trauma. Psychological Services, 11(1), 75-86. doi: 10.1037/a0033798

Clark, C.C. (1980). Burnout: Assessment and intervention. Journal of Nursing Administration, 10, 39-43.

Cohen, H. J., \& Koenig, H. G. (Eds.). (2002). The link between religion and health: Psychoneuroimmunology and the faith factor. New York, NY: Oxford University Press.

Cohen, J. (1992). A power primer. Psychological Bulletin, 112(1), 155-159.

Cohen-Katz, J., Wiley, S. D., Capuano, T., Baker, D. M., \& Shapiro, S. (2004). The effects of mindfulness-based stress reduction on nurse stress and burnout: A quantitative and qualitative study. Holistic Nursing Practice, 18(6), 302-308. 
Collins, S., Coffey, M., \& Morris, L. (2010). Social work students: Stress, support and well-being. British Journal of Social Work, 40(3), 963-982.

Conrad, D., \& Kellar-Guenther, Y. (2006). Compassion fatigue, burnout, and compassion satisfaction among Colorado child protection workers. Child Abuse \& Neglect, 30(10), 1071-1080.

Corbett, J. M. (1990). Religion in America. Englewood Cliffs, NJ: Prentice-Hall.

Cordes, C. L., \& Dougherty, T. W. (1993). A review and an integration of research on job burnout. Academy of Management Review, 18(4), 621-656.

Council on Social Work Education . (2012). Statistics on social work education in the United States. Retrieved from http://www.cswe.org/CentersInitiatives/DataStatistics/68984.aspx

Cunningham, W. C. (1983). Teacher burnout-solutions for the 1980s: A review of the literature. Urban Review, 1, 37-51.

Cunningham, M. (2004). Teaching social workers about trauma: Reducing the risks of vicarious traumatization in the classroom. Journal of Social Work Education, 40(20), 305-317.

Dane, B. (2000). Child welfare workers: An innovative approach for interacting with secondary trauma. Journal of Social Work Education, 36(1), 27-38.

de Bruin, E. I., Topper, M., Muskens, J. G., Bögels, S. M., \& Kamphuis, J. H. (2012). Psychometric properties of the Five Facets Mindfulness Questionnaire (FFMQ) in a meditating and a non-meditating sample. Assessment, 19(2), 187-197.

Deci, E. L., Connell, J. P., \& Ryan, R. M. (1989). Self-determination in a work organization. Journal of Applied Psychology, 74(4), 580-587. 
Derogatis, L. R., \& Melisaratos, N. (1983). The Brief Symptom Inventory: An introductory report. Psychological Medicine, 3, 595-605.

Devilly, G. J., Wright, R., \& Varker, T. (2009). Vicarious trauma, secondary traumatic stress or simply burnout? Effect of trauma therapy on mental health professionals. Australasian Psychiatry, 43(4), 373-385.

Dion, G., \& Tessier, R. (1994). Validation and translation of the burnout inventory of Maslach and Jackson. Canadian Journal of Behavior Science, 26, 210-227.

Drake, B., \& Yadama, G. N. (1996). A structural equation model of burnout and job exit among child protective services workers. Social Work Research, 20(3), 179-187.

Dundas, I., Vøllestad, J., Binder, P. E., \& Sivertsen, B. (2013). The Five Factor Mindfulness Questionnaire in Norway. Scandinavian Journal of Psychology, 54, 250-260. doi: 10.1111/sjop.12044

Dyrbye, L. N., \& Shanafelt, T. D. (2011). Physician burnout. JAMA: The Journal of the American Medical Association, 305(19), 2009-2013.

Dziegielewski, S. F., Turnage, B., \& Roest-Marti, S. (2004). Addressing stress with social work students: A controlled evaluation. Journal of Social Work Education, 105-119.

Edelwich, J., \& Brodsky, A. (1980). Burnout: Stages of disillusionment in the helping professions. New York, NY: Human Sciences Press.

Ellwood, R. S. (1992). Many peoples, many faiths (4th ed.). Englewood Cliffs, NJ: Prentice-Hall. 
Eisenlohr-Moul, T. A., Walsh, E. C., Charnigo, R. J., Lynam, D. R., \& Baer, R. A. (2012). The "What" and the "How" of dispositional mindfulness: Using interactions among subscales of the Five-Facet Mindfulness Questionnaire to understand its relation to substance use. Assessment, 19(3), 276-286. doi:10.1177/1073191112446658

Epstein, R. M. (1999). Mindful practice. The Journal of the American Medical Association, 282(9), 833-839.

Erikson, E. H. (1950). Childhood and society. New York, NY: Norton.

Erisman, S. M., \& Roemer, L. (2012). A preliminary investigation of the process of mindfulness. Mindfulness, 3(1), 30-43.

Evans, B. K., \& Fischer, D. G. (2011). The nature of burnout: A study of the three-factor model of burnout in human service and non-human service samples. Journal of Occupational and Organizational Psychology, 66(1), 29-38.

Farber, B. A. (1983). Introduction: A critical perspective on burnout. In B. A. Farber (Ed.), Stress and burnout in the human service professions (pp. 1-20). New York, NY: Pergamon Press.

Farber, B. A., \& Heifetz, L. J. (1982). The process and dimensions of burnout in psychotherapists. Professional Psychology, 13, 293-301.

Fauri, D. P. (1978). Points and viewpoints protecting the child protective service worker. Social Work, 23, 62-64. 
Feldman, G. C., Hayes, A. M., Kumar, S. M., Greeson, J. M., \& Laurenceau, J. P. (2007). Mindfulness and emotion regulation: The development and initial validation of the Cognitive and Affective Mindfulness Scale (CAMS-R). Journal of Psychopathology and Behavioral Assessment, 29(3), 177-190.

Figley, C. R. (1995). Compassion fatigue as secondary traumatic stress disorder: An overview. In C. R. Figley (Ed.), Compassion fatigue (pp. 1-20). New York, NY: Brunner Mazel.

Figley, C. R. (2002). Treating compassion fatigue. New York, NY: Brunner/Mazel.

Folkman, S. (1997). Positive psychological states and coping with severe stress. Social Science and Medicine, 45(3), 207-221.

Fryer, G. E., Jr., Miyoshi, T., \& Thomas, P. J. (1989). The relationship of child protection worker attitudes to attrition from the field. Child Abuse \& Neglect, 13, 345-350.

Freudenberger, H. J. (1974). Staff burn-out. Journal of Social Issues, 30(1), 159-165.

Freudenberger, H. J. (1975). The staff burn-out syndrome in alternative institutions. Psychotherapy: Theory, Research and Practice, 12(1), 73-82.

Freudenberger, H. J. (1983). Burnout: Contemporary issues, trends, and concerns. In B. A. Farber (Ed.), Stress and burnout (pp. 23-28). New York, NY: Anchor Press/Doubleday.

Galanakis, M., Moraitou, M., Garivaldis, F. J., \& Stalikas, A. (2009). Factorial structure and psychometric properties of the Maslach Burnout Inventory (MBI) in Greek midwives. Europe's Journal of Psychology, 4, 52-70. 
Galantino, M. L., Baime, M., Maguire, M., Szapary, P. O., \& Farrar, J. T. (2005). Association of psychological and physiological measures of stress in health-care professionals during an 8-week mindfulness meditation program: Mindfulness in practice. Stress and Health, 21(4), 255-261.

Gascón, S., Leiter, M. P., Stright, N., Santed, M. A., Montero-Marín, J., Andrés, E., \& ... García-Campayo, J. (2013). A factor confirmation and convergent validity of the "areas of worklife scale" (AWS) to Spanish translation. Health \& Quality Of Life Outcomes, 11(1), 1-11. doi:10.1186/1477-7525-11-63

Gelman, C. R. (2004). Anxiety experienced by foundation-year MSW students entering field placement: Implications for admissions, curriculum, and field education. Journal of Social Work Education, 40, 39-54.

George, L. K., Larson, D. B., Koenig, H. G., \& McCullough, M. E. (2000). Spirituality and health: What we know, what we need to know. Journal of Social and Clinical Psychology, 19(1), 102-116.

Geurts, S. A., Schaufeli, W. B., \& De Jonge, J. (1998). Burnout and intention to leave among mental health-care professionals: A social psychological approach. Journal of Social and Clinical Psychology, 17(3), 341-362.

Gilbar, O. (1998). Relationship between burnout and sense of coherence in health social workers. Social Work in Health Care, 26, 39-49.

Gillespie, G. F. (1982). Correlates for active and passive types of burnout. Journal of Social Science Research, 4(2), 1-16.

Girdin, D. A., Everly, G. S., \& Dusek, D. E. (1996). Controlling stress and tension. Needham Heights, MA: Allyn \& Bacon. 
Gockel, A., Burton, D., James, S., \& Bryer, E. (2012). Introducing mindfulness as a selfcare and clinical training strategy for beginning social work students. Mindfulness, 4(4), 343-353.

Goh, E. C. (2012). Integrating mindfulness and reflection in the teaching and learning of listening skills for undergraduate social work students in Singapore. Social Work Education, 31(5), 587-604.

Goleman, D. J., \& Schwartz, G. E. (1976). Meditation as an intervention in stress reactivity. Journal of Consulting and Clinical Psychology, 44(3), 456-462.

Golembiewski, R. T., \& Munzenrider, R. T. (1988). Phases of burnout: Development in concepts and applications. New York, NY: Praeger.

Gough, H. G. (1987). The California Psychological Inventory administrator's guide. Palo Alto, CA: Consulting Psychologist Press.

Grant, L., \& Kinman, G. (2012). Enhancing wellbeing in social work students: Building resilience in the next generation. Social Work Education, 31(5), 605-621.

Grossman, P., Niemann, L., Schmidt, S., \& Walach, H. (2004). Mindfulness-based stress reduction and health benefits: A meta-analysis. Journal of Psychosomatic Research, 57, 35-43.

Hagen, J. L. (1989). Income maintenance workers. Journal of Social Service Research, 13(1), 47-63.

Hallsten, L. (1993). Burning out: A framework. In W. Schaufeli, C. Maslach, \& T. Marek (Eds.). Professional burnout: Recent developments in theory and research (pp. 95-113). Washington DC: Taylor \& Francis. 
Han, M., Lee, S. E., \& Lee, P. A. (2012). Burnout among entering MSW students: Exploring the role of personal attributes. Journal of Social Work Education, 48(3), 439-457.

Harr, C., \& Moore, B. (2011). Compassion fatigue among social work students in field placements. Journal of Teaching in Social Work, 31(3), 350-363.

Harrison, D. W. (1980). Role strain and burnout in child-protective service workers. The Social Service Review, 54(1), 31-44.

Hathaway, W. L., \& Pargament, K. I. (1992). The religious dimensions of coping: Implications for prevention and promotion. In K. I. Pargament, K. I., Maton, \& R. E. Hess (Eds.), Religion and prevention in mental health: Research, vision, and action (pp. 129-154). New York, NY: Haworth Press.

Hayes, S. C., Strosahl, K., Wilson, K. G., Bissett, R. T., Batten, S. V., Bergan, J., ... \& Eifert, G. H. (2006). The Acceptance and Action Questionnaire (AAQ) as a measure of experiential avoidance. Psychological Record, 54, 553-578.

Heeren, A., Douilliez, C., Peschard, V., Debrauwere, L., \& Philippot, P. (2011). Crosscultural validity of the Five Facets Mindfulness Questionnaire: Adaptation and validation in a French-speaking sample. Revue Européenne de Psychologie Appliquée/European Review of Applied Psychology, 61(3), 147-151.

Hellman, I. D., Morrison, T. L., \& Abramowitz, S. I. (1986). The stresses of psychotherapeutic work: A replication and extension. Journal of Clinical Psychology, 42, 197-205. 
Hiscott, R. D., \& Connop, P. J. (1989). Job stress and occupational burnout: Gender differences among mental health professionals. Sociology and Social Research, $74,10-15$.

Hodge, D. R. (2000). Spiritual ecomaps: A new diagrammatic tool for assessing marital and family spirituality. Journal of Marital and Family Therapy, 26(1), 229-240.

Hofmann, S. G., Sawyer, A. T., Witt, A. A., \& Oh, D. (2010). The effect of mindfulnessbased therapy on anxiety and depression: A meta-analytic review. Journal of Consulting and Clinical Psychology, 78(2), 169-175.

Hou, J., Wong, S. Y. S., Lo, H. H. M., Mak, W. W. S., \& Ma, H. S. W. (2013). Validation of a Chinese Version of the Five Facet Mindfulness Questionnaire in Hong Kong and Development of a Short Form. Assessment (ahead-of-print), 4-16. doi: $10.1177 / 1073191113485121$

Irving, J. A., Dobkin, P. L., \& Park, J. (2009). Cultivating mindfulness in health care professionals: A review of empirical studies of mindfulness-based stress reduction (MBSR). Complementary Therapies in Clinical Practice, 15(2), 61-66.

Iwanicki, E. F., \& Schwab, R. L. (1981). A cross validation study of the Maslach Burnout Inventory12. Educational and Psychological Measurement, 41(4), 1167-1174.

Jain, S., Shapiro, S. L., Swanick, S., Roesch, S. C., Mills, P. J., \& Schwartz, G. E. (2007). A randomized controlled trial of mindfulness meditation versus relaxation training: Effects on distress, positive states of mind, rumination, and distraction. Annals of Behavioral Medicine, 33(1), 11-21.

Jayaratne, S., \& Chess, W. A. (1984). Job satisfaction, burnout, and turnover: A national study. Social Work, 24, 448-453. 
Jayaratne, S., Chess, W. A., \& Kunkel, D. A. (1986). Burnout: Its impact on child welfare workers and their spouses. Social Work, 31(1), 53-59.

Jayaratne, S., Davis-Sacks, M. L., \& Chess, W. A. (1991). Private practice may be good for your health and well-being. Social Work, 36, 224-229.

Jayaratne, S., Himle, D. P., \& Chess, W. A. (1988). Dealing with work stress and strain: Is the perception of support more important than its use? Journal of Applied Behavioral Science, 24, 191-202.

Jones, J. W. (2004). Religion, health, and the psychology of religion: How the research on religion and health helps us understand religion. Journal of Religion and Health, 43(4), 317-328.

Jones, S. H. (2007, January). Secondary trauma and burnout in child protective workers: Implications for preparation of social workers. Paper presented at the 11th Annual Conference of the Society for Social Work and Research, San Francisco, CA.

Jourdain, G., \& Chênevert, D. (2010). Job demands-resources, burnout and intention to leave the nursing profession: A questionnaire survey. International Journal of Nursing Studies, 47(6), 709-722.doi: 10.1016/j.ijnurstu.2009.11.007

Kabat-Zinn, J. (1982). An out-patient program in behavioral medicine for chronic pain patients based on the practice of mindfulness meditation: Theoretical considerations andpreliminary results. General Hospital Psychiatry, 4, 33-47. Kabat-Zinn, J. (2003). Mindfulness-based interventions in context: Past, present, and future. Clinical Psychology, 10, 144-156. 
Kabat-Zinn, J., Lipworth, L., \& Burney, R. (1985). The clinical use of mindfulness meditation for the self-regulation of chronic pain. Journal of behavioral medicine, $8(2), 163-190$.

Kang, J. S. (2012). Relationship among job burnout, organizational commitment and organizational citizenship behavior in social workers using structural equation modeling. International Journal of Contents, 8(3), 88-94.

Kantas, A., \& Vassilaki, E. (1997). Burnout in Greek teachers: Main findings and validity of the Maslach Burnout Inventory. Work \& Stress, 11(1), 94-100.

Kelloway, E. K., \& Barling, J. (2011). Job characteristics, role stress and mental health. Journal of Occupational Psychology, 64(4), 291-304.

Khoury, B., Lecomte, T., Fortin, G., Masse, M., Therien, P., Bouchard, V., ... Hofmann, S. G. (2013). Mindfulness-based therapy: A comprehensive meta-analysis. Clinical Psychology Review, 33, 763-771.

Kim, H., Ji, J., \& Kao, D. (2011). Burnout and physical health among social workers: A three-year longitudinal study. Social Work, 56(3), 258-268.

Kim, H., \& Stoner, M. (2008). Burnout and turnover intention among social workers: Effects of role stress, job autonomy and social support. Administration in Social Work, 32(3), 5-25.

Koeske, G. E, \& Koeske, R. D. (1991). Student burnout as a mediator of the stressoutcome relationship. Research in Higher Education, 32, 415-131.

Lazarus, R., \& Folkman, S. (1984). Stress, appraisal and coping. New York, NY: Springer. 
Lee, R. T., \& Ashforth, B. E. (1990). On the meaning of Maslach's Three Dimensions of Burnout. Journal of Applied Psychology, 75(6), 743-747.

Lee, J. J., \& Miller, S. E. (2013). A self-care framework for social workers: Building a strong foundation for practice. Families in Society: The Journal of Contemporary Social Services, 94(2), 96-103.

Leiter, M. P., \& Durup, J. (1994). The discriminant validity of burnout and depression: A confirmatory factor analytic study. Anxiety, Stress, and Coping, 7(4), 357-373.

Leiter, M. P., Frank, E., \& Matheson, T. J. (2009). Demands, values, and burnout. Relevance for physicians. Canadian Family Physician, 55(12), 1224-1225.

Leiter, M. P., \& Maslach, C. (1988). The impact of interpersonal environment on burnout and organizational commitment. Journal of Organizational Behavior, 9(4), 297308.

Lilja, J. L., Frodi-Lundgren, A., Hanse, J. J., Josefsson, T., Lundh, L. G., Sköld, C., ... Broberg, A. G. (2011). Five facets mindfulness questionnaire - reliability and factor structure: a Swedish version. Cognitive Behaviour Therapy, 40(4), 291303.

Lloyd, C., King, R., \& Chenoweth, L. (2002). Social work, stress and burnout: A review. Journal of Mental Health, 11(3), 255-265.

Lykins, E. L., \& Baer, R. A. (2009). Psychological functioning in a sample of long-term practitioners of mindfulness meditation. Journal of Cognitive Psychotherapy, 23(3), 226-241. 
Mackenzie, C. S., Poulin, P. A., \& Seidman-Carlson, R. (2006). A brief mindfulnessbased stress reduction intervention for nurses and nurse aides. Applied Nursing Research, 19(2), 105-109.

Mark, C., Pierce, B., \& Geoffrey, N. M. (1989). The construct validity of the Maslach Burnout Inventory: Some data from down under. Psychological Reports, 65(3), 1340-1342.

Martin, U., \& Schinke, S. (1998). Organizational and individual factors influencing job satisfaction and burnout of mental health workers. Social Work in Health Care, $28,51-62$.

Maslach, C. (1982). Burnout: The cost of caring. Englewood Cliffs, NJ: Prentice Hall.

Maslach, C. (2011). Burnout and engagement in the workplace: New perspectives. The European Health Psychologist, 13(3), 44-47.

Maslach, C., \& Goldberg, J. (1998). Prevention of burnout: New perspectives. Applied and Preventive Psychology, 7, 63-74.

Maslach, C., \& Jackson, S. E. (1981). The measurement of experienced burnout. Journal of Occupational Behavior, 2, 99-115.

Maslach, C., \& Jackson, S. E. (1984). Burnout in organizational setting. Applied Social Psychology Annual, 5, 133-153.

Maslach, C., Jackson, S. E., Leiter, M. P., Schaufeli, W. B., \& Schwab, R. L. (1986). Maslach Burnout Inventory Manual. Mountain View, CA: CPP, Inc. Maslach C., \& Leiter, M. P. (1997). The truth about burnout. San Francisco, CA: Jossey Bass. 
Maslach, C., Schaufeli, W. B., \& Leiter, M. P. (2001). Job burnout. Annual Review of Psychology, 52, 397- 422.

May, G. G. (1982). Will and spirit: A contemplative psychology. San Francisco, CA: Harper \& Row.

McCann, I. L., \& Pearlman, L. A. (1990). Vicarious traumatization: A framework for understanding the psychological effects of working with victims. Journal of Traumatic Stress, 3(1), 131-149.

McCracken, L. M., Gauntlett-Gilbert, J., \& Vowles, K. E. (2007). The role of mindfulness in a contextual cognitive-behavioral analysis of chronic pain-related suffering and disability. Pain, 131(1), 63-69.

McIntosh, W. D. (1997). East meets West: Parallels between Zen Buddhism and social psychology. The International Journal for the Psychology of Religion, 7(1), 3752.

McIntyre, T. C. (2011). The relationship between locus of control and teacher burnout. British Journal of Educational Psychology, 54(2), 235-238.

Mc Nair, D. M., Lorr, M., \& Doppleman, L. F. (1981). Manual for the Profile of Mood States. San Diego, CA: Educational and Industrial Testing Service.

Meier, S. T. (1984). The construct validity of burnout. Journal of Occupational Psychology, 57(3), 211-219.

Meyer, J. H. (1982). Burnout: Developmental influences. Canadian Counselor, 16, 6773. 
Miller, J. J., Fletcher, K., \& Kabat-Zinn, J. (1995). Three-year follow-up and clinical implications of a mindfulness meditation-based stress reduction intervention in the treatment of anxiety disorders. General Hospital Psychiatry, 17(3), 192-200.

Moore, S. E., Bledsoe, L. K., Perry, A. R., \& Robinson, M. A. (2011). Social work students and self-care: A model assignment for teaching. Journal of Social Work Education, 47(3), 545-553.

Mor Barak, M. E., Nissly, J. A., \& Levin, A. (2001). Antecedents to retention and turnover among child welfare, social work, and other human service employees: What can we learn from past research? A review and metanalysis. Social Service Review, 75(4), 625-661.

National Alliance for Caregiving and AARP. (2009). Caregiving in the US, 2009. www.caregiving.org/data/Caregiving_in_the_US_2009_full_report.pdf

National Association of Social Workers. (2008). Code of Ethics. Retrieved from http://www.socialworkers.org/pubs/code/code.asp

National Study of the Changing Workforce (Families and Work Institute [FWI]. (2008). Familiesandwork.org/downloads/TheElderCareStudy.pdf

Neff, K. D. (2003). Self-compassion: An alternative conceptualization of a healthy attitude toward oneself. Self and Identity, 2, 85-101.

Newell, J. M., \& MacNeil, G. A. (2010). Professional burnout, vicarious trauma, secondary traumatic stress, and compassion fatigue: A review of theoretical terms, risk factors, and preventive methods for clinicians and researchers. Best Practice in Mental Health, 6(2), 57- 68. 
Newsome, S., Christopher, J. C., Dahlen, P., \& Christopher, S. (2006). Teaching counselors self-care through mindfulness practices. Teachers College Record, $108,1881-1900$.

Ngai, S. S. Y., \& Cheung, C. K. (2009). Idealism, altruism, career orientation, and emotional exhaustion among social work undergraduates. Journal of Social Work Education, 45(1), 105-121.

Noble, C., \& Irwin, J. (2009). Social work supervision an exploration of the current challenges in a rapidly changing social, economic and political environment. Journal of Social Work, 9(3), 345-358.

Oktay, J. S. (1992). Burnout in hospital social workers who work with AIDS patients. Social Work, 37(5), 432-439.

Olson, J., \& Matuskey, P. V. (1982). Causes of burnout in SLD teachers. Journal of Learning Disabilities, 15, 97-99.

O'Sullivan, D., \& Bates, J. K. (2014). The relationship among personal and work experiences: Implications for rehabilitation counselor well-being and service provision. Rehabilitation Research, Policy, and Education, 28(1), 45-60.

Partridge, E. (Ed.). (1961). A Dictionary of slang and unconventional English (5th ed., Vols. 1-2). Adelaide, South Australia: Mary Martin Books.

Persing, J. M. (2000). An exploration of the effects of spirituality on psychologist burnout. (Doctoral Dissertation, California School of Professional Psychology, 2000). Dissertation Abstracts International, 61, 545.

Pines, A. M., Aronson, A., \& Kafry, D. (1981). Burnout from tedium to personal growth (pp.202-205). New York, NY: The Free Press. 
Pisanti, R., Lombardo, C., Lucidi, F., Violani, C., \& Lazzari, D. (2013). Psychometric properties of the Maslach Burnout Inventory for Human Services among Italian nurses: a test of alternative models. Journal of Advanced Nursing, 69(3), 697-707. doi:10.1111/j.1365-2648.2012.06114.x

Plante, T. G., \& Boccacini, M. T. (1997). The Santa Clara strength of religious faith questionnaire. Pastoral Psychology, 45(5), 375-387.

Pottage, D., \& Huxley, P. (1996). Stress and mental health social work: A developmental perspective. International Journal of Social Psychiatry, 42(2), 124-131.

Poulin, P. A., Soloway, G., Mackenzie, C. S., \& Karayolas, E. (2008). Mindfulness training as an evidenced-based approach to reducing stress and promoting wellbeing among human services professionals. International Journal of Health Promotion and Education, 46, 2, 72-80.

Poulin, J. E., \& Walter, C. A. (1993a). Burnout in gerontological social work. Social Work, 38(3), 305-310.

Poulin, J., \& Walter, C. (1993b). Social worker burnout: A longitudinal study. Social Work Research and Abstracts, 29(4), 5-11.

Powell, M. J., \& York, R. O. (1992). Turnover in county public welfare agencies. Journal of Applied Social Sciences, 16(2), 111-127.

Pross, C. (2006). Burnout, vicarious traumatization and its prevention. Torture, 16(1), 19.

Richards, P. S., \& Bergin, A. E. (2005). A spiritual strategy for counseling and psychotherapy (2nd ed.). Washington, DC: American Psychological Association. 
Richardsen, A. M., \& Martinussen, M. (2004). The Maslach Burnout Inventory: Factorial validity and consistency across occupational groups in Norway. Journal of Occupational and Organizational Psychology, 77(3), 377-384.

Robb, M. (2004). NASW. Burn-out and at risk. Retrieved from http://www.naswassurance.org/practice_pointers.php

Robichaud, C. M. (2004). The relationship of spirituality and coping to burnout in child welfare workers (Doctoral Dissertation, The Catholic University of America, 2004). Dissertation Abstracts International, 65, 1122.

Roelofs, J., Verbraak, M., Keijsers, G. J., De Bruin, M. N., \& Schmidt, A. M. (2005). Psychometric properties of a Dutch version of the Maslach Burnout Inventory General Survey (MBI-DV) in individuals with and without clinical burnout. Stress \& Health: Journal of the International Society for the Investigation of Stress, 21(1), 17-25. doi:10.1002/smi.1032

Roeser, R. W., Schonert-Reichl, K. A., Jha, A., Cullen, M., Wallace, L., Wilensky, R., ... \& Harrison, J. (2013). Mindfulness training and reductions in teacher stress and burnout: Results from two randomized, waitlist-control field trials. Journal of Educational Psychology, 105(3), 787-804. doi: 10.1037/a0032093

Roeser, R. W., Skinner, E., Beers, J., \& Jennings, P. A. (2012). Mindfulness training and teachers' professional development: An emerging area of research and practice. Child Development Perspectives, 6(2), 167-173.

Rompf, E. L., Royse, D., \& Dhooper, S. S. (1993). Anxiety preceding field work. Journal of Teaching in Social Work, 7(2), 81-95. 
Rosenzweig, S., Greeson, J. M., Reibel, D. K., Green, J. S., Jasser, S. A., \& Beasley, D. (2010). Mindfulness-based stress reduction for chronic pain conditions: Variation in treatment outcomes and role of home meditation practice. Journal of Psychosomatic Research, 68(1), 29-36.

Rössler, W. (2012). Stress, burnout, and job dissatisfaction in mental health workers. European Archives of Psychiatry and Clinical Neuroscience, 262(2), 65-69.

Ryan, R. M., \& Deci, E. L. (2000). Self-determination theory and the facilitation of intrinsic motivation, social development, and well-being. American Psychologist, $55(1), 68-73$.

Sabbah, I., Sabbah, H., Sabbah, S., Akoum, H., \& Droubi, N. (2012). Burnout among Lebanese nurses: Psychometric properties of the Maslach Burnout InventoryHuman Services Survey (MBI-HSS). Health, 4(9), 644-652. doi:10.4236/health.2012.49101

Salmon, P., Sephton, S. E., Weissbecker, I., Hoover, K., Ulmer, C., \& Studts, J. (2004). Mindfulness meditation in clinical practice. Cognitive and Behavioral Practice, $11,434-446$.

Shapiro, S. L., Carlson, L. E., Astin, J. A., \& Freedman, B. (2006). Mechanisms of mindfulness. Journal of Clinical Psychology, 62(3), 373-386.

Schaufeli, W., \& Enzmann, D. (1998). The burnout companion to study and practice: A critical analysis. Philadelphia: PA: Taylor \& Francis.

Schaufeli, W. B., Leiter, M. P., \& Maslach, C. (2009). Burnout: 35 years of research and practice. Career Development International, 14(3), 204-220. 
Schaufeli, W. B., Leiter, M. P., Maslach, C., \& Jackson, S. E. (1996). MBI-General Survey. In C. Maslach, S. E. Jackson, \& M. P. Leiter (Eds.), Maslach Burnout Inventory Manual (3rd ed.). Palo Alto, CA: Consulting Psychologists Press.

Schutte, N., Toppinen, S., Kalimo, R., \& Schaufeli, W. (2000). The factorial validity of the Maslach Burnout Inventory-General Survey (MBI-GS) across occupational groups and nations. Journal of Occupational and Organizational Psychology, 73(1), 53-66.

Schwartz, R. H., Tiamiyu, M. F., \& Dwyer, D. J. (2007). Social worker hope and perceived burnout: The effects of age, years in practice, and setting. Administration in Social Work, 31(4), 103-119.

Shannon, C., \& Saleebey, D. (1980). Training child welfare workers to cope with burnout. Child Welfare, 59(8), 463-468.

Shapiro, S. L., Astin, J. A., Bishop, S. R., \& Cordova, M. (2005). Mindfulness-based stress reduction for health care professionals: Results from a randomized trial. International Journal of Stress Management, 12(2), 164-175.

Shapiro, S. L., Brown, K. W., \& Biegel, G. M. (2007). Teaching self-care to caregivers: Effects of mindfulness-based stress reduction on the mental health of therapists in training. Training and Education in Professional Psychology, 1(2), 105-111.

Schaufeli, W.B. (2006). The balance of give and take: Toward a social exchange model of burnout. The International Review of Social Psychology, 19, 87-131.

Schaufeli, W. B., \& Buunk, B. P. (2003). Burnout: An overview of 25 years of research and theorizing. The Handbook of Work and Health Psychology, 2, 282-424. 
Sherman, W. R., \& Wenocur, S. (1983). Empowering public welfare workers through mutual support. Social Work, 28(5), 375-379.

Shinn, M. (1982). Methodological issues: Evaluating and using information. In W. S. Paine (Ed.), Job stress and burnout: Research, theory, and intervention perspectives (pp. 61-79). Beverly Hills, CA: Sage.

Siebert, D. C. (2006). Personal and occupational factors in burnout among practicing social workers. Journal of Social Service Research, 32(2), 25-44.

Siegel, K., Anderman, S. J., \& Schrimshaw, E. W. (2001). Religion and coping with health-related stress. Psychology and Health, 16(6), 631-653.

Skinner, E. A., Kindermann, T. A., Connell, J. P., \& Wellborn, J. G. (2009). Engagement and disaffection as organizational constructs in the dynamics of motivational development. In K. Wentzel \& D. Miele (Eds.), Handbook of Motivation at School (pp.223-245). New York, NY: Routledge.

Sofield, L., \& Juliano, C. (2000). Collaboration: Uniting our gifts in ministry. Notre Dame, IN: Ave Maria Press.

Spielberger, C., Gorsuch, R. L., \& Lushene, R. E. (1970). Manual for the State Trait Anxiety Inventory. Palo Alto, CA: Consulting Psychologist Press.

Sprang, G., Craig, C., \& Clark, J. (2011). Secondary traumatic stress and burnout in child welfare workers: A comparative analysis of occupational distress across professional groups. Child Welfare, 90(6), 149-168.

Stamm, B. H. (2005). Professional quality of life: Compassion satisfaction and fatigue subscales, $R-I V$ (ProQOL). Retrieved from www.isu.edu/bhstamm. 
Stanard, R. P., Sandhu, D. S., \& Painter, L. C. (2000). Assessment of spirituality in counseling. Journal of Counseling \& Development, 78, 204-210.

Stoll, R. I. (1989). The essence of spirituality. In V. B. Carson (Ed.), Spiritual dimensions of nursing practice (pp. 4-23). Philadelphia, PA: Saunders.

Suran, B. G., \& Sheridan, E. P. (1985). Management of burnout: training psychologists in professional life span perspectives. Professional Psychology: Research and Practice, 16(6), 741-752.

Tabachnick, B. G., \& Fidell, L. S. (2001). Using multivariate statistics $\left(5^{\text {th }} \mathrm{ed}\right.$.). New York, NY: Pearson Education Inc.

Taylor, R. B. (1982). Are you heading for burnout? Physicians in Management, 22, 186193.

Tobin, P. J., \& Carson, J. (1994). Stress and the student social worker. Social Work and Social Sciences Review, 5, 246-246.

Tovar-Murray, D. (2011). The multiple determinants of religious behaviors and spiritual beliefs on well-being. Journal of Spirituality in Mental Health, 13(3), 182-192.

Tran, U. S., Glück, T. M., \& Nader, I. W. (2013). Investigating the Five Facet Mindfulness Questionnaire (FFMQ): Construction of a short form and evidence of a two-factor higher order structure of mindfulness. Journal of Clinical Psychology, 69(9), 951-965.

Um, M. Y. \& Harrison, D. F. (1998). Role stressors, burnout, mediators, and job satisfaction: A stress strain outcome model and an empirical test. Social Work Research, 22, 100-115. 
U.S. Census Bureau. (2012). The American Community Survey. Retrieved from http://www.census.gov/acs/www/Downloads/questionnaires/2012/Quest12.pdf

U.S. General Accounting Office. (2003). HHS could play a greater role in helping child welfare agencies recruit and retain staff (GAO-03-357). Washington, DC: U.S. Government Printing Office.

Weinstein, N., \& Ryan, R. M. (2011). A self-determination theory approach to understanding stress incursion and responses. Stress and Health, 27(1), 4-17.

Wheeler, D. L., Vassar, M., Worley, J. A., \& Barnes, L. L. (2011). A reliability generalization meta-analysis of coefficient alpha for the Maslach Burnout Inventory. Educational and Psychological Measurement, 71(1), 231-244.

Wood, A. (n.d). The Upanishads. An introduction. Retrieved from http://www.advaitin.net/ananda/UpanishadsIntro.pdf

Van Dam, N. T., Hobkirk, A. L., Danoff-Burg, S., \& Earleywine, M. (2012). Mind your words: Positive and negative items create method effects on the Five Facet Mindfulness Questionnaire. Assessment, 9(2), 198-204. doi:10.1177/1073191112438743

Van Hook, M. P., \& Rothenburg, M. (2009). Quality of life and compassion satisfaction/fatigue and burnout in child welfare workers: A study of the child welfare workers in community-based care organizations in central Florida. Social Work and Christianity, 36, 36- 54. 
Veehof, M., Klooster, P., Taal, E., Westerhof, G., \& Bohlmeijer, E. (2011). Psychometric properties of the Dutch Five Facet Mindfulness Questionnaire (FFMQ) in patients with fibromyalgia. Clinical Rheumatology, 30(8), 1045-1054. doi:10.1007/s10067-011-1690-9

Viveros, G. O., \& Herrera, M. R. O. E. (2009). The burnout in psychologists and its relation to symptoms associated with stress. Psychology and Health, 19(2), 207214.

Yee, B. H. (1981). The dynamics and management of burnout. Nursing Management, 12, 14-16.

Ying, Y. W. (2008). The buffering effect of psychological detachment against emotional exhaustion among social work students. Journal of Religion and Spirituality in Social Work: Social Thought, 27(1-2), 131-150.

Ying, Y. W. (2009a). Contribution of self-compassion to competence and mental health in social work students. Journal of Social Work Education, 45(2), 309-323.

Ying, Y. W. (2009b). Religiosity, spirituality, mindfulness, and mental health in social work students. Critical Social Work, 10(1), 97-114.

Ying, Y. W., \& Han, M. (2007, June). The importance of self-compassion to social work students: Empirical evidence. Paper presented at the Second North American Conference on Spirituality and Social Work, Dominican University, River Forest, IL.

Zapf, D., Seifert, C., Schmutte, B., Mertini, H., \& Holz, M. (2001). Emotion work and job stressors and their effects on burnout. Psychology \& Health, 16, 527-545. 
APPENDIX A : Survey Instruments 


\section{PART A}

\section{5 - FACET M QUESTIONNAIRE (Baer, R. A., 2006)}

In this part we are interested in finding out how much "in tune" you are with your body and your surroundings.

Please rate each of the following statements using the scale provided. Write the number in the blank that best describes your own opinion of what is generally true for you.

\begin{tabular}{|c|c|c|c|c|}
\hline 1 & 2 & 3 & 4 & 5 \\
\hline $\begin{array}{c}\text { never or very } \\
\text { rarely true }\end{array}$ & $\begin{array}{c}\text { rarely } \\
\text { true }\end{array}$ & $\begin{array}{c}\text { sometimes } \\
\text { true }\end{array}$ & $\begin{array}{c}\text { often } \\
\text { true }\end{array}$ & $\begin{array}{c}\text { very often or } \\
\text { always true }\end{array}$ \\
\hline
\end{tabular}

1. When I'm walking, I deliberately notice the sensations of my body moving.

2. I'm good at finding words to describe my feelings.

3. I criticize myself for having irrational or inappropriate emotions.

4. I perceive my feelings and emotions without having to react to them.

5. When I do things, my mind wanders off and I'm easily distracted.

6. When I take a shower or bath, I stay alert to the sensations of water on my body.

7. I can easily put my beliefs, opinions, and expectations into words.

8. I don't pay attention to what I'm doing because I'm daydreaming, worrying, or otherwise distracted.

9. I watch my feelings without getting lost in them.

10. I tell myself I shouldn't be feeling the way I'm feeling.

11. I notice how foods and drinks affect my thoughts, bodily sensations, and emotions.

12. It's hard for me to find the words to describe what I'm thinking.

13. I am easily distracted.

14. I believe some of my thoughts are abnormal or bad and I shouldn't think that way.

15. I pay attention to sensations, such as the wind in my hair or sun on my face.

16. I have trouble thinking of the right words to express how I feel about things

17. I make judgments about whether my thoughts are good or bad.

18. I find it difficult to stay focused on what's happening in the present. 


\section{Continuing 5 - FACET M QUESTIONNAIRE}

\begin{tabular}{|c|c|c|c|c|}
\hline 1 & 2 & 3 & 4 & 5 \\
\hline $\begin{array}{c}\text { never or very } \\
\text { rarely true }\end{array}$ & $\begin{array}{c}\text { rarely } \\
\text { true }\end{array}$ & $\begin{array}{c}\text { sometimes } \\
\text { true }\end{array}$ & $\begin{array}{c}\text { often } \\
\text { true }\end{array}$ & $\begin{array}{c}\text { very often or } \\
\text { always true }\end{array}$ \\
\hline
\end{tabular}

Please rate each of the following statements using the scale provided. Write the number in the blank that best describes your own opinion of what is generally true for you.

19. When I have distressing thoughts or images, I "step back" and am aware of the thought or image without getting taken over by it.

20. I pay attention to sounds, such as clocks ticking, birds chirping, or cars passing.

21. In difficult situations, I can pause without immediately reacting.

22. When I have a sensation in my body, it's difficult for me to describe it because I can't find the right words.

23. It seems I am "running on automatic" without much awareness of what I'm doing.

24. When I have distressing thoughts or images, I feel calm soon after.

25. I tell myself that I shouldn't be thinking the way l'm thinking.

26. I notice the smells and aromas of things.

27. Even when I'm feeling terribly upset, I can find a way to put it into words.

28. I rush through activities without being really attentive to them.

29. When I have distressing thoughts or images I am able just to notice them without reacting.

30. I think some of my emotions are bad or inappropriate and I shouldn't feel them.

31. I notice visual elements in art or nature, such as colors, shapes, textures, or patterns of light and shadow.

32. My natural tendency is to put my experiences into words.

33. When I have distressing thoughts or images, I just notice them and let them go.

34. I do jobs or tasks automatically without being aware of what I'm doing. 


\section{Continuing 5 - FACET M QUESTIONNAIRE}

\begin{tabular}{|c|c|c|c|c|}
\hline 1 & 2 & 3 & 4 & 5 \\
\hline $\begin{array}{c}\text { never or very } \\
\text { rarely true }\end{array}$ & $\begin{array}{c}\text { rarely } \\
\text { true }\end{array}$ & $\begin{array}{c}\text { sometimes } \\
\text { true }\end{array}$ & $\begin{array}{c}\text { often } \\
\text { true }\end{array}$ & $\begin{array}{c}\text { very often or } \\
\text { always true }\end{array}$ \\
\hline
\end{tabular}

Please rate each of the following statements using the scale provided. Write the number in the blank that best describes your own opinion of what is generally true for you.

35. When I have distressing thoughts or images, I judge myself as good or bad, depending what the thought/image is about.

36. I pay attention to how my emotions affect my thoughts and behavior.

37. I can usually describe how I feel at the moment in considerable detail.

38. I find myself doing things without paying attention.

39. I disapprove of myself when I have irrational ideas. 


\section{PART B}

\section{MBI-HUMAN SERVICES SURVEY}

Taken from the Maslach Burnout Inventory Manual, (Maslach et al., 1986), with the permission

of the Mind Garden, Inc., www.mindgarden.com 


\section{PART C STRESS REDUCTION PRACTICES QUESTIONNAIRE}

In this section I would like to ask you to provide information about your stress reduction practices.

Please rate each of the following statements using the scale provided. Write the number in the blank that best describes your own opinion of what is generally true for you.

\begin{tabular}{|c|c|c|c|c|}
\hline 1 & 2 & 3 & 4 & 5 \\
\hline $\begin{array}{c}\text { never or very } \\
\text { rarely true }\end{array}$ & $\begin{array}{c}\text { rarely } \\
\text { true }\end{array}$ & $\begin{array}{c}\text { sometimes } \\
\text { true }\end{array}$ & $\begin{array}{c}\text { often } \\
\text { true }\end{array}$ & $\begin{array}{c}\text { very often or } \\
\text { always true }\end{array}$ \\
\hline
\end{tabular}

1. When stressed out I (Please rate the items below from 1 to 5 using the above scale):

\section{Exercise}

Go for a walk

Listen to music

Play with a pet/animal

Read a book

Take a bath

Take a nap

Talk to a friend

Watch TV

Write a journal

Other forms of stress reduction practices (Please specify and rate):

2. Some people believe that religious or spiritual practice leads to stress reduction. Religiosity relates to a system of beliefs, experiences, and rituals shared among members of a religious group (Corbett. 1990); spirituality relates to the sense of meaning and purpose acquired through life experiences (May, 1982). (Please rate the items below from 1 to 5 using the above scale):

I consider myself active in my faith or church.

I pray daily.

I meditate daily [meditation is a form of mental activity based on self-regulating one's attention by observing internal and external experiences without judgment (Goleman \& Schwartz, 1976)].

I use other forms of spiritual practices.

3. What term best describes you? (Please, check one):

Spiritual

Religious

Both religious and spiritual

Neither religious nor spiritual

Other (please specify)

Corbett, J. M. (1990). Religion in America. Englewood Cliffs, NJ: Prentice-Hall.

May, G. G. (1982). Will and spirit: A contemplative psychology. San Francisco: Harper \& Row.

Plante, T. G., \& Boccacini, M. T. (1997). The Santa Clara strength of religious faith questionnaire. Pastoral Psychology, 45(5), 375-387. 


\section{PART D}

\section{DEMOGRAPHIC INFORMATION}

I would also like to know who you are, to see how different people feel about the issues examined in this study. Please provide the information by checking appropriate category. If necessary you may check more than one answer for each question.

1. What is your date of birth (month and year only)?

2. How do you identify yourself?

Female

Male

Other (please specify)

3. Are you of Hispanic, Latino, or Spanish origin?

No

Yes

4. How do you identify yourself? (check ALL that apply)

White

Black or African American

American Indian, or Alaska Native

Pacific Islander

Asian

Other race(s) (please specify)

5. What is your current relationship status? (check one)

Married/In legally recognized union

Living with a partner/ partners

Widowed

Divorced

Separated

Single

Other (please specify)

6. Are you a parent or guardian of any child under 18 years of age who lives in your home for at least 6 months a year?

Yes 


\section{Continuing DEMOGRAPHIC INFORMATION}

7. In the last 12 months, have you provided unpaid care to a relative or friend 18 years or older or helped them take care of themselves?

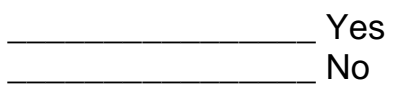

8. In the last 12 months, have you given unpaid care to any child under the age of 18 because of a medical, behavioral, or other condition or disability?

Yes
No

9. What was your total household income (income available for your use) during the past 12 months?

Under $\$ 25,000$

$\$ 25,000$ to $\$ 49,999$

$\$ 50,000$ to $\$ 74,999$

$\$ 75,000$ and over

10. How many years or months prior to your entry into MSW program were you employed in human services?

human services? Years

Months

11. Are you currently practicing in human services outside of a field placement?

Yes
No

12. Are you currently in a field placement?

Yes

No

13. What is your year in the MSW Program?

First

Second

Third

Fourth

Other (please specify) 


\section{Continuing DEMOGRAPHIC INFORMATION}

14. Are you a full-time or a part-time student?

Full-time

Part-time

15. What is your concentration?

Direct Human Services (DHS)

Community Based Practice (CBP)

Social Service Administration and Leadership (SSAL) Not decided

16. What led you to become a social worker?

THANK YOU FOR PARTICIPATING IN THIS SURVEY (-) 
APPENDIX B : Cover Letters 
Dear Prospective Participant,

My name is Jolanta Piatkowska. I am a doctoral student from Portland State University. I am conducting an anonymous survey about the stress reduction practices and human services job experiences (either in paid positions, field placement, or both) among MSW students. To participate, you must be 18 years or older. The survey is voluntary.

Since your answers are to remain anonymous, PLEASE DO NOT PUT YOUR NAME ON THIS SURVEY.

The survey will take less than 30 minutes to complete. Please answer the questions to your comfort level.

The results will be reported for the group of respondents as a whole.

Thank you for your consideration.

Please complete this questionnaire booklet ASAP and place it in the sealed box at the front desk in the SSW (for on-campus students), or return it to the assigned person (with a marked envelope) in your class (for off-site students).

If you would like to have access to the results please contact me at jolanta@pdx.edu

1

If you have any questions about your rights as a research subject, please contact the PSU Office of Research Integrity at (503) 725-2227 or 1 (877) $480-4400$.

Please print a copy of this letter for your records.

Sincerely,

Jolanta Piatkowska

jolanta@pdx.edu 


\section{E-mails inviting students to participate in the study}

\section{Campus students:}

Hello MSW Students,

My name is Jolanta Piatkowska. I am a doctoral student from Portland State University. Starting this week I will be conducting paper-and-pencil anonymous survey about the stress reduction practices and burnout among MSW students. The participation in the survey is voluntary.

I invite you TO PARTICIPATE in this important study. You will be asked to complete a questionnaire booklet, distributed in class, either on the same day, or the following week and place it in the sealed box at the front desk in the SSW. The survey should take less than 30 minutes to be completed.

Thank you - JP

If you have any questions please contact me at jolanta@pdx.edu

\section{Off-site students:}

Hello MSW Students,

My name is Jolanta Piatkowska. I am a doctoral student from Portland State University. Starting next week I will be conducting paper-and-pencil anonymous survey about the stress reduction practices and burnout among MSW students. The participation in the survey is voluntary.

I invite you TO PARTICIPATE in this important study. You will be asked to complete a questionnaire booklet, distributed in class by your instructor, either on the same day, or the following week and return it to the assigned person (with a marked envelope) in your class. The survey should take less than 30 minutes to be completed.

Thank you - JP

If you have any questions please contact me at jolanta@pdx.edu 


\section{Letter to campus students}

Hello Everybody,

I am conducting an anonymous and voluntary survey about the stress reduction practices and human services job experiences (either in paid positions, field placement, or both) among MSW students. In view of the fact that even social work students are already prone to experience excessive stress, which can lead to occupational burnout, I am interested in finding the ways you, as SW students, reduce your stress, and how such practices influence your experienced burnout levels.

I am inviting you to take a part in this study, since it might have significant implications for the social work field (e.g., it might open new directions in educating social work students). If you choose to participate, please complete this questionnaire booklet ASAP (either today, during breaks in the entire day of lectures, or take it home and bring it next Friday). Deposit the questionnaire in the secure box, clearly marked "Stress Reduction Study," in the PSU SSW lobby.

As a token of appreciation for completing the questionnaires you will receive a tea bag. In addition, you can take a numbered ticket (attached to the tea bag), so you can have the opportunity to win a $\$ 50$ gift certificate to an online bookstore. After the results are collected the winning number will be drawn by the researcher without her knowing the identity of the winner. The winning number announced through email. The winner will present the winning ticket and collect the gift certificate, without needing to reveal a name.

I hope that you decide to take part in this important study. Jolanta 


\section{Letter to off-site students}

Hello Everybody,

This is a message from Jolanta Piatkowska, a social work doctoral student at PSU:

I am conducting an anonymous and voluntary survey about the stress reduction practices and human services job experiences (either in paid positions, field placement, or both) among MSW students. In view of the fact that even social work students are already prone to experience excessive stress, which can lead to occupational burnout, I am interested in finding the ways you, as SW students, reduce your stress, and how such practices influence your experienced burnout levels.

I am inviting you to take a part in this study, since it might have significant implications for the social work field (e.g., it might open new directions in educating social work students). If you choose to participate, please complete this questionnaire booklet ASAP (either today, during breaks in the entire day of lectures, or take it home and bring it next Friday). By the end of the day student volunteer will deliver collected questionnaires in the marked envelope to the office of the site coordinator. A second collection of completed questionnaires will be held the following week. (Is there anybody here who would volunteer to collect the questionnaires?)

As a token of appreciation for completing the questionnaires you will receive a tea bag. In addition, you can take a numbered ticket (attached to the tea bag), so you can have the opportunity to win a $\$ 50$ gift certificate to an online bookstore. After the results are collected the winning number will be drawn by the researcher without her knowing the identity of the winner. The winning number announced through email. The winner will present the winning ticket and collect the gift certificate, without needing to reveal a name.

I hope that you decide to take part in this important study.

Jolanta 